\title{
Text und Translation. Strategien zur Mobilisierung spiritueller Ressourcen im Frankenreich Ludwigs des Frommen
}

\begin{abstract}
Darum müssen wir uns in Acht nehmen, damit mit uns nicht Ähnliches geschieht, wie wir es bereits über viele gentes lesen können. Denn keineswegs grundlos, würde ich sagen, sind die Wunder der Heiligen, die schon lange Zeit in Christus erstrahlen, jüngst wieder aufgeblitzt, und von so großen Wundern dieser Art hat man auf dieser Welt nie gehört, die alle zur selben Zeit bei den Reliquienschreinen der Heiligen geschehen sind, weil die Heiligen, die von hier und da in dieses Reich gebracht worden sind, wie beim Hahnenschrei sich gegenseitig aufstacheln, wie zu einem Wettgesang. So sollte zu verstehen gegeben werden, daß unser Unglauben dies erforderlich gemacht hat, denn die Zeichen (signa) werden, wie der Apostel bezeugt, wahrhaftig nicht den Gläubigen, sondern den Ungläubigen übermittelt. ${ }^{1}$
\end{abstract}

Als Paschasius Radbertus in seinem Epitaphium Arsenii rückblickend die Krise des Karolingerreiches zur Zeit Ludwigs des Frommen kommentierte, bewies er große Sensibilität für die sozialen und diskursiven Funktionen von Reliquien in der karolingischen Politik. Die Wunder an den Reliquienschreinen im Reich verstand er als Teil der Kommunikation zwischen Gott und den Menschen: Die göttlichen signa waren Warnsignale für einen sündigen populus, der auf anderem Weg nicht zu Umkehr und Besserung gebracht werden konnte, und gehörten wie Seuchen, Hungersnöte oder Visionen zu sicheren Anzeichen für die politische Krise des Reiches. In der modernen Forschung ist ein ähnliches Verständnis von Wundern an Heiligenschreinen und die politische Interpretation von Reliquientranslationen zur Zeit Ludwigs des Frommen vor allem mit einem besonders eindrucksvollen Beispiel verknüpft: Mit Einhards Übertragung der Heiligen Marcellinus und Petrus aus Rom ins Frankenreich im Jahr 827 und seinen Versuchen, das symbolische Kapital der römischen Reliquien zur Intervention in aktuellen politischen Diskussionen am Hof zu nutzen. ${ }^{2}$

\footnotetext{
${ }^{1}$ Paschasius Radbertus, Epitaphium Arsenii (ed. Ernst Dümmler, Radbert’s Epitaphium Arsenii, in: Abhandlungen der königlichen Akademie der Wissenschaften zu Berlin 2 [1900] 1-98) 61f.: Unde timendum ne fiat in nobis, quod in multis iam gentibus actum legimus. Nequaquam igitur dixerim sine causa miracula sanctorum longe diu in Christo quiescentium nuper coruscasse, quanta et qualia numquam sunt audita a sęculo facta uno in tempore ad reliquias sanctorum, quia omnino, quasi in gallicino, sancti hoc in regno huc illucque delati, se invicem excitarunt quasi ad concentum cantus, ut daretur intelligi, quod nostra infidelitas, iuxta apostolum id exigeret, quia signa non fidelibus, ipso teste, verissime dantur. Dieser Artikel entstand im Rahmen des vom Fonds zur Förderung der wissenschaftlichen Forschung (www.fwf.ac.at) an Univ.-Prof. Dr. Walter Pohl verliehenen Wittgenstein-Preises, der das Projekt „Ethnische Identitäten im frühmittelalterlichen Europa“ ermöglicht (www.oeaw.ac.at/gema/wittg_pro/wittg_pro. htm), auf der Grundlage meiner Diplomarbeit (Reliquien, Texte, Translationen. Gestaltung und Aneignung spiritueller Traditionen im karolingischen Frankenreich, Univ. Wien 2005).

2 Einhard, Translatio et miracula sanctorum Marcellini et Petri (ed. Georg Waitz, MGH SS 15, 1, Hannover 1887) $238-264$. Englische Übersetzung: Paul Dutton, Charlemagne's courtier. The complete Einhard (Readings in Medieval Civilizations and Cultures 2, Peterborough-Ontario 1998) 69-130. Zur Translation und zum Text siehe Martin Heinzelmann, Einhards „Translatio Marcellini et Petri“. Eine hagiographische Reformschrift von 830, in: Einhard. Studien zu Leben und Werk, ed. Hermann Schefers (Darmstadt 1997) 269-298; Julia M.H. Smith, „Emending evil ways and praising God’s omnipotence“: Einhard and the uses of Roman martyrs, in: Conversion in Late Antiquity and the Early Middle Ages: Seeing and Believing, ed. Kenneth Mills/Anthony Grafton (Rochester-New York 2003) 189-223; dies., Einhard: The sinner and the saints, in: Transactions of the Royal Historical Society 13 (2003) 55-77; Paul Dutton, The Politics of Dreaming in the Carolingian Empire (Lincoln-Nebraska/London 1994) 91-98; Patrick J. Geary, Furta sacra. Thefts of Relics in the Central Middle Ages (Princeton ${ }^{2} 1990$ ) bes. 45-48, 118-120; Hans Reinhard Seeliger, Einhards römische Reliquien. Zur Übertragung der Heiligen Marzellinus und Petrus ins Frankenreich, in: Römische Quartalschrift 83 (1988) 58-75; Josef Fleckenstein, Einhard, seine Gründung und sein Vermächtnis in Seligenstadt, in: ders., Ordnungen und formende Kräfte des Mittelalters. Ausgewählte Beiträge (Göttingen 1989) 84-111; Marguerite Bondois, La translation des saints Marcellin et Pierre. Étude sur Einhard et sa vie politique de 827 à 834 (Bibliothèque de l’École des Hautes Études, Sciences Historiques et Philologiques 160, Paris 1907).
} 
In einer Vision erschien der Erzengel Gabriel in Gestalt des heiligen Marcellinus dem blinden Mann Alberich, der zuvor durch die Reliquien von seiner Schüttellähmung geheilt worden war, und diktierte ihm Anweisungen für die Reform des Reiches. ${ }^{3}$ Wenig später gestand ein Dämon namens Wiggo während eines Exorzismus seine Verantwortung für Katastrophen und Mißstände im Frankenreich in den vorhergehenden Jahren. ${ }^{4}$ Diese beiden übernatürlichen Botschaften erreichten Einhard in schriftlicher Form, als er im Winter 828/29 in Aachen an den Diskussionen zum status regni teilnahm. ${ }^{5}$ Einhard berichtete nicht nur in der Translatio über diese Ereignisse und seine Überarbeitung der Botschaften zu libelli. Der libellus mit Gabriels Anweisungen und wahrscheinlich auch die Aussagen Wiggos zirkulierten in diesem Winter am Hof. ${ }^{6}$

Einhards Translatio und ihre politische Bedeutung ordnen sich in einen Kontext vielfältiger Bemühungen von Mitgliedern der politischen und intellektuellen Elite des Frankenreiches zur Zeit Ludwigs des Frommen ein, Reliquien zur Durchsetzung und Darstellung von politischen und religiösen Positionen in aktuellen Auseinandersetzungen zu nutzen. Im Jahr 826 transferierte der Erzkaplan Hilduin von St. Denis die Reliquien des römischen Märtyrers Sebastian aus Rom nach Soissons - es war dies die erste Translation aus Rom mit päpstlicher Zustimmung seit gut einem halben Jahrhundert, die am Beginn einer Reihe ähnlicher Reliquienimporte aus Rom in den folgenden Jahren stand. ${ }^{7}$ In den Annales regni Francorum erscheint der ausführliche Bericht über die Ankunft der Sebastiansreliquien als eindrückliches Symbol des göttlichen Wirkens zum Wohl des populus im Frankenreich im Kontrast zu einer Reihe von Einträgen für die vorhergehenden und folgenden Jahre, in denen sich steigende Unsicherheit angesichts innerer und äußerer Spannungen abzeichnet. ${ }^{8}$ Einhards Translation, die nicht zuletzt eine Reaktion auf die Sebastianstranslation war, trug ihrerseits zur Popularität von Reliquienimporten aus Rom in den folgenden Jahren bei, und sein Text wurde zum Modell ähnlicher Translationsberichte. ${ }^{9}$

${ }^{3}$ Einhard, Translatio III, 13, ed. Waitz 252f. Für eine umfassende Neuinterpretation der Regierungszeit Ludwigs des Frommen und der Grundlagen des politischen Diskurses der 820er und 830er Jahre siehe nun Mayke de Jong, The Penitential State. Authority and Atonement in the Age of Louis the Pious, 814-840 (Cambridge 2009), bei der ich mich für zahlreiche Diskussionen und die Möglichkeit der Einsichtnahme in das Manuskript vor der Publikation herzlich bedanken möchte. Zum politischen Kontext vgl. auch die Beiträge in Charlemagne’s Heir. New Perspectives on the Reign of Louis the Pious (814-840), ed. Peter Godman/Roger Collins (Oxford 1990); Egon Boshof, Ludwig der Fromme (Darmstadt 1996).

${ }^{4}$ Einhard, Translatio III, 14, ed. Waitz 253f.

${ }^{5}$ Einhard, Translatio III, 12, ed. Waitz 252.

${ }^{6}$ Dutton, Politics of Dreaming 96f.

7 Siehe zu den (römischen) Translationen der Karolingerzeit Julia M.H. Smith, Old saints, new cults. Roman martyrs in Carolingian Francia, in: Early Medieval Rome and the Christian West. Essays in honour of Donald Bollough, ed. dies. (Leiden 2000) 317-334; Geary, Furta sacra, bes. 28-49; ders., The ninth-century relic trade - a response to popular piety?, in: Religion and the People, ed. James Obelkevich (Chapell Hill 1979) 8-19, wieder abgedruckt in: Patrick J. Geary, Living with the Dead in the Middle Ages (Ithaca 1994) 177-193; Klaus Herbers, Rom im Frankenreich - Rombeziehungen durch Heilige in der Mitte des 9. Jahrhunderts, in: Mönchtum - Kirche - Herrschaft 750-1050, Festschrift Josef Semmler, ed. Dieter R. Bauer/Rudolf Hiestand/Brigitte Kasten/ Sönke Lorenz (Sigmaringen 1998), 133-169; Martina Caroli, Bringing saints to cities and monasteries: translationes in the making of a sacred geography (ninth-tenth centuries), in: Towns and Their Territories between Late Antiquity and the Early Middle Ages, ed. Gian Pietro Brogiolo/Nancy Gauthier/Neil Christie (The Transformation of the Roman World 9, Leiden/Boston/Köln 2000) 259-274; Maximilian Diesenberger, Rom als virtueller Raum der Märtyrer. Zur gedanklichen Aneignung der Roma suburbana in bayerischen Handschriften um 800, in: Imaginäre Räume. Raumwahrnehmung und Raumvorstellung im Mittelalter, ed. Elisabeth Vavra (Wien 2007) 67-96. Für die komplexen Strategien der Päpste im Umgang mit Märtyrerreliquien siehe Conrad Leyser, The temptations of cult. Roman martyr piety in the age of Gregory the Great, in: EME 9, 3 (2000) 289-307; Thomas F.X. Noble, Topography, celebration, and power: the making of a papal Rome in the eighth and ninth centuries, in: Topographies of Power in the Early Middle Ages, ed. Mayke de Jong/Frans Theuws/Carine van Rhijn (The Transformation of the Roman World 6, Leiden/ Boston/Köln 2001) 45-91. Zur Frage der Weitergabe von Körperreliquien John McCulloh, From Antiquity to the Middle Ages: Continuity and change in papal relic policy, in: Pietas. Festschrift Bernhard Kötting, ed. Ernst Dassman/Karl Suso Frank (Jahrbuch für Antike und Christentum, Ergänzungsband 8, Münster 1980) 313-324; mit anderem Akzent Arnold Angenendt, Der römische und der gallisch-fränkische Anti-Ikonoklasmus, in: Frühmittelalterliche Studien 35 (2001) 201-225. Zum Prestige und Kult römischer Heiliger nördlich der Alpen Alan Thacker, Roman Apostles and Martyrs in the $7^{\text {th }}$ and $8^{\text {th }}$ centuries, in: Early Medieval Rome and the Christian West. Essays in honour of Donald Bullough, ed. Julia M.H. Smith (Leiden 2000) 247-277.

${ }^{8}$ Annales Regni Francorum, a. 826 (ed. Friedrich Kurze, MGH SS rer. Germ. in us. schol. sep. ed. [6], Hannover 1895) 171f. Vgl. Dutton, Politics of dreaming $87 \mathrm{ff}$.

9 Z.B. Rudolf von Fulda, Miracula sanctorum in Fuldensium ecclesias translatum (ed. Georg Waitz MGH SS 15, 1, Hannover 1887) 328-341. Zur Verwendung von Einhards Text durch spätere Autoren vgl. Geary, Furta sacra 118 -124 mit Anm. 49, sowie Heinzelmann, Hagiographische Reformschrift 271, 297. 
Karolingisches Interesse beschränkte sich allerdings keineswegs auf römische Reliquien. In den Jahren nach der politischen Krise des Jahres 833 arbeitete Hilduin gemeinsam mit Ludwig dem Frommen daran, die Identität des heiligen Dionysius mit Dionysius Areopagita zu etablieren und so den Anspruch durchzusetzen, die Reliquien eines Märtyrers zu besitzen, der in den Anfängen des christlichen Gallien gewirkt hatte. ${ }^{10}$ Das Prestige der Dionysius-Reliquien auf diese Weise zu erhöhen, war zweifellos eine attraktive Perspektive für den Abt von St. Denis, hatte aber auch weitere politische Implikationen. Der Briefwechsel mit Ludwig dem Frommen, der der überarbeiteten Passio vorangestellt ist, unterstreicht die Rechtmäßigkeit der Wiedereinsetzung Ludwigs ebenso wie Hilduins eben wiederhergestellte gute Beziehungen zum Kaiser. ${ }^{11}$ Die gemeinsame Förderung des Dionysius-Kultes bildete außerdem Teil von Bemühungen, Dionysius als pecularius patronus für den zukünftigen Herrscher Karl den Kahlen zu positionieren. ${ }^{12}$ In den folgenden Jahren wurden sowohl römische als auch fränkische Heilige in neue politische Kontexte transferiert: Berichte über Reliquientranslationen nach Sachsen waren Teil der Diskussionen über die Integration und nachhaltige Christianisierung der Sachsen. ${ }^{13}$

Daß sowohl das Verständnis von Reliquien und Wundern als Formen des Kontaktes mit dem Himmel als auch die politische Nutzung von Heiligenkulten im lateinischen Westen eine lange Tradition seit der Spätantike hat, braucht nicht besonders betont zu werden. ${ }^{14}$ Im 9. Jahrhundert konnte der Rückgriff auf Reliquien zur Etablierung und Festigung von politischen Positionen außerdem bereits auf eine spezifische Tradition des Umgangs mit diesen spirituellen Ressourcen innerhalb der mit den karolingischen Herrschern assoziierten Elite aufbauen. ${ }^{15}$ Die Regierungszeit Ludwigs des Frommen war aber zweifellos eine Periode der besonders

${ }^{10}$ Hilduin, Passio Dionysii, PL 106, 23-50. Die These von der Gleichsetzung des Dionysius mit dem in der Apostelgeschichte genannten Dionysius Areopagita, in dem man im Frühmittelalter auch den Autor eines Korpus neuplatonischer Schriften sah, dürfte im Frankenreich bereits einige Zeit vorher im Umlauf gewesen sein. Zur Entstehung der Legende und den möglichen Kontexten siehe Raymond Loenertz, La légende parisienne de S. Denys l'Aréopagite. Sa genèse et son premier témoin, in: Analecta Bollandiana 69 (1951) 217-237; Giles Brown, Politics and Patronage at the Abbey of Saint-Denis: The Rise of a Royal Patron Saint (ungedr. phil. Diss., Oxford 1989) 217-282; David Luscombe, Denis the Pseudo-Areopagite in the Middle Ages from Hilduin to Lorenzo Valla, in: Fälschungen im Mittelalter 1, ed. Horst Fuhrmann (MGH Schriften 33, 1, Hannover 1988) 133-152; Max Buchner, Die Areopagitika des Abtes Hilduin von St. Denis und ihr kirchenpolitischer Hintergrund. Studien zur Gleichsetzung Dionysius’ des Areopagiten mit dem heiligen Dionysius von Paris sowie zur Fälschungstechnik am Vorabend der Entstehung der Pseudoisidorischen Dekretalien, in: Historisches Jahrbuch 56 (1936) 441-480; 57 (1937) 31-60; 58 (1938) 55-96, 361-403; 59 (1939) 69-117.

${ }^{11}$ Epistolae variorum inde a morte Caroli usque ad divisionem imperii collectae 19 (Ludwig der Fromme an Hilduin von St. Denis) (ed. Ernst Dümmler, MGH EE 5, Karolini aevi 3, Berlin 1898/99, ND München 1978) 261-378, hier 325-327. Vgl. Brown, Politics and Patronage 283ff.

12 Brown, Politics and Patronage 305-323. In diesen Zusammenhang setzt Brown auch die Entstehung der Revelatio et Gesta Stephani (ed. Georg Waitz, MGH SS 15, 1, Hannover 1887, ND Stuttgart 1992) 2f. sowie der Clausula de unctione Pippini (ed. Georg Waitz, MGH SS 15, 1, Hannover 1887, ND Stuttgart 1992) 1 um das Jahr 830.

13 Translatio s. Viti martyris (ed. Irene Schmale-Ott, Veröffentlichungen der historischen Kommission für Westfalen 41, Münster 1979); Translatio s. Alexandri (ed. Bruno Krusch, Die Übertragung des hl. Alexander von Rom nach Wildeshausen durch den Enkel Widukinds 851. Das älteste niedersächsische Geschichtsdenkmal, in: Nachrichten von der Gesellschaft der Wissenschaften zu Göttingen, phil.-hist. Klasse, Fachgruppe III, 1933) 405-436. Siehe Hedwig Röckelein, Reliquientranslationen nach Sachsen im 9. Jahrhundert. Über Kommunikation, Mobilität und Öffentlichkeit im Frühmittelalter (Beihefte der Francia 48, Stuttgart 2002); Helmut Beumann, Die Hagiographie bewältigt die Unterwerfung und Christianisierung der Sachsen durch Karl den Großen, in: ders., Ausgewählte Aufsätze (Sigmaringen 1987) 289-323.

${ }^{14}$ Grundlegend Peter Brown, The Cult of the Saints. Its Rise and Function in Latin Christianity (Chicago 1981); ders., Relics and social status in the age of Gregory of Tours, in: ders., Society and the Holy in Late Antiquity (London 1982) 222-250, mit den Kommentaren bei Paul Antony Hayward, Demystifying the role of sanctity in Western Christendom, in: The Cult of Saints in Late Antiquity and the Middle Ages. Essays on the Contribution of Peter Brown, ed. James Howard-Johnston/Paul Antony Hayward (Oxford 1999) 115-142; Neil McLynn, Ambrose of Milan. Church and Court in a Christian Capital (Berkeley 1994) 209-237; Robert Markus, How on earth could places become holy?, in: Journal of Early Christian Studies 2, 3 (1994) 257-271. Für den politischen Gebrauch römischer Märtyrer in Rom selbst siehe beispielsweise Leyser, Temptations of cult; zur Bedeutung merowingerzeitlicher Prozesse für den karolingischen Umgang mit Heiligen siehe Paul Fouracre, The origins of the Carolingian attempt to regulate the cult of saints, in: The Cult of Saints in Late Antiquity and the Middle Ages. Essays on the Contribution of Peter Brown, ed. James Howard-Johnston/Paul Anthony Hayward (Oxford 1999) 143-165.

15 Als Beispiel sei auf die Translationen römischer Reliquien durch Fulrad von St. Denis und Chrodegang von Metz in den 50er und 60er Jahren des 8. Jahrhunderts verwiesen. Vgl. dazu Friedrich Prinz, Stadtrömisch-italische Märtyrerreliquien und fränkischer Reichsadel im Maas-Moselraum, in: Historisches Jahrbuch 87 (1967) 1-25; Martin A. Claussen, The Reform of the Frankish 
intensiven Mobilisierung von Reliquien in vielfältigen politischen Zusammenhängen, die auch mit einer verstärkten Tendenz zur Verschriftlichung von Translationsberichten einherging. ${ }^{16}$

Diese intensiven Bemühungen um Reliquien als spirituelle Ressourcen mußten sich allerdings in einem Feld der Diskussion um die Bedeutung der Reliquien und der Konkurrenz zwischen verschiedenen Akteuren und Kultzentren bewegen. Für solche Rivalitäten sind die Auseinandersetzungen zwischen Einhard und Hilduin das bekannteste Beispiel. Einerseits war die Katakombe Inter duas lauros an der Via Labicana, der ursprüngliche Begräbnisort von Einhards Heiligen, ein Schnittpunkt konkurrierender Interessen - Einhard zufolge bemühte sich Hilduin vergeblich um die Reliquien des ebenfalls dort bestatteten Tiburtius. ${ }^{17}$ Andererseits war die Verfügungsmacht über die Marcellinus- und Petrusreliquien umstritten, eine Auseinandersetzung, auf die Einhard in seiner Translatio reagierte, die aber auch in anderen Texten wie den Annales regni Francorum aufgegriffen wurde. ${ }^{18}$ Fränkische Ansprüche auf römische Heilige konkurrierten darüber hinaus mit päpstlichen. Der Liber pontificalis berichtet zu den ersten Jahren der Amtszeit Gregors IV. 828/9, daß der Papst die Reliquien des Tiburtius und des Sebastian gemeinsam mit denen Gregors des Großen nach St. Peter überführt habe. ${ }^{19}$ Die Sebastianstranslation löste auch im Frankenreich Diskussionen aus - so reagierte man in St. Quentin darauf mit Gegentexten zum Prestige des römischen Märtyers. ${ }^{20}$ Die Identifikation des Dionysius mit dem Areopagiten, die keineswegs unwidersprochen bleiben sollte, mußte Hilduin in den die Passio begleitenden Texten mit großem rhetorischen Aufwand untermauern und gegen Kritiker verteidigen. ${ }^{21}$

Church. Chrodegang of Metz and the Regula canonicorum in the Eighth Century (Cambridge Studies in Medieval Life and Thought, Fourth Series 61, Cambridge 2004) 248-289.

${ }^{16}$ Martin Heinzelmann, Translationsberichte und andere Quellen des Reliquienkultes (Typologie des sources du moyen âge occidental 33, Tournhout 1979) 94-99; ders., Hagiographische Reformschrift 297; Hans-Werner Goetz, Wunderberichte im 9. Jahrhundert. Ein Beitrag zum literarischen Genus der frühmittelalterlichen Mirakelsammlung, in: Mirakel im Mittelalter. Konzeptionen, Erscheinungsformen, Deutungen, ed. Martin Heinzelmann/Klaus Herbers/Dieter R. Bauer (Beiträge zur Hagiographie 3, Stuttgart 2002) 180-226.

17 Einhard, Translatio I, 1 und I, 5, ed. Waitz 240, 243. In der Passio Marcellini et Petri fordert Tiburtius die matrona Lucina dazu auf, die Märtyrer in der Krypta seiner eigenen Grabeskirche zu bestatten: Passio Marcellini et Petri 12, AASS 2. Juni, Bd. 1, 167-169, hier 169. Zur Diskussion, ob Einhard die Passio Marcellini et Petri gekannt hat, siehe Heinzelmann, Hagiographische Reformschrift 294 mit Anm. 143. Tiburtius spielt auch in der Passio Sebastiani eine Rolle, siehe Passio Sebastiani 16-19, PL 17, 1021C-1058A, hier 1044D-1051D.

${ }^{18} \mathrm{Zu}$ den Rivalitäten zwischen Einhard und Hilduin vgl. Seeliger, Römische Reliquien 61f.; Heinzelmann, Hagiographische Reformschrift 284ff. und 293f.; Smith, Emending evil ways 201-205. In den Annales regni Francorum findet sich nur eine kurze und unterkühlte Notiz zu Marcellinus und Petrus, die Destinationsort und Auftraggeber unerwähnt läßt, dafür aber die Differenz zwischen päpstlicher Erlaubnis, die für den Erwerb Sebastians hervorgehoben wird, und Diebstahl deutlich macht. Annales regni Francorum a. 827, ed. Kurze 174: Corpora beatissimorum Christi martyrum Marcellini et Petri de Roma sublata Octobrio mense in Franciam translata et ibi multis signis atque virtutibus clarificata sunt. Auch in späteren Texten wurde diese Diskussion weitergeführt. Die Bearbeitung der Notiz durch den Astronomus in seiner Vita Hludowici resultierte in einer deutlich geglätteten Darstellung dieses Ereignisses. Astronomus, Vita Hludowici Imperatoris 41 (ed. Ernst Tremp, MGH SS rer. Germ. in us. schol. NS 64, Hannover 1995) 279-555, hier 442. In den Annales Fuldenses ist die Nachricht über die Rückgabe der Reliquien an Einhard so gestaltet, daß sie Einhards Version des Geschehens entspricht. Annales Fuldenses a. 828 (ed. Friedrich Kurze, MGH SS rer. German. in usum schol. [7], Hannover 1891, ND Hannover 1993) 25. Vgl. dazu Heinzelmann, Hagiographische Reformschrift 269f.; Bondois, La translation 4-9.

${ }^{19}$ Liber Pontificalis CIII (Gregor IV.) 6 (ed. Louis Duchesne, Le Liber Pontificalis. Texte, introduction et commentaire, Bibliothèque des Écoles françaises d'Athènes et de Rome 2, Paris ${ }^{2}$ 1955) 75; vgl. die Anmerkung des Übersetzers in: Raymond Davis, The Lives of the Ninth-Century Popes (Liber Pontificalis) (Translated Texts for Historians 20, Liverpool 1995) 51f.

${ }^{20}$ In St. Quentin entstanden bald nach 834 vermutlich im Zusammenhang mit der Translation der Gebeine des Heiligen in die neue Abteikirche die Miracula Quintini. In diesem Text wird die chronologische Ordnung der Wunder nach den Erfordernissen der Reaktion auf römische Importe ausgerichtet. Nachdem die Kultgeschichte dieses Märtyrers, der zum sog. Rictiovarus-Zyklus gehört, und die posthumen Wunder bis in die Zeit Karls des Großen resümiert werden, wird die Abfolge der Wunder durch folgende Zäsur unterbrochen: Haec diversis temporibus audita, et a nobis aliqua visa; reliqua quae sequuntur, efferbuerunt eo tempore quo Suessionis S. Sebastiani allata fuerunt reliquiarum ossa (Miracula Quintini 27, AASS 31. Oktober, Bd. 13, 801-814, hier 809). Daraufhin werden für einen wesentlich kürzeren Zeitraum Wunder, die sich oft im Abstand von nur wenigen Tagen zutragen, berichtet. Sehr häufig betonen diese Wunder explizit die größere Wirkmacht der Quintinusreliquien gegenüber denen Sebastians: Miracula Quintini 28-44, AASS 31. Oktober, Bd. 13, 809f. Vgl. Jean-Luc Vilette, Passiones et Inventiones S. Quintini. L'élaboration d'un corpus hagiographique du haut moyen âge, in: Mélanges de science réligieuse 56, 2 (1999) 49-77.

${ }^{21}$ Epistolae variorum inde a morte Caroli magni usque ad divisionem imperii collectae 20 (Hilduin an Ludwig den Frommen) und 21 (Hilduin an omnes filii ecclesiae catholici) (ed. Ernst Dümmler, MGH EE 5, Aevi Karolini 3, Berlin 1899, ND München 1978) 328-335 und 336f. 
Abgesehen von solchen Auseinandersetzungen sorgte die gleichzeitige Infragestellung und Problematisierung der theologischen und pastoralen Grundlagen des Reliquienkultes im Zusammenhang mit der Wiederaufnahme der Bilderdebatte im Westen für zusätzliche Spannung im Umgang mit den sterblichen Überresten von Heiligen. In den Diskussionen innerhalb des karolingischen Episkopats, die vor allem Claudius von Turin mit der ikonoklastischen Politik in seiner Diözese ausgelöst hatte, spielten Reliquien eine ungleich wichtigere, aber auch stärker umstrittenere Rolle als in den Debatten des 8. Jahrhunderts. ${ }^{22}$ Die Traktate, die Dungal von Pavia und Jonas von Orléans gegen Claudius schrieben, widmen neben Bilder- und Kreuzeskult Fragen der Reliquienverehrung breiten Raum. ${ }^{23}$ Auch wenn sich die Positionen der karolingischen Theologen im einzelnen von einander unterschieden, zeigen die Reaktionen auf Claudius deutlich das Bedürfnis zur Reflexion über die Grundlagen des Reliquienkultes, aber auch zur Rechtfertigung der gängigen Praxis. ${ }^{24}$ Reliquien bildeten dabei Teil einer breiteren Diskussion um die Formen der Mediation zwischen Himmel und Erde, den relativen Stellenwert materieller und spiritueller Formen der Verehrung und den Status von materiellen Objekten wie Bildern, Kreuz und Eucharistie. ${ }^{25}$

Mit den Versuchen, die Legitimität von Reliquienkulten als Medium der Interaktion zwischen Gott und den Menschen durch die sterblichen Überreste seiner Heiligen zu affirmieren, ging auch der Wille zur institutionellen Kontrolle darüber einher. ${ }^{26}$ Aufmerksamkeit für Schwierigkeiten mit unautorisierten Kulten und falschen Formen der Devotion läßt sich bereits in den Bestimmungen karolingischer Konzilien seit der Mitte des 8. Jahrhunderts feststellen. ${ }^{27}$ Auch zur Zeit Ludwigs des Frommen wurden die Auseinandersetzungen nicht

${ }^{22}$ David F. Appleby, Holy relic and holy image: saints' relics in the Western controversy over images in the eighth and ninth centuries, in: Word and Image 8, 4 (1992) 333-343; Alain Boureau, Les théologiens carolingiens devant les images religieuses. La conjoncture de 825, in: Nicée II, 787-1987. Douze siècles d'images religieuses. Actes du colloque international Nicée II, tenu au Collège de France, Paris, 2-4 octobre 1986, ed. François Boespflug/Nicolas Lossky (Paris 1987) 247-262; Jean-Marie Sansterre, Les justifications des reliques dans le haut Moyen Âge, in: Les reliques: objets, cultes, symboles. Actes du colloque international de l’Université du Littoral-Côte d’Opale (Boulogne-sur-Mer) 4-6 septembre 1997, ed. Edina Bozóky/Anne-Marie Helvétius (Hagiologia 1, Brepols 1999) 81-93; Marc van Uytfanghe, Le culte des saints et la prétendue ‘Aufklärung’ carolingienne, in: Le culte des saints aux IX ${ }^{\mathrm{e}}-\mathrm{XIII}$ e siècles. Actes du colloque tenu à Poitiers, 15-17 septembre 1993, ed. Robert Favreau (Civilisation médiévale 1, Poitiers 1995) 151-166; Thomas F.X. Noble, The varying roles of biblical testimonies in the Carolingian image controversies, in: Medieval Transformations. Texts, Power, and Gifts in Context, ed. Esther Cohen/Mayke de Jong (Cultures, Beliefs and Traditions 11, Leiden/Boston/Köln 2001) 101-119; Angenendt, Der römische und der gallisch-fränkische Anti-Ikonoklasmus; Gert Haendler, Epochen karolingischer Theologie. Eine Untersuchung über die karolingischen Gutachten zum byzantinischen Bilderstreit (Theologische Arbeiten 10, Berlin 1958) bes. 130ff.

${ }^{23}$ Für eine übersichtliche Zusammenfassung der Debatten und detaillierte Diskussion von Claudius’ Position siehe Pascal Boulhol, Claude de Turin. Un évêque iconoclaste dans l’occident carolingien. Étude suivie de l'édition du Commentaire sur Josué (Collection des Études Augustiniennes, Serie Moyen Âge et Temps Modernes 38, Paris 2002) 115-149. Vgl. mit anderer Interpretation Johannes Heil, Claudius von Turin - Eine Fallstudie zur Geschichte der Karolingerzeit, in: Zeitschrift für Geschichtswissenschaften 45 (1997) 389-412, hier 394-406. Claudius' Thesen sind lediglich in einem am Hof zusammengestellten Exzerpt seines Liber Apologeticus überliefert: Claudius von Turin, Apologeticum atque rescriptum adversus Theutmirum abbatem (ed. Paolo Zanna, Responsa contra Claudium. A Controversy on Holy Images, Per Verba. Testi mediolatini con traduzione, Firenze 2002) 274-291; (ed. Ernst Dümmler, MGH EE 4, Karolini aevi 2, Berlin 1895, ND München 1978) 610-613.

${ }^{24}$ Jonas von Orléans, De cultu imaginum, PL 106, 305-388; Dungal, Responsa contra perversas Claudii Taurinensis episcopi sententias (ed. Paolo Zanna, Responsa contra Claudium. A Controversy on Holy Images, Per Verba. Testi mediolatini con traduzione, Firenze 2002). Im Vergleich zu Jonas und Dungal beurteilte Agobard von Lyon den spirituellen Nutzen materieller Objekte wesentlich skeptischer. Agobard von Lyon, De picturis et imaginibus (ed. Lieven van Acker, Agobardi Lugdunensis Opera Omnia, CC CM 52, Turnhout 1981) 149-181; vgl. Noble, Varying role 111f.; Boulhol, Claude de Turin 80f.; Egon Boshof, Erzbischof Agobard von Lyon. Leben und Werk (Köln/Wien 1969) 139-158.

${ }^{25}$ David Ganz hat diese Diskussion unter der Überschrift „Iconoclasm and the tools of salvation“ zusammengefaßt: Theology and the organisation of thought, in: The New Cambridge Medieval History 2: c. 700-c. 900, ed. Rosamond McKitterick (Cambridge 1995) 758-785, hier 773; Celia Chazelle, The Crucified God in the Carolingian Era. Theology and Art of Christ’s Passion (Cambridge 2001).

${ }^{26}$ In diesem Sinn ist auch die karolingische Aufmerksamkeit für römische Märtyrer und „long dead saints“ interpretiert worden, die den Fokus der Devotion auf akzeptierte Kulte im Anschluß an karolingische Reformpolitik richtet, siehe Pierre Riché, Les Carolingiens en quête de sainteté, in: Les fonctions des saints dans le monde occidental ( $\mathrm{III}^{\mathrm{e}}-\mathrm{XIII} \mathrm{e}^{\mathrm{e}}$ siècles). Actes du colloque organisé par l’École française de Rome avec le concours de l’Université de Rome La Sapienza, 27-29 oct. 1988 (Collection de l’École française de Rome 149, Rome 1991) 217-224; Geary, The ninth-century relic trade 179ff.; ders., Furta sacra 38ff.; Appleby, Holy relic 339f.

27 Die Admonitio generalis verfügt z.B., ut falsa nomina martyrum et incertae sanctorum memoriae non venerentur (Admonitio generalis 42 [ed. Alfred Boretius, MGH LL Capitularia regum Francorum 1, Hannover 1883] nr. 22, 52-62, hier 56); der bekann- 
zuletzt um die Definitionsmacht und Kontrolle über das Heilige geführt, die in der Sicht karolingischer Theologen wie etwa Jonas von Orléans klar in der Hand der Bischöfe liegen sollte. ${ }^{28}$ Ein gutes Beispiel dafür ist ein Brief, den Bischof Agobard von Lyon kurze Zeit nach den Translationen durch Hilduin und Einhard an seinen Kollegen Bartholomäus von Narbonne über den Umgang mit den zweifelhaften Reliquien des heiligen Firminus von Usèz schrieb. Darin verurteilte er die Zeichen und Wunder an dessen Schrein als leere Täuschungen, deren Kultivierung nur der Habgier Einzelner diente. ${ }^{29}$ In einem ähnlichen Brief an Bischof Theutbald von Langres schloß Agobards Nachfolger Amolo die Reliquien unbekannter römischer Märtyrer, die zwei anonyme Mönche nach Dijon gebracht hatten, ebenfalls aus dem Kreis der anerkannten Kulte aus. ${ }^{30}$ Für Agobard und Amolo mußte sich Reliquienverehrung innerhalb institutionell vorgegebener Formen bewegen: Amolo setzte den unautorisierten Kultstätten, an denen der rudis populus abergläubisch zusammenströmte, die jeweiligen parrochiae als geeignete Orte der Instruktion durch Bischöfe und Priester entgegen, die die Gläubigen durch Sakramente und Predigt unterweisen sollten. ${ }^{31}$ Die beiden Schreiben betonen nicht nur die legitime Definitionsmacht der Bischöfe, sondern auch die damit verbundene Verantwortung und die Vorsicht, die sie im Umgang mit Reliquien an den Tag legen mußten. ${ }^{32}$ Die beiden Texte sind ein gutes Beispiel dafür, daß die Diskussionen dieser Jahre nicht nur um die soziale und pastorale Funktion von Reliquienkulten geführt wurden, sondern auch um die möglichen Gefahren im Umgang mit heiligen Objekten und die Notwendigkeit, Wahres von Falschem zu unterscheiden.

Innerhalb der Versuche zur Formulierung von sozialer und politischer Ordnung, deren Diskussion zur Zeit Ludwigs des Frommen immer auch mit Fragen nach den moralischen Grundlagen und der richtigen Form des cultus divinus verbunden waren, ${ }^{33}$ spielten Reliquien eine bedeutende Rolle. Trotzdem sollten Reliquien keineswegs einfach als „Trumphkarten“ in politischen Diskussionen verstanden werden. Vielmehr stand das Prestige spezifischer Reliquien häufig selbst zur Diskussion, und ihre erfolgreiche Nutzung zur Etablierung von politischen und religiösen Positionen war im Kontext der grundsätzlichen Problematisierung des Reliquienkultes alles andere als selbstverständlich.

te Kanon 42 des Frankfurter Konzils 794 untersagt die Verehrung „neuer“ Heiliger, deren Status nicht durch die Autorität ihrer Passion oder ihres Lebens abgesichert ist: Capitulare Franconofurtense 42 (ed. Albert Werminghoff, MGH LL, Concilia 2,1, Concilia aevi Karolini 1, Hannover/Leipzig 1906) 165-171, hier 170. In den Capitula de causis cum episcopis et abbatibus tractandis (811) 7 (ed. Alfred Boretius, MGH LL Capitularia regum Francorum 1, Hannover 1883) nr. 72, 162-164, hier 163, werden die Bischöfe befragt, quid de his dicendum, quasi ad amorem Dei et sanctorum sive martyrum sive confessorum, ossa et reliquias sanctorum corporum de loco ad locum transferunt ibique novas basilicas construunt et, quouscumque potuerint ut res suas illuc tradant, instantissime adhortantur. Das Konzil von Mainz 813 sieht für Reliquientranslationen strenge institutionelle Kontrolle und die Zustimmung des Herrschers und einer Synode vor: Concilium Monguntinense (813) 51 (ed. Albert Werminghoff, MGH LL Concilia 2, Hannover/Leipzig 1906) 258-273, hier 272. Gleichzeitig muß aber in jedem Altar eine Reliquie enthalten sein. Vgl. Riché, Les Carolingiens 219f.; Nicole Hermann-Mascard, Les reliques des saints. Formation coutumière d'un droit (Collection d'histoire du droit. Collection d'histoire institutionelle et sociale 6, Paris 1975) 80ff.

${ }^{28}$ Boureau, Les théologiens 261; Appleby, Sight and church reform, bes. 20ff.; Raffaele Savigni, Giona di Orleans. Una ecclesiologia carolingia (Bologna 1989) 172-175.

29 Das macht den Brief zu einem vielzitierten Dokument für die karolingische Skepsis gegenüber Reliquienkulten und für die Bemühungen um Kontrolle der Kulte und der Devotion. Agobard von Lyon, De quorundam inlusione signorum (ad Bartholomeum) (ed. Lieven van Acker, Agobardi Lugdunensis Opera, CC CM 52, Turnhout 1981) 235-243; (ed. Ernst Dümmler, MGH EE 5, Karolini aevi 3, Berlin 1899) 206-210. Vgl. Geary, Furta sacra 31ff.; Riché, Les Carolingiens en quête de sainteté 220f.; Boshof, Erzbischof Agobard 176ff.

30 Amolo von Lyon, Epistola 1 (Epistola ad Theutbaldum) (ed. Ernst Dümmler, MGH EE 5, Karolini aevi 3, Berlin 1899) 361-378, hier 363-368. Vgl. Geary, Furta sacra 28f.

31 Amolo von Lyon, Epistola ad Theutbaldum 3 (rudis populus), 7 und 9, ed. Dümmler 364, 367f.

32 Z.B. Amolo von Lyon, Epistola ad Theutbaldum 3, ed. Dümmler 364f.

${ }^{33}$ De Jong, Penitential State; dies., The empire as ecclesia. Hrabanus Maurus and biblical historia for rulers, in: The Uses of the Past in the Early Middle Ages, ed. Yitzhak Hen/Matthew Innes (Cambridge 2000) 191-226; dies., Ecclesia and the early medieval polity, in: Staat und Staatlichkeit im Frühmittelalter, ed. Stuart Airlie/Walter Pohl/Helmut Reimitz (Forschungen zur Geschichte des Mittelalters, Wien 2006) 113-132; dies., Sacrum palatium et ecclesia. L'autorité religieuse royale sous les Carolingiens (790-840), in: Annales. Histoire, Sciences sociales 58 (2003) 1243-1269; Nikolaus Staubach, ,Cultus divinus' und karolingische Reform, in: Frühmittelalterliche Studien 18 (1984) 546-581; Philippe Depreux, Louis le Pieux réconsideré? À propos des travaux récents consacrés à l'héritier de Charlemagne et à son règne, in: Francia 21 (1994) 181-212; Karl Ferdinand Werner, Hludovicus Augustus. Gouverner l'empire chrétien - idées et réalités, in: Charlemagne’s Heir. New Perspectives on the Reign of Louis the Pious (814-840), ed. Peter Godman/Roger Collins (Oxford 1990) 3-123. 
Ausgehend von diesen Überlegungen soll im Folgenden Einhards Translatio Marcellini et Petri gemeinsam mit einem zeitgleichen Fallbeispiel diskutiert werden, der Translation der Reliquien des heiligen Hubert von Liège nach Andagne/St. Hubert, die sein Nachfolger auf dem Bischofstuhl, Walcaud von Liège, im Jahr 825 organisierte. Dieser Transfer, der im Kontext von Reformbemühungen Walcauds in seiner Diözese stand, war der Anlaß für die Entstehung der Vita et Translatio Huberti, die Jonas von Orléans zwischen 825 und 831 schrieb. ${ }^{34}$ Für die vergleichende Lektüre der beiden Texte steht die Frage nach den Strategien zur textuellen Umsetzung des spirituellen und politischen Potentials von Reliquien im Zentrum der Überlegungen. Die parallele Untersuchung der beiden Texte ermöglicht nicht nur einen Vergleich zwischen Strategien zur Integration importierter Reliquien und jenen zur Aktualisierung bereits länger im Frankenreich verankerter Traditionen. Sie kann auch dabei helfen, das Verständnis für das Spannungsfeld zu schärfen, in dem sich Texte über Reliquientranslationen in den späten 820er Jahren bewegen mußten. Die Frage nach den Bedingungen zur Nutzung dieser spirituellen Ressourcen soll dabei auch als Frage nach den Verhandlungen über die Bedeutung von Reliquien verstanden werden, die sich in den jeweiligen Texten abzeichnen. Diese Verhandlungen betreffen nicht nur die Positionen der jeweiligen Autoren in aktuellen Auseinandersetzungen, sondern auch die Autorität von Reliquien in solchen Diskursen.

\section{STRATEGIEN DER WIEDERSCHRIFT: LIÈGE UND ST. HUBERT}

Mit Jonas von Orléans war einer der bedeutendsten politischen Berater Ludwigs des Frommen für die Abfassung der Vita et Translatio Huberti verantwortlich, der aufgrund seiner zahlreichen Beiträge zu den Reformdiskussionen unter Ludwig dem Frommen als einer der wichtigsten Vertreter des karolingischen Reformepiskopats gilt. ${ }^{35}$ Jonas' Vita et Translatio ist die Wiederschrift einer älteren Version der Vita des heiligen Hubert, die um die Mitte des 8. Jahrhunderts entstand. Seine Neufassung der Vita und sein Bericht über die Translation 825 sollte nicht nur Walcauds Reformprojekt in Andagne unterstützen - der Text ordnet sich auch in Diskussionen ein, die Jonas in den späten 820er Jahren auch in anderen Texten beschäftigten. Seine Beiträge zur Bilder- und Reliquiendebatte zielten vor allem auf die pastorale Dimension dieser Kultpraktiken und den spirituellen Nutzen richtig eingesetzter materieller Objekte unter bischöflicher Kontrolle; seine Sicht dieser Problematik war dabei eng mit seinen ekklesiologischen Konzepten verbunden. ${ }^{36}$ Jonas war außerdem an der Neuformulierung und theoretischen Grundlegung des Amtes und der Position von Bischöfen innerhalb des christlichen Imperium, wie sie vor allem auf dem Konzil von Paris 829 formuliert wurde, entscheidend beteiligt. ${ }^{37}$ Beide Themen sind auch in der Vita et Translatio von großer Bedeutung, die deshalb für die Analy-

\footnotetext{
${ }^{34}$ Jonas von Orléans, Vita secunda et Translatio S. Huberti (ed. Carolus de Smedt, AASS 3. November, Bd. 1) 806-818. Zu Walcaud und seiner Arbeit in der Diözese Liège siehe Alain Dierkens, La christianisation des campagnes de l'empire de Louis le Pieux. L'exemple du diocèse de Liège sous l'épiscopat de Walcaud (c. 809-c. 831), in: Charlemagne’s Heir. New Perspectives on the Reign of Louis the Pious, ed. Roger Collins/Peter Godmann (Oxford 1990) 309-329; vgl. Satoshi Tada, The creation of a religious centre: Christianisation in the diocese of Liège in the Carolingian period, in: Journal of Ecclesiastical History 54,2 (2003) 209227.

35 Siehe die umfassende Studie von Savigni, Giona di Orleans; Alain Dubreucq, Introduction, in: Jonas d’Orléans, Le métier de roi (De institutione regia). Introduction, texte critique, traduction, notes et index (SC 407, Paris 1995) 1-117, hier 1-55; Hans Hubert Anton, Fürstenspiegel und Herrscherethos in der Karolingerzeit (Bonner Historische Forschungen 32, Bonn 1968) 211ff.; Étienne Delaruelle, Jonas d’Orléans et le moralisme carolingien, in: Bulletin de Littérature ecclésiastique 55 (1954) 129-143; $221-228$. Werner, Hludovicus Augustus 55 mit Anm. 191, bezeichnet Jonas als „homme clé de la reforme“.

${ }^{36}$ Appleby, Sight and church reform; ders., Holy relic and holy image 338ff.; Boulhol, Claude de Turin 156-163; Boureau, Les théologiens 260f. Jonas arbeitete in der zweiten Hälfte der 820er Jahre nicht nur an seinem Traktat gegen Claudius, den er schliesslich um 840 fertigstellte, sondern war auch unter den Teilnehmern der Pariser Synode zur Bilderverehrung 825 sowie einer der kaiserlichen Gesandten, die deren Ergebnisse in Rom dem Papst übermitteln sollte. Vgl. Wilfried Hartmann, Die Synoden der Karolingerzeit im Frankenreich und in Italien (Konziliengeschichte Reihe A, Paderborn/Wien/München/Zürich 1989) 168f.

37 Siehe Savigni, Giona di Orleans, bes. Kap. 6, 145-175. Zur Zuschreibung der Redaktion der Pariser Konzilsakten an Jonas (ebenso wie jener von Aachen 836) Dubreucq, Metier de roi 18-42; Anton, Fürstenspiegel 204ff., 213ff. Vgl. Hartmann, Synoden 169f., 179-196. Auf Jonas von Orléans geht vermutlich auch die Zusammenstellung eines Florilegs aus patristischen Texten zu diesen Fragen zurück, siehe dazu Gerhard Laehr, Ein karolingischer Konzilsbrief und der Fürstenspiegel Hinkmars von Reims. Aus dem Nachlaß Gerhard Laehrs herausgegeben von C. Erdmann, in: NA 50 (1935) 106-135; Anton, Fürstenspiegel $221-231$.
} 
se von Jonas' Standpunkten in diesen Fragen eine wichtige Rolle gespielt hat. ${ }^{38}$ Seine Strategien bei der Wiederschrift der Vita Huberti prima, die ihre Aktualisierung und damit die Bedeutung des Textes in sehr spezifischen zeitgenössischen Diskussionen herstellten, sind allerdings bisher kaum untersucht. ${ }^{39}$

Als Jonas die Vita et Translatio schrieb, hatte die Verbindung der beiden Anliegen - die Diskussion um die Position von Bischöfen einerseits und um die Bedeutung von Reliquienkulten andererseits - in der hagiographischen Tradition der Diözese Maastricht/Liège bereits eine lange Geschichte. Für das Verständnis von Jonas' und Walcauds Aneignung der spirituellen Ressourcen der Diözese ist daher zunächst ein Blick auf die Entstehungszusammenhänge der Lièger Bischofsviten des 8. Jahrhunderts notwendig.

Die Vita Huberti prima, die die Grundlage für Jonas’ Text darstellt, ist ihrerseits das Ergebnis einer sorgfältigen Auseinandersetzung mit den spirituellen Traditionen der Diözese. Für gewöhnlich wird ihre Entstehung in engem Zusammenhang mit einer ersten Elevation von Huberts Gebeinen im Jahr 743, an der der karolingische Hausmeier Karlmann mitwirkte, angenommen. ${ }^{40}$ Während die Beschreibung dieser Elevation den Schlußpunkt der Vita Huberti bildet, steht eine andere Translation am Beginn des Textes: Die Übertragung der Reliquien von Huberts Vorgänger Lambert von Maastricht nach Liège im Jahr 716/8. Die Vita Lamberti, die vermutlich zwischen 727 und 743 entstand, ist wiederum die wichtigste textuelle Grundlage für die Vita Huberti; eine weitere wichtige Quelle war die Lebensbeschreibung des Bischofs Arnulf von Metz. ${ }^{41}$

${ }^{38}$ Für die Einordnung der Vita et Translatio in diese Diskussionen siehe vor allem Savigni, Giona di Orleans 145-175, 201-213; vgl. Appleby, Sight and church reform. Auf die Bedeutung des Textes kann vielleicht die Tatsache hinweisen, daß die Vita et Translatio eine Generation später das Interesse von Hinkmar von Reims erregte. Der älteste erhaltene Kodex (Paris B.N.F. 5609), der nur das neu zusammengestellte Dossier zu Hubert enthält (Widmungsbrief, Vita, Translatio), gehört zu den Handschriften, die Hinkmar dem Remigius-Kloster hinterließ. Siehe Joseph-Claude Poulin, Les libelli dans l'édition hagiographique avant le XII siècle, in: Livrets, collections et textes. Études sur la tradition hagiographique latine, ed. Martin Heinzelmann (Beihefte der Francia 63, Sigmaringen 2006) 15-193, hier 106.

${ }^{39}$ Siehe aber Léopold Genicot, Discordiae Concordantium. Sur l'intérêt des textes hagiographiques, in: Académie royale de Belgique, Bulletin de la classe des lettres et des sciences morales et politiques, 5. ser. 51, 2-3 (1965) 65-75, der anhand von Beispielen aus den Hubert-Viten auf die Fruchtbarkeit der vergleichenden Analyse hinweist. Zur Terminologie und Theorie der réécriture Gérard Genette, Palimpseste. Die Literatur auf zweiter Stufe (Frankfurt am Main 1993). Zur mediävistischen Diskussion vgl. die Beiträge in: La réécriture hagiographique dans l'occident médiéval. Transformations formelles et idéologiques, ed. Monique Goullet/Martin Heinzelmann (Beihefte der Francia 58, Paris 2003). Für Überlegungen zu Möglichkeiten und Grenzen der Anwendung literaturwissenschaftlicher Typologien auf hagiographische Texte des Mittelalters siehe vor allem die Diskussion in Monique Goullet, Vers une typologie des réécritures hagiographiques, à partir de quelques exemples du Nord-Est de la France. Avec une édition synoptique des deux Vies de saint Èvre de Toul, in: ebd. 109-144. Vgl. auch Marc van Uytfanghe, Le remploi dans l’hagiographie: une „loi du genre“ qui étouffe l’originalité?, in: Ideologie e pratiche del reimpiego nell'alto medioevo (Settimane di studio del centro italiano di studi sull' alto medioevo 46, Spoleto 1999) 359-411. Zu karolingischen Bearbeitungen älterer Viten aus einer stärker philologischen Perspektive Katrien Heene, Merovingian and Carolingian hagiography. Continuity or change in public and aims?, in: Analecta Bollandiana 107 (1989) 415-428; dies., Audire, legere, vulgo: an attempt to define public use and comprehensibility of Carolingian hagiography, in: Latin and the Romance Languages in the Early Middle Ages, ed. Roger Wright (University Park-Pennsylvania 1996) 146-163.

${ }^{40}$ Vita Huberti episcopi Traiectensis (ed. Wilhelm Levison, MGH SS rer. Merov. 6, Hannover 1913) 471-496; dt. (ed. Clemens Heydenreich, Der heilige Hubert und die Vita Hugberti Episcopi Traiectensis [um 750], in: Mirakelberichte des frühen und hohen Mittelalters, ed. Klaus Herbers/Lenka Jiroušková/Bernhard Vogel (Freiherr-vom-Stein-Gedächtnisausgabe 43, Darmstadt 2005)] 68-89. Die genaue Datierung der Vita ist aufgrund der späten Überlieferung schwierig zu bestimmen, siehe Levisons Einleitung zur Edition 474f.; Léon van der Essen, Étude critique et littéraire sur les Vitae des saints mérovingiennes de l’ancienne Belgique (Recueil de travaux de l’Université de Louvain, 1ère série 17, Louvain/Paris 1907) 59-63; Matthias Werner, Der Lütticher Raum in frühkarolingischer Zeit. Untersuchungen zur Geschichte einer karolingischen Stammlandschaft (Veröffentlichungen des MaxPlanck-Institutes für Geschichte 62, Göttingen 1980) 275f.; Ian N. Wood, Genealogy defined by women: the case of the Pippinids, in: Gender in the Early Medieval World. East and West, 300-900, ed. Leslie Brubaker/Julia M.H. Smith (Cambridge 2004) 234-256, hier 244 mit Anm. 59: „the text appears to be of the eighth century.“ Zum Text vgl. außerdem Genicot, Discordiae Concordantium 67f; ders., Aspects de Saint Hubert, in: Leodium 63 (1978) 5-18; François Baix, Saint Hubert. Sa mort, sa canonisation, ses reliques, in: Études sur l’histoire du pays mosan au Moyen Âge. Mélanges Felix Rousseau (Bruxelles 1958) 7180.

41 Vita Lamberti vetustissima (ed. Bruno Krusch, MGH SS rer. Merov. 6, Hannover 1913) 353-384; Vita Arnulfi (ed. Bruno Krusch, MGH SS rer. Merov. 2, Hannover 1888) 426-446. Über die Vorlagen der Vita Huberti vgl. van der Essen, Étude critique 59-63; Génicot, Discordiae concordantium. Für Prolog und Schlußabsatz nennt Levison auch die Vita Amandi prima als Quelle der Vita 
Durch eine umsichtige Montage von Textbausteinen wird in der Vita Huberti prima in Auseinandersetzung mit ihren Vorlagen die Lebensgeschichte eines idealen Bischofs entworfen. Im Zentrum dieses Modells steht die Beschreibung der pastoralen Beziehung des Bischofs zu seiner Gemeinde. Für die Begründung von Huberts Heiligkeit ist weiters der persönliche spirituelle Fortschritt des Amtsträgers ein wichtiger Aspekt. Wesentliche Schritte der Argumentation und Erzählung von Huberts Leben als heiliger Bischof sind der Bericht über seine Erhebung zum Bischof am Beginn der Vita und die Translation der Lambert-Reliquien, weiters eine in direkter Rede wiedergegebene Predigt Huberts in der Mitte des Textes sowie die Ereignisse nach Huberts Tod, die rückwirkend den Erfolg seiner pastoralen Tätigkeit demonstrieren. Die Erzählung vom Offenbarwerden seiner Heiligkeit mit dem Wunder der körperlichen Unversehrtheit als Endpunkt handelt auch von der Neudefinition der Beziehung zwischen der grex und dem nunmehr toten pastor als Patron, und so ist auch die posthume Geschichte Huberts in vielfacher Hinsicht eine Fortsetzung des „pastoralen Schwerpunktes“ der Vita. ${ }^{42}$

Huberts Amtsantritt bietet zu Beginn der Vita die Gelegenheit, die Grundzüge des Bischofsideals zu skizzieren. ${ }^{43}$ Das Zitat einer der zentralen Bibelstellen zur Berufung der Apostel (Mt 21,19) positioniert Hubert als Nachfolger Christi und der Apostel, während gleichzeitig die Orientierung an seinem Amtsvorgänger Lambert eine wesentliche Rolle spielt. Daß Hubert die Anforderungen an einen guten Bischof von Beginn an erfüllte, wird in der Vita durch eine eindrucksvolle Aufzählung seiner Tugenden und pastoral-karitativen Tätigkeiten postuliert. ${ }^{44}$ Im weiteren Verlauf des Textes wird die Umsetzung dieses Ideals anhand beispielhafter Episoden aus Huberts Leben beschrieben. Zu den wichtigsten narrativen Strategien für die Konstruktion Huberts als Modellbischof gehört die Wahl eines iterativen Darstellungsmodus: Einzelne Ereignisse werden selten chronologisch verankert, erhalten aber durch geraffte Beschreibungen ähnlicher Vorgänge und Gewohnheiten Huberts, die als Rahmen für die einzelnen Episoden dienen, exemplarischen Charakter. ${ }^{45}$ Der Bischof wird dabei vor allem in seiner liturgischen Funktion, als Prediger, der zur Buße aufruft, und als Lehrer für die ihm anvertrauten Gläubigen, aber auch für den engeren Kreis seiner Schüler, dargestellt. ${ }^{46}$ Das Zusammenstellen von Tätigkeiten und Epitheta zu Katalogen bischöflicher Tugenden wie anläßlich von Huberts Amtsantritt, ein verbreitetes Stilmittel merowingischer Hagiographie, wird in der Vita Huberti auch zur Vernetzung der einzelnen Episoden untereinander eingesetzt. So wird nach Huberts Tod der Gemeinde eine Klagerede in den Mund gelegt, die die Liste seiner Vorzüge aus der Anfangsszene beinahe wortgleich reproduziert und so die Erfüllung des am Beginn des Textes postulierten Ideals verdeutlicht. ${ }^{47}$

Huberti, deren Datierung ebenfalls umstritten ist, vgl. dazu Adriaan Verhulst/Georges Declerq, L'action et le souvenir de saint Amand en Europe centrale. À propos de la découverte d’une Vita Amandi antiqua, in: Aevum inter utrumque. Mélanges Gabriel Sanders, ed. Marc van Uytfanghe/Roland Demeulenaere (Instrumenta patristica 23, Steenbrugge 1991) 503-526; Ian N. Wood, The Missionary Life. Saints and the Evangelisation of Europe, 400-1500 (Harlow 2001) 39-42.

42 Vita Huberti prima 1, ed. Levison 483 (Bischofserhebung); ebd. 11, ed. Levison 489f. (Predigt); 15 und 16, ed. Levison 491-493 (Begräbnis).

43 Vita Huberti prima 1, ed. Levison 483.

44 Vita Huberti prima 1, ed. Levison 483: [...] fuit igitur largitor indigencium, refocilator pauperum, sustentator orfanorum, consolator viduarum, adminiculum obpressorum, misertus inopum, monasteriorum visitator, pater miserorum, in tribulacione subveniens, dolentes in merore concussos consolatoria indicens verba, trusos in carcerem exenia per fenestram mittens, eminentissimus omnium largitor, largus ad dandas elemosinas, argenteis ligatis in palleis iugiter secum deportans, non surdus auditor ad se clamantes, paratus semper daturus invenitur. Vgl. zu diesem Darstellungsmittel in merowingischer Hagiographie Uytfanghe, Le remploi 379f.; Anton Voegtle, Art. Tugendkataloge, in: Lexikon für Theologie und Kirche 10 (1965) 399-401.

45 Zum Begriff des „iterativen Modus“ siehe Gérard Genette, Die Erzählung, 2. erw. Aufl. (München 1998) 81-114 und 217f. Siehe z.B. die direkte Rede, in der Hubert das Martyrium Lamberts betrauert und seine eigene Unwürdigkeit beklagt (Vita Huberti prima 1, ed. Levison 483), wonach mit folgender Bemerkung zur Translation übergeleitet wird: Iam ista ei dicente per annis XII et crebrius sermonicante [...] (Vita Huberti prima 2, ed. Levison 484), oder die Einleitung zum Bericht über Huberts Missionstätigkeit ebd. 3, ed. Levison 484; siehe auch ebd. 6, ed. Levison 486: iuxta consuetam ordinem [...] egrediens, verba Domini plebem sibi comissam, ut solebat, dulciter infundens [...]; ebd. 9, ed. Levison 488: promptior in vigiliis, in oracionibus, in ieiuniis, in elemosinis, magis erogavit infra annum [...].

${ }^{46}$ Sowohl die Vita Huberti als auch ihre Vorlage, die Vita Lamberti, erwähnen darüber hinaus die Missionstätigkeit der beiden Bischöfe in den Ardennen, Toxandrien und Brabant: Vita Huberti prima 3, ed. Levison 484f.; Vita Lamberti 10, ed. Krusch 363f.

47 Vita Huberti prima 15, ed. Levison 492: Hic erat defensor noster, adiutor in periculo, dolencium consolator, misertus inopum, pius pastor ovium, nutritor orfanorum, adminiculum viduarum, doctor ecclesiae, monita Christi prebens, patriarcharum exsempla secutus, persecutor diaboli, pompa seculi dispiciens, lubricam mundi calcavit. 
Die Konzeption der Position des Bischofs in seiner Diözese und der an ihn gestellten Anforderungen, wie die Vita Huberti sie vermittelt, ist deutlich anders akzentuiert als in jenen Viten, aus denen das Material für große Teile des Textes stammt. ${ }^{48}$ Anders als die Vita Lamberti enthält die Vita Huberti keinerlei Hinweise auf Herkunft oder politische Stellung des Heiligen. Umgekehrt steht in der Vita Lamberti die Ausübung des pastoralen Amtes nicht in vergleichbarer Weise im Mittelpunkt. So finden sich in der Vita Lamberti zwar ebenfalls katalogartige Aneinanderreihungen von positiven Eigenschaften des Bischofs, ${ }^{49}$ hier fehlt aber der systematische Einsatz der Tugendkataloge als Argumentationsstrategie ebenso wie die konsequente Bemühung um die Illustration dieses Ideals im restlichen Text. Zudem ist die Auswahl, die die Vita Huberti aus den Tugendkatalogen der Vorlage trifft, interessant. Die Vita Lamberti beschreibt den Bischof nicht nur in seinen sozialen und karitativen Funktionen in der civitas, sondern hebt auch seine vornehme Herkunft und Schönheit sowie seine sozialen, intellektuellen und politischen Fähigkeiten hervor. ${ }^{50} \mathrm{Im}$ Vergleich dazu ist die Auswahl in der Vita Huberti ausschließlich auf Elemente beschränkt, die in direktem Zusammenhang mit dem pastoralen Amt und den dafür nötigen spirituellen und asketischen Voraussetzungen stehen. Das Tugendideal, das die Vita Huberti vermittelt, ist also wesentlich präziser definiert und anders akzentuiert. ${ }^{51}$

Mit der Vita Arnulfi verbindet beide Lièger Viten die Sorge um den richtigen Einsatz von materiellen Gütern für die klassischen Funktionen des Bischofs als Wohltäter der Armen und Kranken. In der Vita Arnulfi ist die Vereinbarkeit von politischer und finanzieller Macht und Bischofsamt eines der wichtigsten Themen, wobei in diesem Text - anders als in der Vita Huberti - pastorales Amt und asketischer Ehrgeiz in einem spannungsreichen Verhältnis zueinander stehen. ${ }^{52}$ Aufgrund dieser thematischen Schwerpunkte bildete die Vita Arnulfi eine gute Grundlage für den Entwurf eines Bischofsideals. ${ }^{53}$ Auch im Umgang mit der Vita

${ }^{48}$ Im Gegensatz zur Vita Huberti wurden sowohl die Vita Arnulfi als auch die Vita Lamberti häufig zur Illustration der Theorie vom merowingischen „Adelsheiligen“ herangezogen. Friedrich Prinz, Heiligenkult und Adelsherrschaft im Spiegel merowingischer Hagiographie, in: Historische Zeitschrift 204 (1967) 529-544; ders., Frühes Mönchtum im Frankenreich. Kultur und Gesellschaft in Gallien, den Rheinlanden und Bayern am Beispiel der monastischen Entwicklung, 4. bis 8. Jahrhundert (Darmstadt ${ }^{2} 1988$ ) 489-503. Für Lambert siehe etwa Jean-Louis Kupper, Saint Lambert: De l’histoire à la légende, in: Revue d’histoire ecclésiastique 79 (1984) 5-49, hier 11f.; Georg Scheibelreiter, Der Tod Landberts von Maastricht, in: Bischofsmord im Mittelalter, ed. Natalie Fryde (Veröffentlichungen des Max-Planck-Instituts für Geschichte 191, Göttingen 2003) 51-82. Zur Kritik an diesem Konzept und seinen Implikationen Ian N. Wood, The use and abuse of Latin hagiography, in: East and West: Modes of Communication, ed. Evangelos Chrysos/Ian N. Wood (The Transformation of the Roman World 5, Leiden/Boston/Köln 1999) 93-109, hier 102ff.; für einen alternativen Entwurf siehe auch Fouracre, Carolingian attempt.

${ }^{49}$ Die ausführlichste Zusammenstellung, die ausgehend von den persönlichen Vorzügen auch die bischöflichen Funktionen Lamberts hervorhebt und die cura pastoralis stark betont, findet sich nach der Wiedereinsetzung Lamberts in Maastricht: siehe Vita Lamberti vetustissima 8-9, ed. Krusch 362f.

${ }^{50}$ Vgl. z.B. den Beginn der Lambert-Vita: Vita Lamberti vetustissima 2, ed. Krusch 354f., wo Lamberts Herkunft und Ausbildung erwähnt wird; ebd. 3, ed. Krusch 356, beschreibt ihn u.a. als sapiens, aspectu amabilis, conloquio affabilis, recta conversatione cum pontifice quam et in domo regia [...] forma precipuus, fortis et velox [...] firmus in bello [...] caritate et castitatem et humilitatem fundatus. Bei der Bischofserhebung wird das Lob auf seine äußerlich sichtbaren Tugenden mit der Betonung von moderatio, cura und sapientia als Regierungstugenden verbunden: ebd. 4, ed. Krusch 357: Erat autem Landibertus pontifex statura procerus, faciem derogata, cesaria formonsa, inclitis oculis, manus honestas, digita longa, carnem candidam [...]. Erat enim consiliarius fortis et omnem sapientiam cum cura et moderatione gerebat. Apud regem summum tenebat locum.

${ }^{51}$ Von den stärker auf die Person ausgerichteten Tugenden übernimmt die Vita Huberti die Aufzählung der asketischen Fähigkeiten. Aus dem Bericht über Lamberts Exil (Vita Lamberti vetustissima 5, ed. Krusch 358) wird in der Vita Huberti eine Aufzählung von asketischen Tugenden, deren Auswahl durch 2 Kor 6, 5f. inspiriert ist, aufgenommen. Während der biblische Hintergrund in der Vita Lamberti dazu dient, Lamberts Standhaftigkeit in Leid und Verfolgung anzudeuten, erhält das Bibelzitat in der Vita Huberti eine allgemeinere Funktion und wird zudem um den Aspekt der pastoralen Tätigkeit ergänzt: Vita Huberti 3, ed. Levison 483: Postea igitur Hugbertus in timore Dei magis confirmatus, amplius se certaminam dedit; in ieiuniis, in castitate, in longanimitate, in omni sanctorum patriarchum exempla secutus, more apostolico intrepidus verbis docebat, exemplo monstrabat. Vgl. auch Vita Lamberti vetustissima 10, ed. Krusch 364, und Vita Huberti 9, ed. Levison 488.

52 Zu diesem Text siehe Monique Goullet, Les saints du diocèse de Metz (SHG X), in: Miracles, vies et réécritures dans l'occident médiéval, ed. dies./Martin Heinzelmann (Beihefte der Francia 65, Ostfildern 2006) 149-317, hier 212-224; Lellia Cracco Ruggini, The crisis of the noble saint: the Vita Arnulfi, in: Le septième siècle: changement et continuités/The seventh century: change and continuity, ed. Jacques Fontaine/Jocelyn N. Hillgarth (London 1992) 116-149; Ian N. Wood, Forgery in Merovingian hagiography, in: Fälschungen im Mittelalter 5, ed. Horst Fuhrmann (MGH Schriften 33, 5, Hannover 1988) 369-384, hier 370f.; Maria Teresa Fattori, I santi antenati carolingi fra mito e storia: agiografie e genealogie come strumento di potere dinastico, in: Studi Medievali, 3a serie 34, 2 (1993) 487-561, hier 496f., 508-512.

${ }^{53}$ Im Zusammenhang mit der Erhebung von Huberts Reliquien durch Karlmann konnte ihre Verwendung auch die Verbindung zu einem der möglichen Entwürfe karolingischer Vergangenheit herstellen helfen. 
Arnulfi entschied man sich in der Vita Huberti dafür, die Darstellung der Position des Bischofs in seiner Diözese auf die pastoralen und liturgischen Aufgaben des Bischofs zu konzentrieren. Anders als die Vita Arnulfi legt die Vita Huberti den Schwerpunkt dabei weniger einseitig auf die asketischen Tugenden eines Möchtegern-Eremiten. Für den erhöhten Stellenwert der Pastoral in der Vita Huberti ist unter anderem die Auswahl an Wundererzählungen ein Beispiel, für die die Vita Arnulfi die Vorlage bietet: Hier werden gezielt jene Wunder übernommen, die sich im Rahmen der Liturgie ereignen, und diese Berichte gegebenenfalls durch Bemerkungen über Predigt und Pastoral ergänzt. ${ }^{54}$ Die gezielt gebauten Bezüge zu den Vorlagen, die Auswahl der Textbausteine sowie die Umsicht bei ihrer Aneignung und Umgestaltung können darauf hinweisen, daß Entwurf und Diskussion eines Bischofsmodells in Auseinandersetzung mit den zugrundeliegenden Texten eines der wesentlichen Anliegen der Vita Huberti prima ist. ${ }^{55}$

\section{2.}

Das Bild konsensualer und weitgehend konfliktfreier bischöflicher Herrschaft, das die Vita Huberti entwirft, kann vor dem Hintergrund der komplexen politischen Geschichte der Diözese Maastricht-Liège zu Huberts Lebzeiten durchaus verwundern. Die Kontrolle über das Bistum, dessen Zentrum sich im Lauf des Frühmittelalters von Tongern nach Maastricht und später von Maastricht nach Liège verlagerte, war lange umstritten und offenbar sowohl für lokale Gruppierungen als auch für die Könige und Hausmeier schwer zu monopolisieren. ${ }^{56}$ Vor allem in den Jahrzehnten um 700 war die Diözese ein stark umkämpfter Raum, und die Auseinandersetzungen um die Kontrolle darüber eng mit den Machtkämpfen verknüpft, die mit der Durchsetzung Karl Martells einhergingen. ${ }^{57}$

Huberts Vorgänger Lambert verlor sein Amt in den politischen Unruhen der 70er und 80er Jahre des 7. Jahrhunderts; kurz nach seiner Wiedereinsetzung wurde er in den Auseinandersetzungen zwischen rivalisierenden lokalen Fraktionen vom königlichen domesticus Dodo ermordet. ${ }^{58}$ Sein Nachfolger Hubert, der wahrscheinlich ein Verwandter Plektruds war und dessen Erhebung Pippin II. unterstützt hatte, gehörte zu den

\footnotetext{
${ }^{54}$ So übernimmt die Vita Huberti aus einer Serie von drei Dämonenaustreibungen durch den Heiligen genau das zweite Wunder, das sich in der Vita Arnulfi im Gegensatz zu den beiden anderen während der Liturgie ereignet. Anders als in der Vita Arnulfi wird hier aber nicht nur von einer Prozession anläßlich des dreitägigen Fastens berichtet, sondern auch von der Predigt, die Hubert bei dieser Gelegenheit hält und in der er die Gläubigen zu Gehorsam den bischöflichen Ermahnungen gegenüber auffordert: Vita Huberti prima 6, ed. Levison 486; vgl. Vita Arnulfi 10, ed. Krusch 435f. Siehe zu diesem Vergleich und zur größeren Bedeutung der Predigt gegenüber der Vita Arnulfi Genicot, Discordiae concordantium 70f. Auch ein Strafwunder, das auf die Sonntagsheiligung zielt, wird in der Vita Huberti nicht nur von einem posthumen Wunder in die Lebenszeit des Heiligen transponiert, sondern auch um den Aspekt der Pastoral ergänzt, vgl. Vita Huberti prima 4, ed. Levison 485, mit Vita Arnulfi 28, ed. Krusch 444f.

${ }^{55}$ Für diese Sichtweise von Viten als aufeinander reagierende Texte Wood, Use and abuse; vgl. van Uytfanghe, Le remploi.

56 Siehe aus der umfangreichen Literatur zur Geschichte der Diözese vor allem die rezenten Neuinterpretationen bei Frans Theuws, Maastricht as a centre of power in the early Middle Ages, in: Topographies of Power in the Early Middle Ages, ed. Mayke de Jong/Frans Theuws/Carine van Rhijn (The Transformation of the Roman World 6, Leiden/Boston/Köln 2001) 155-216, und Alain Dierkens, Réflexions sur l'histoire réligieuse de Maastricht à l'époque mérovingienne, in: L'évangélisation des régions entre Meuse et Moselle et la fondation de l'abbaye d'Echternach ( $V^{\mathrm{e}}-\mathrm{IX}{ }^{\mathrm{e}}$ siècle). Actes des $10^{\text {es }}$ journées lotharingiennes, 28-30 octobre 1998, Centre Universitaire de Luxembourg, ed. Michel Polfer (Publications de la Section Historique de l'Institut Grand-Ducal de Luxembourg 117, Publications du CLUDEM 16, Luxemburg 2000) 541-567. Vgl. außerdem Werner, Lütticher Raum 228-340; Piet Leupen, Maastricht in de vroege middeleeuwen, in: Einhard. Studien zu Leben und Werk, ed. Hermann Schefers (Darmstadt 1997) 209-211.

57 Paul Fouracre, The Age of Charles Martell (The Medieval World, Harlow 2000) 33-75; Ian N. Wood, The Merovingian Kingdoms, 450-751 (London/New York 1994) 255-272, und siehe die Beiträge in: Karl Martell in seiner Zeit, ed. Jörg Jarnut/Ulrich Nonn/ Michael Richter (Beihefte der Francia 37, Sigmaringen 1994); Waltraud Joch, Legitimität und Integration. Untersuchungen zu den Anfängen Karl Martells (Historische Studien 456, Husum 1999).

${ }^{58}$ Für Exil und Absetzung Lamberts siehe Vita Lamberti vetustissima 5-7, ed. Krusch 357-361. Der Text der Vita Lamberti würde nahelegen, daß Lambert sich ohne die Unterstützung Childerichs II. in Maastricht nicht mehr halten konnte. Die Vita Lamberti vetustissima 4, ed. Krusch 357, behauptet, daß Childerich cum almitatem et prudentiam eius percunctasset, diligebat illum super omnis pontefecis et obtimatibus suis [...], und daß Lambert apud regem summum tenebat locum. Der Bericht über die Absetzung ebd. 5, ed. Krusch 357f., verbindet die Geschehnisse direkt mit dem Mord an Childerich. Dementsprechend argumentiert Werner, Lütticher Raum 241-274, für die Absetzung durch Pippin. Die Wiedereinsetzung Lamberts wäre dann als Reaktion auf lokalen Druck und als Versuch, die Kontrolle über die Diözese auf diesem Weg zu etablieren, zu interpretieren. Vgl. ähnlich auch Joch, Legitimität und Integration 133f. Zum Konflikt mit Dodo und zu Lamberts Ermordung Vita Lamberti vetustissima 11-17, ed. Krusch 364-370.
} 
ersten austrasischen Großen, die in den Auseinandersetzungen zwischen Plektrud und Karl Martell die Seiten wechselten und sich für letztere Option entschieden. ${ }^{59}$

In diesem Zusammenhang wurde die politische Bedeutung der Translation der Lambert-Reliquien durch Hubert im Jahr 716/8 in der modernen Forschung ausführlich diskutiert. Während die Translation in der älteren Forschung als Symbol für die Verlegung des Bischofssitzes nach Liège gesehen wurde, haben zuletzt Frans Theuws und Alain Dierkens überzeugend dafür argumentiert, sie als Teil von Huberts Strategien zur Etablierung nicht eines neuen Bischofssitzes, sondern eines neuen Machtzentrums zu interpretieren, das besser an die neuen politischen Verhältnisse und die Zusammenarbeit mit den Pippiniden/Karolingern adaptiert war. ${ }^{60}$ Der Kult Lamberts war schon zuvor von Plektruds Seite der Familie gefördert worden. ${ }^{61} \mathrm{Ob}$ die gemeinsame Förderung des Kultes durch Karl Martell und Hubert und die Reliquientranslation als demonstrative Geste der Annäherung an Plektrud und ihre Familie gesehen werden kann oder nicht ${ }^{62}$ - in jedem Fall konnte die Aneignung des Reliquienkultes und die Translation, durch die vorhergehende Assoziationen überlagert werden sollten, dabei helfen, die Kontrolle über den Raum zu stärken und zu repräsentieren. ${ }^{63}$ Auch innerhalb der Diözese läßt sich die Reliquientranslation als Versuch der Glättung der Spannungen nach dem Mord an Lambert interpretieren. ${ }^{64}$

Durch den Vergleich der Berichte über die Lambert-Translation in der Vita Lamberti einerseits und der Vita Huberti andererseits, die beide innerhalb eines kurzen Zeitraumes nach Huberts Tod entstanden sind, lassen sich Spuren der zeitnahen Diskussionen und Verhandlungen über die Bedeutung dieses Ereignisses nachvollziehen. Die Vita Lamberti sucht sehr vorsichtig und sorgfältig Liège als Ort des legitimen Kultes und des Konsenses zu etablieren, was auf einen gewissen Rechtfertigungsbedarf für die Translation schließen läßt. Gleichzeitig wurde hier die Rolle des lebenden Bischofes bei der Translation so weit wie möglich heruntergespielt: Die Vita Lamberti schreibt nur die liturgische Ausführung der Elevation dem Bischof zu und betont

${ }^{59}$ Richard Gerberding, The Rise of the Carolingians and the Liber Historiae Francorum (Oxford Historical Monographs, Oxford 1987) 116-140; ders., 716 - A crucial year for Charles Martell, in: Karl Martell in seiner Zeit, ed. Jörg Jarnut/Ulrich Nonn/ Michael Richter (Beihefte der Francia 37, Sigmaringen 1994) 205-216, mit den Kommentaren bei Joch, Legitimität und Integration 116ff.; Fouracre, Charles Martell 55-64, bes. 61f. Für eine Zusammenfassung der Diskussion und Literatur zur HugobertIrmina-Sippe siehe Joch, Legitimität und Integration 25ff. und 118ff.; skeptisch bezüglich einer Verwandtschaft zwischen Hubert und Plektrud vor allem Werner, Lütticher Raum $277 \mathrm{f}$.

${ }^{60}$ Theuws, Maastricht 174f., 190-193; Dierkens, Réflexions 551-555, mit ausführlicher Bibliographie zur älteren Interpretation der Translation 716/8 als Markierung der Verlegung des Bischofssitzes und für Kritik an der dafür vorgebrachten Argumentation.

${ }^{61}$ Hinweise darauf sind die Ermordung Grimoalds am Lambert-Schrein im Jahr 714, worüber der Liber historiae Francorum 50 (ed. Bruno Krusch, MGH SS rer. Merov. 2, Hannover 1888) 215-328, hier 324, berichtet. Planung und Bau der Basilika, für die sehr wahrscheinlich pippinidische Unterstützung angenommen werden kann, begannen schon vor 714, vgl. Werner, Lütticher Raum 301-303, 306f. Auf ein gutes Verhältnis zwischen Hubert und Plektrud läßt auch dessen Nennung in zwei Urkunden für Echternach schließen, vgl. Joch, Legitimität und Integration 119f.; Theuws, Maastricht 190.

62 Die Beantwortung der Frage, ob der Lambert-Kult einen Fokus für Pippin und Plektrud gegen Alpaida und Karl Martell bieten konnte, hängt von der Deutung der Ereignisse um Lamberts Martyrium und dem Problem der Verwandtschaft zwischen Karl Martells Mutter Alpaida und Lamberts Mörder Dodo, wie sie spätere Traditionen behaupten, ab. Dem Bericht der Vita Lamberti vetustissima zufolge wurde Lambert im Zuge eines lokalen Konfliktes, als dessen Grund die Vita Auseinandersetzungen um Kirchengut angibt, von Dodo ermordet: Vita Lamberti vetustissima 11-17, ed. Krusch 364-370. Spätere Traditionen geben als Grund für das Martyrium Lamberts Kritik an Pippins bigamen Verhältnis mit Alpaida an und lassen Dodo zum Mörder werden, weil er der Bruder Alpaidas war. Zur stufenweisen Entstehung dieser Legende und ihrer Einordnung in jeweils aktuelle politische Zusammenhänge Kupper, Saint Lambert 27-46. Gerberding, Rise 117-119, hält die Verwandtschaft zwischen Dodo und Alpaida aufgrund einer von ihm als zeitgenössisch angenommenen Marginalie in einer Handschrift des Liber Historiae Francorum zu c. 49 aus dem dritten Viertel des 9. Jahrhunderts (Paris BN. Lat. 10911), die allerdings von einer Hand des 15. Jahrhunderts geschrieben wurde, für wahrscheinlich. Siehe zur Diskussion des Materials und zur Kritik an Gerberdings Thesen Joch, Legitimität und Integration 27-30 und 130-144. Unlängst hat Ian Wood mit Verweis auf die Ermordung Grimoalds am Lambert-Schrein und die guten Gründe, die Karl Martell für eine Politik des „,appeasement“ gegenüber Plektrud und ihrer Familie gehabt hätte, wieder für Alpaida als soror Dodonis optiert, obwohl die eben erwähnte Notiz nicht als früher Beleg für diese Tradition herangezogen werden kann, vgl. Wood, Genealogy defined by women 242-244; siehe schon ders., Merovingian kingdoms 271.

${ }^{63}$ Ein paralleles (und komplementäres) Beispiel ist die gleichzeitige Förderung des Servatius-Kultes in Maastricht durch Hubert und Karl Martell: siehe Alain Dierkens, Carolus monasteriorum multorum eversor et ecclesiasticarum pecuniarum in usus proprios commutator? Notes sur la politique monastique du maire du palais Charles Martel, in: Karl Martell in seiner Zeit, ed. Jörg Jarnut/ Ulrich Nonn/Michael Richter (Beihefte der Francia 37, Sigmaringen 1994) 277-294, hier 286f.; ders., Réflexions 561-563.

${ }^{64}$ Zur lokalen Dimension des Konfliktes Dierkens, Réflexions 560ff.; Theuws, Maastricht 186-193. 
den Konsens der seniores von Liège. ${ }^{65}$ Der Bau der Basilika in Liège ging diesem Text zufolge auf die Bewohner der Stadt zurück. ${ }^{66}$ Die Vita Huberti beschreibt diese Ereignisse aus einer deutlich anderen Perspektive. Indem mithilfe der Vita Arnulfi die Darstellung des Reliquienzuges von Maastricht nach Liège erheblich gekürzt wurde, ${ }^{67}$ blieb Liège von Anfang an der Bezugspunkt der Erzählung. Im Gegenzug wurde durch die sorgfältige Umarbeitung des Textes der Vita Lamberti sprichwörtlich mehr Raum für Hubert als Orchestrator des Reliquienkultes geschaffen: Wo in der Vita Lamberti der Märtyrer einem Ungenannten erscheint, um seinen Willen zur Translation kundzutun, wird in der Vita Huberti der lebende Bischof per visiones plurimas comminatus und trifft seine Entscheidung auch nicht in Beratung mit den seniores illius loci. Zudem erhebt die Vita Huberti unmißverständlich Anspruch auf den Bau der Basilika in Liège durch den Bischof. ${ }^{68}$ Die Vita argumentiert so vor allem die souveräne Kontrolle Huberts, des lebendigen Bischofs, über die Reliquien seines Vorgängers. ${ }^{69}$

Bedenkt man, daß die Vita Lamberti und die Vita Huberti nach Huberts Tod wohl im 2. Viertel des 8. Jahrhunderts entstanden, könnte sich in den unterschiedlichen Darstellungen der Lambert-Translation eine weitere Etappe in den Auseinandersetzungen um die spirituellen Traditionen der Region abzeichnen - die Vita Huberti wäre nicht zuletzt als Neuansatz für die Interpretation der Translation als Zeichen der Integration und zur Argumentation der Ansprüche auf Kontrolle über den Lambert-Kult zu sehen. Auf die Bedeutung dieses Arguments weist auch die Betonung der Kontinuität zwischen Huberts Episkopat und dem Lamberts in der Vita Huberti hin: Die Orientierung an Lamberts Vorbild wird als wesentlich für Huberts Ausübung seines Amtes dargestellt, und die Translation der Reliquien als wichtiger Schritt für Huberts Entwicklung zu einem idealen Bischof. ${ }^{70}$

Die hagiographischen Texte aus Liège sind daher ein gutes Beispiel für die Prozesse der Verhandlung über die Kontrolle von Reliquien und Translationen und über ihre Interpretation. In der Vita Huberti prima wird die Durchsetzung bischöflicher Macht nicht zuletzt anhand der (literarischen) Aneignung und Kontrolle über Heiligenkulte verhandelt - aufgrund dieses Schwerpunktes eignete sie sich hervorragend als textuelle Grundlage, auf der Jonas seine eigene Diskussion aufbauen konnte.

3.

Auch Jonas verband in seinem Bericht über die Translation von Huberts Reliquien nach Andagne 825 die Verhandlung über die Bedeutung der Reliquientranslation mit der über die Position von Bischöfen. ${ }^{71}$ An den Beginn des Berichtes stellte Jonas eine Skizze der Regierungstätigkeit Ludwigs des Frommen, der die Leistungen Karls des Großen konsolidiert und fortführt. Die Perspektive verengt sich danach auf Bischof Walcaud und dessen Reformbestrebungen in der Diözese. Walcauds „,benediktinisches Projekt“ im Kloster Andagne fungiert dabei als Illustration der erfolgreichen Arbeit eines Bischofs, der seiner Rolle als bedeutender und vorbildhafter Exponent des bischöflichen ordo vor allem aufgrund seiner Konformität mit der kaiserlichen

\footnotetext{
65 Vita Lamberti vetustissima 25-27, ed. Krusch 378-382. Vgl. Werner, Lütticher Raum 301-303.

${ }_{66}$ Vita Lamberti vetustissima 22, ed. Krusch 375: Et iam, cum basilica populus ibidem coepissent fundare [...]. Ebd. 23, ed. Krusch 375: Item ex hoc amplius concurrebat mixtus vulgus utriusque sexus, seni et parvoli, ad basilica in honore ipsius sancti aedificare.

67 Vita Huberti 2, ed. Levison 484. Vgl. Vita Arnulfi 23 und 26, ed. Krusch 442f., 444.

${ }^{68}$ Vita Huberti 2, ed. Levison 484.

${ }^{69}$ Im Kontrast dazu steht das Fehlen der Figur des lebenden Bischofs bei der Elevation von Huberts eigenen Reliquien 743. Die rituelle Funktion des Bischofs wird auf mehrere Akteure - die custodes der Basilika und Deo timentes homines, den Klerus und schließlich Karlmann und seine proceres - aufgeteilt. Ohne den spirituellen Experten, der die Deutungsmacht über Visionen und die Angemessenheit des Vorhabens ausübt, verlangsamt sich die Entscheidungsfindung. Siehe Vita Huberti 18, ed. Levison 493f. und vgl. dazu Arnold Angenendt, Corpus incorruptum. Eine Leitidee der mittelalterlichen Reliquienverehrung, in: Saeculum 42 (1991) 320-348, hier 329; Genicot, Discordiae concordantium 73. Werner, Lütticher Raum 310 mit Anm. 161 weist die daraus abgeleitete These von der Sedisvakanz zum Zeitpunkt der Elevation zurück.

70 Vita Huberti 1, ed. Levison 483; ebd. 3, ed. Levison 483: Postea [i.e. nach der Translation] igitur Hugbertus in timore Domini magis confirmatus, amplius se certaminam dedit [...].

${ }^{71}$ Jonas, Vita et Translatio 28-33, ed. de Smedt 817f. Die Edition der Translatio in den MGH enthält den vorangehenden Vitentext nicht: (ed. Lothar Heinemann, MGH SS 15,1 Hannover 1887, ND Stuttgart 1992) 234-237.
} 
Gesetzgebung in hervorragender Weise gerecht wird. ${ }^{72}$ Die Mönche, die Walcaud zuvor durch regularis optimi praeceptores in den Pflichten des ordo monasticus unterwiesen hatte, erbaten die Reliquien Huberts, weil sie sich davon spirituellen Halt im Kampf um größere perfectio erhofften. ${ }^{73}$ Die Translation der Hubertreliquien präsentierte Jonas als wirkungsvollen Schlußpunkt der Reform und als Mittel zur Stabilisierung der neuetablierten spirituellen und materiellen Ordnung in Andagne. ${ }^{74}$ Gleichzeitig konnte so die Berechtigung bischöflicher Kontrolle über monastische Gemeinschaften suggeriert werden. Die Verallgemeinerung dieses Modells durch die Einordnung der Reliquientranslation in einen breiteren Kontext der Reform verband Jonas geschickt mit der wirkungsvollen Formulierung der Position von Bischöfen innerhalb des christlichen Imperium. Sein Lob auf Ludwig enthält eine sehr klare Definition der Ziele der Reformgesetzgebung dieser Jahre: Mitgliedern aller drei ordines - laicus, monasticus und episcopalis - soll die Erfüllung ihrer Pflichten und die Einhaltung ihrer Lebensregeln ermöglicht werden. Den Bischöfen wird dabei die Aufgabe zugewiesen, das Funktionieren dieses Gefüges zu überwachen (superintendere) und die Konformität von Laien und Mönchen mit ihren Verhaltensnormen zu garantieren. ${ }^{75}$

Wie sehr sich diese Formulierung der idealen sozialen Ordnung in zeitgenössische Diskussionen über das Verhältnis der ordines des Reiches und ihr jeweiliges ministerium einordnet, braucht nicht besonders betont zu werden. ${ }^{76}$ Die Konzeption und theoretische Grundlegung des bischöflichen Amtes war innerhalb dieser Diskussionen ein wichtiges Anliegen, wie vor allem die Akten des Konzils von Paris 829, die Jonas redigierte, zeigen. In einer Reihe von Arbeiten der letzten Jahre wurde das Verständnis für die Pariser Synode als Versuch der deutlicheren Abgrenzung und Definition des Bischofsamtes, aber auch des kritischen Nachdenkens über seine richtige Erfüllung durch die karolingischen Bischöfe angesichts manifester Zeichen göttlichen Zornes über menschliche Verfehlungen, geschärft. ${ }^{77}$ Wie in den Pariser Akten zeichnet sich auch in Jonas'

72 Walcaud wird als pars non minima des Reformepiskopats beschrieben, dessen gute Amtsführung partim divinitatis instinctu et mercedis intuitu, partim vero hujus sacratissimi principis talibus monitionibus incitatus ist: Jonas, Vita et Translatio 29, ed. de Smedt 817.

73 Jonas, Vita et Translatio 31, ed. de Smedt 817.

${ }^{74}$ Das glanzvolle Bild vom Wiederaufbau des Klosters unter der Ägide Walcauds entfaltet seine besondere Wirkung vor dem Hintergrund der obligaten Erzählung vom vorherigen Verfall. Für die Einzelheiten der Reform ist die Translatio die einzige sichere zeitgenössische Quelle; die Authentizität einer Urkunde Walcauds aus dem Jahr 817 ist umstritten. Vgl. Dierkens, Christianisation 321. Zur Geschichte des Klosters Andrée Despy-Meyer/Pierre-Paul Dupont, Abbaye de Saint-Hubert, in: Monasticon Belge 5: Province de Luxembourg (Liège 1975) 9-83, bes. 9-28; Georges Despy, Questions sur les origines de l'abbaye de Saint-Hubert, in: Saint-Hubert d'Ardenne. Hommage à Léon Hannecart, ed. Jean-Marie Duvosquel/Jacques Charneux (Saint-Hubert d'Ardenne, Cahiers d'Histoire 8, Saint-Hubert 1991) 242-256; vgl. Helga Müller-Kehlen, Die Ardennen im Frühmittelalter. Untersuchungen zum Königsgut in einem karolingischen Kernland (Veröffentlichungen des Max-Planck-Institutes für Geschichte 38, Göttingen 1973) 50-55.

75 Jonas, Vita et Translatio 29, ed. de Smedt 817: Hic ergo imperii sui primordia talibus tantisque dedicare instituit auspiciis, ut incorrecta corrigerentur, bona collapsa erigerentur et stantia solidarentur, et quisque ordo in regno sibi tradito non passim levitate jactatus a propria regula exorbitaret, sed laicus ordo justitiae deserviret atque armis pacem sanctae Ecclesiae defenderet, monasticus ordo quietem diligeret, orationi vacaret, et qui saeculi actibus secrevisset, eisdem iterum nec voluntate nec necessitate semet subderet, episcopalis autem ordo, ut his omnibus superintenderet, scilicet ut si qui ab his aut voluntate aut necessitate deviarent, eorum sollerti judicio prudentique consilio ad lineam rectitudinis correcti redirent.

${ }^{76}$ Olivier Guillot, Une „ordinatio“ méconnue. Le capitulaire de 823-825, in: Charlemagne’s Heir. New Perspectives on the Reign of Louis the Pious, ed. Roger Collins/Peter Godman (Oxford 1990) 455-486; Thomas Zotz, In Amt und Würden. Zur Eigenart „offizieller“ Positionen im früheren Mittelalter, in: Tel Aviver Jahrbuch für deutsche Geschichte 22 (1993) 1-23.

77 De Jong, Penitential State 170-184; dies., Sacrum palatium, bes. 1261-1265; dies., Ecclesia and the early medieval polity 129ff.; Steffen Patzold, Redéfinir l’office épiscopal: les évêques francs face à la crise des anées 820/30, in: Les élites au haut Moyen Âge. Crises et renouvellements, ed. François Bougard/Laurent Feller/Régine Le Jan (Collection Haut Moyen Âge 1, Turnhout 2006) 337-359; ders., Die Bischöfe im karolingischen Staat. Praktisches Wissen über die politische Ordnung im Frankenreich des 9. Jahrhunderts, in: Staat im frühen Mittelalter, ed. Stuart Airlie/Walter Pohl/Helmut Reimitz (Forschungen zur Geschichte des Mittelalters 11, Wien 2006) 133-162; Savigni, Giona di Orleans 145-175, bes. 167ff. Vgl. auch Hans Hubert Anton, Zum politischen Konzept karolingischer Synoden und zur karolingischen Brüdergemeinschaft, in: Historisches Jahrbuch 99 (1979) 55-132, bes. 55-74; Alain Dubreucq, Le pouvoir de l'évêque au IX siècle: étude sur le vocabulaire du pouvoir, in: Hommes de pouvoir. Ressources et lieux de pouvoir, $\mathrm{V}^{\mathrm{e}}-\mathrm{XIII}{ }^{\mathrm{e}}$ siécles, ed. Elisabeth Magrou-Nortier (Aux sources de la gestion publique 3, Lille 1997) 97-110. Vor allem die Arbeiten Mayke de Jongs haben gezeigt, daß Interpretationen, die die Pariser Akten im Sinn des Antagonismus zwischen weltlicher und geistlicher Macht im Hinblick auf die Ereignisse des Jahres 833 und die Absetzung Ludwigs des Frommen lesen, zu kurz greifen. Für besonders deutliche Formulierungen dieser letzteren Sicht siehe Etienne Delaruelle, En relisant le De institutione regia de Jonas d’Orléans. L'entrée en scène de l'épiscopat carolingien, in: Mélanges d'his- 
Vita eine sehr differenzierte Sicht des bischöflichen Amtes und ein klares Bewußtsein für die moralischen Herausforderungen und spirituellen Gefahren ab, die mit der Position des Bischofs als supervisor oder speculator verbunden sein konnten. ${ }^{78}$

Ein gutes Beispiel dafür ist der Bericht über eine Predigt, die Hubert anläßlich einer Kirchweihe in Nivelles-sur-Meuse hält. ${ }^{79}$ Der Text der in direkter Rede wiedergegebenen Predigt enthält einerseits eine eindringliche Aufforderung zur Buße an die Gläubigen, andererseits illustriert er die Notwendigkeit zur Selbstreflexion für einen speculator. Dabei vermittelt der Text vor allem das Bewußtsein von der eigenen Unzulänglichkeit angesichts der Anforderungen des dem Bischof auferlegten Amtes: Nam et mihi non mediocris institit angor reminiscenti ministerii mihi injuncta quanta debeat esse perfectio, et e contra quam sit temnibilis vitae meae inofficiosa incorrectio. ${ }^{80}$ Ausgehend von Mt 25, 1-30 wird in der Folge die Theorie von der Verantwortung des Bischofs für seine Gemeinde entwickelt, und diese Passagen durch eine Paraphrase von Ezechiel, die in der Vorlage fehlt, in ihrer Bedeutung auf den pastor und seine grex zugespitzt. ${ }^{81}$ Die einzige Möglichkeit, am jüngsten Tag Verdienste vorweisen zu können, ist untrennbar mit dem Erfolg von praedicatio und cura animarum verbunden, der sich an der Lebensführung der Gemeindemitglieder zeigt, an deren Mitarbeit deshalb appelliert wird: Perpendite, quaeso, quod mihi responsum quaeve restet excusatio coram judice tanto [...]. ${ }^{82}$ Anders als die Pariser Konzilsväter 829, die die entsprechenden Ezechiel-Stellen in einem Kanon über die pericula des Bischofsamtes ebenfalls zitierten, bemühte sich Jonas in der Vita nicht darum, diese Stelle durch den Hinweis auf ein weiteres Ezechiel-Zitat $(E z 3,18)$ zu entschärfen, das einen gewissenhaften Priester von der Verantwortung für die Mißachtung seiner Ermahnungen durch die Gläubigen freispricht. ${ }^{83}$ Wenn diese Stelle die Gefahren des Bischofsamtes problematisiert, so bildet sie in der Vita allerdings auch Teil einer Erzählung von ihrer erfolgreichen Überwindung. Die selbstbewußte Formulierung der Position von Bischöfen innerhalb der karolingischen Gesellschaft im Translationsbericht wird durch den vorhergehenden Vitentext vorbereitet und unterstützt, in dem Jonas in sorgfältiger Auseinandersetzung mit der Vita prima seinerseits ein Bischofsmodell entwickelte. ${ }^{84}$

Grundsätzlich folgt Jonas’ Text dabei sehr genau der narrativen Struktur der Vita prima. So übernahm Jonas viele der oben beschriebenen narrativen Strategien, wie etwa die Wahl eines iterativen Darstellungsmodus oder den wirkungsvollen Einsatz der Tugendkataloge als Argumentationsstrategie durch ihre Positionierung am Anfang von Huberts Karriere und nach dessen Tod. ${ }^{85}$ Auch die in der Vita prima aufgeworfenen Themen boten hervorragende Anschlußpunkte für Jonas, wie das Beispiel des eben erwähnten Kapitels über die Predigt Huberts zeigt. Auch im Abschnitt über Huberts Bischofserhebung am Beginn des Textes gibt die Vita prima die wesentlichen Themen vor: der Tod Lamberts von Maastricht; die Nachfolge Huberts als von

toire du moyen âge dediées à la mémoire de Louis Halphen (Paris 1951) 185-192; Élisabeth Magnou-Nortier, La tentative de subversion de l'État sous Louis le Pieux et l'œuvre des falsificateurs, in: Le Moyen Âge 105 (1999) 331-365; vgl. Monika Suchan, Kirchenpolitik des Königs oder Königspolitik der Kirche? Zum Verhältnis Ludwigs des Frommen und des Episkopats während der Herrschaftskrisen um 830, in: Zeitschrift für Kirchengeschichte 111, 3 (2000) 1-27.

${ }^{78}$ Siehe zu diesen Fragen die Arbeiten von Conrad Leyser, Authority and Ascetism from Augustine to Gregory the Great (Oxford Historical Monographs, Oxford 2000); ders., „Let me speak, let me speak“: Vulnerability and authority in Gregory’s homilies on Ezekiel, in: Gregorio Magno e il suo tempo 2 (Studia Ephemeridis Augustinianum 33, Roma 1991) 169-182. Zum Begriff des speculator mit zahlreichen Beispielen aus Spätantike und Frühmittelalter Christine Mohrmann, Episkopos - speculator, in: dies., Études sur le latin des chrétiens 4: Latin chrétien et médiéval (Storia e letteratura. Raccolta di studi e testi 143, Roma 1977) 231-252, bes. 237-250.

79 Jonas, Vita et Translatio 14, ed. de Smedt 812f.

80 Jonas, Vita et Translatio 14, ed. de Smedt 813.

${ }^{81}$ Jonas, Vita et Translatio 14, ed. de Smedt 813: Gregis mei te posui pastorem exercitusque ecclesiastici ducem; lactis eorum ubertate famem, lanarumque tegmine frigoris cinsuisti propellere algorem. Vgl. dazu Ez 34, 2f: haec dicit Dominus Deus: vae pastoribus Israhel qui pascebant semet ipsos nonne greges pascuntur a pastoribus/lac comedebatis et lanis operiebamini et quod crassum erat occidebatis, gregem autem meum non pascebatis.

82 Jonas, Vita et Translatio 14, ed. de Smedt 813.

${ }^{83}$ Concilium Parisiense (829) I, 5 (ed. Albert Werminghoff, MGH Concilia 2,2, Hannover/Leipzig 1906) 606-680, hier 613f.

${ }^{84}$ Vgl. Dubreucq, Metier de roi 28, im Anschluß an Delaruelle, Jonas et le moralisme 137, der die Vita Huberti in Anlehnung an De institutione regia und De institutione laicarum als „De institutione episcoporum“ bezeichnet. Siehe dazu Savigni, Giona di Orleans, bes. 210-213.

${ }^{85}$ Vgl. bes. Vita Huberti prima 1 bzw. 15, ed. Levison 485 bzw. 492, mit Jonas, Vita et Translatio 2 und 19, ed. de Smedt 808f. und 814. 
Christus eingesetzter pastor, der als imitator Lamberts weltlichem Besitz entsagt; der Katalog von Tugenden und karitativen Tätigkeiten Huberts; die Trauer um seinen Vorgänger. ${ }^{86}$ Trotzdem wäre es irreführend, das Verhältnis zwischen Jonas' Neufassung und der Vita prima als rein formale réécriture aufzufassen. Vielmehr zeigt der Vergleich der beiden Texte, wie sorgfältig Jonas die Vita prima an den Interpretationshorizont und die Diskussionen der 820er Jahre anzupassen versuchte. Das Verhältnis zwischen diesen Diskursen und den Strategien der Wiederschrift läßt sich anhand der ersten Kapitel der Vita, die von Huberts Erhebung auf den Bischofstuhl handeln, veranschaulichen.

Jonas arbeitete im Wesentlichen mit der Dehnung seiner Vorlage: obwohl der „Handlung“ nichts hinzugefügt wird, läßt sich erheblicher Textzuwachs feststellen. Indem sich das Erzähltempo verlangsamt, entsteht mehr Raum für eine stärkere Präsenz des Erzählers in seiner kommentierenden Funktion. ${ }^{87}$ Die Erzählung wird immer wieder durch längere Einschübe unterbrochen, die Jonas zur theoretischen Reflexion und präziseren Formulierung der Anforderungen an einen Bischof nutzte. ${ }^{88}$ Wie auch im Kapitel über Huberts Predigt wird hier das Bischofsamt als ministerium charakterisiert, das durch seinen Inhaber im wahrsten Sinn des Wortes ausgefüllt werden muß.$^{89}$ Das Konzept vom pastor, das Jonas in enger Anlehnung an die entsprechenden Stellen bei Ezechiel ausgestaltet, bildet den Ausgangspunkt für die folgenden Überlegungen, die vor allem auf die besondere Stellung des Gemeindevorstehers als Überwacher und Lehrer und auf die aus dieser Verantwortung resultierenden Ansprüche an seinen Lebensstil zielen. ${ }^{90}$ An das Verhalten des Bischofs werden besonders hohe Maßstäbe angelegt, weil er die Verantwortung für das Seelenheil anderer trägt und ein judex vitae alienae sein muß. ${ }^{91}$ Voraussetzung für die moralische Herrschaft über andere sind Selbstberrschung (sibi praeesse) und ein beispielhaftes Leben, aber auch theoretisches Wissen darüber, das durch die Lektüre der heiligen Schrift und die Nachahmung heiliger Werke erlangt werden kann. ${ }^{92}$

Durch die Erweiterungen der Eröffnungsszene zeichnet sich in Jonas’ réécriture ein Bischofsideal ab, das im Vergleich zur Vita prima wesentlich abstrakter wirkt. ${ }^{93}$ Die sprachliche Nähe zu Ezechiel, aber auch zu grundlegenden patristischen Texten wie Gregors Regula pastoralis oder Julianus Pomerius' De vita contemplativa, verbinden den Text mit anderen zeitgenössischen Versuchen, Amt und Position der Bischöfe zu definieren. ${ }^{94}$ Das gilt nicht nur für die Theorie vom Episkopat als ministerium. Auch die Kombination des

${ }^{86}$ Vita Huberti prima 1, ed. Levison 483.

${ }^{87}$ Zum Verhältnis zwischen Erzählzeit und erzählter Zeit Genette, Die Erzählung 61-60, 213-215; zu den verschiedenen Funktionen des Erzählers ebd. 183-186.

${ }^{88}$ Vgl. Jonas, Vita et Translatio 1-2, ed. de Smedt 808f., mit Vita Huberti prima 1, ed. Levison 483.

89 Jonas, Vita et Translatio 1, ed. de Smedt 808: Indem Hubert seine pastoralen Aufgaben ordnungsgemäß erfüllt (non segnis exsecutor operis pastoralis), erweist er sich als non incongruus minister des ihm anvertrauten officium.

90 Jonas, Vita et Translatio 1, ed. de Smedt 808: Egitque ut adsolet divina provisio, ut quia optimi pastoris destituebantur solatio, non rictibus luporum territae per diversa dispergerentur, dentibusque lacerarentur, sed succederet eis pastor qui humilis gregis curam gerens, fessas sublevaret, fractas alligaret, laceratas sanaret, luporumque rabiem ab earum insectatione procul proturbaret, nec jam ecclesia Domini fieret lustrum ferale, sed expiatum a sorde nocentium et serenatum ab angore luporum, redderetur Domino templum herile. Vgl. dazu besonders die Vorwürfe gegen schlechte Priester in Ezechiel 34,4f. und die Verheißung des pastor optimus in Ez 34, 15f. und 23f.

91 Jonas, Vita et Translatio 2, ed. de Smedt 808: Sciens namque memoratus et saepe memorandus vir aliam legem esse subditorum, aliamque praelatorum, scilicet ut subditus quisque curet ne pereat, neve sui exemplo alios perdat; praelatus autem, ut non solum superintendat suae, sed et judex provisorque cogatur vitae fieri alienae, non ei sufficiebant ea quae sibi olim sectanda proposuerat.

92 Jonas, Vita et Translatio 1, ed. de Smedt 808: Unde actum est, ut idem venerandus vir et lectione scriptuarum quae sibi agenda forent addisceret, opusque lectionis paterna aemulando opera perageret [...] talis ac tantus vir cathedra ut dictum est, praesulatus dominici gregis donatur, ut qui eatenus sibi tantum profuerat, et sub scemate privatorum delituerat, candelabro Dei quasi quidam clarissimus lichnus inponeretur; quatinus ejus exemplo cunctis in domo Dei positis luminis claritas praeberentur.

${ }_{93}$ Darauf kann neben dem starken Zug zur Theoretisierung auch die Tatsache hinweisen, daß Hubert in der gesamten Vita nur zweimal beim Namen genannt wird, während er ansonsten als pontifex, sacerdos, praesul, pastor etc. bezeichnet wird. Zu Jonas Verbindung von Konzepten „subjektiver“ und „objektiver“ Heiligkeit siehe Savigni, Giona di Orleans 201-213, zur Vita Huberti bes. $210 \mathrm{ff}$.

94 So wird in Paris 829 wiederholt das gregorianische docere verbo et exemplo und die Notwendigkeit zur Selbstbeherrschung betont. Vgl. z.B. Concilium Parisiense (829) I, 4, ed. Werminghoff 611f. Hier wird zudem der ideale pastor durch ein langes Zitat aus Pomerius näher definiert. Viele der hier thematisierten Elemente haben Parallelen in den den Hubert-Viten. Beispielsweise findet sich in Jonas' Text (c. 1) ebenso wie in Paris die Bezeichnung als Helfer der Unterdrückten, der Verweis auf die cura animarum und den Bischof als exemplum bonorum, zudem sind die angesprochenen Themen parallel: Bischöfe überwachen die Taten der 
Konzepts vom Bischof als pastor mit dem des speculator, des Überwachers und Mahners, spielt in Paris 829 ebenso wie schon in Aachen 816 ausgehend von patristisch vermittelter Ezechiel-Exegese eine große Rolle. ${ }^{95}$ Auch der richtige Umgang mit materiellen Gütern, dem Jonas im Kapitel über die Bischofserhebung einen kleinen Exkurs widmet und der ein wesentliches Kriterium bischöflicher perfectio ist, wurde in diesen Jahren wiederholt diskutiert. ${ }^{96}$ Darüberhinaus ist in der Vita Huberti der Entwurf des Bischofsideals eng mit der Frage nach der Bedeutung von Heiligenkulten verbunden. Aufgrund der besonderen Verantwortung des Bischofs für das Seelenheil der Gläubigen wird der Vita et Translatio zufolge die richtige Auswahl seiner Vorbilder für ihn besonders dringlich. ${ }^{97}$ Auch auf dem Pariser Konzil wurde die Funktion von exempla sanctorum als Anleitung und Orientierungsmodelle für Bischöfe wiederholt diskutiert und die Bischöfe dazu aufgefordert, dem Beispiel ihrer heiligen Vorgänger zu folgen. ${ }^{98}$ Diese spirituelle Genealogie der perfectio nimmt ihren Ausgangspunkt letztlich vom apostolischen Vorbild; in der Vita Huberti wird aber vor allem die rezente Vergangenheit zum Bezugspunkt. ${ }^{99}$ In diesem Sinn griff Jonas die Kontinuität und Verbindung zwischen Hubert und Lambert, die schon die Vita prima betont hatte, auf. Im Gegensatz zu seiner Vorlage hob Jonas am Beginn des Textes nicht Lamberts Martyrium hervor, sondern sein beispielhaftes Leben. ${ }^{100}$ Auf dieser Grundlage erläuterte er einige Zeilen später die entscheidende Rolle, die die Orientierung an Lamberts Vorbild bei Huberts erfolgreicher Amtstätigkeit spielte:

Es wurde nämlich der vorgenannte Diener des Herren nicht nur durch die Beispiele Christi unterstützt, sondern auch durch jene, die sein Vorgänger jüngst gegeben hatte, weil ja den menschlichen Geist lange vergangene Dinge [pris$c a$ ] nicht so stark unterweisen wie die gegenwärtigen [praesentia], und auch die Schwachen nicht so sehr durch das Beispiel der ihnen um vieles Überlegeneren Kraft schöpfen, als daß sie durch den Anblick von Menschen, die ihnen gleich sind, dazu angespornt werden, es ihnen gleichzutun. ${ }^{101}$

ihnen anvertrauten Herde, sollen sich nicht über die Ehre des Amtes freuen, sondern sich der Last bewußt sein, die damit einhergeht; sie erhalten ihr Amt durch Gott aufgrund ihrer spirituellen Lebensführung, nicht durch Menschen. Weitere Parallelen zu Pomerius/Paris später in der Vita: dispensatores regiae domus (vgl. Jonas, Vita et Translatio 4, ed. de Smedt 809f.); ianuator (Vita et Translatio 14, ed. de Smedt 812f.); decus ecclesiae, columna ecclesiae (Vita et Translatio 21, ed. de Smedt 815). Zu den Konzeptionen von Leitungsfunktion und spiritueller Autorität bei Julianus Pomerius und Gregor dem Großen siehe Leyser, Authority and asceticism 65-80 bzw. 131-187. Zur karolingischen Rezeption der Schriften Gregors des Großen Bruno Judic, La tradition de Grégoire de Grand dans l'idéologie politique Carolingienne, in: La royauté et les élites dans l’Europe Carolingienne (début du IX ${ }^{\text {e }}$ siècle aux environs de 920), ed. Régine le Jan (Paris 1998) 17-57, speziell 42ff. zu Jonas und den normativen Texten der Jahre um 829. Zur großen Bedeutung der Cura pastoralis für die karolingische Konzeption des Bischofsideals vgl. auch Rosamond McKitterick, The Frankish Church and the Carolingian Reforms, 789-895 (London 1977) 45-79.

${ }_{95}$ Savigni, Giona di Orleans 147. Siehe schon Delaruelle, En relisant 189; zur Verbindung von pastor und speculator im Buch Ezechiel Mohrmann, Episkopos - speculator 237-250.

96 Siehe z.B. Concilium Parisiense (829) I, 13; I, 15-18, ed. Werminghoff 619f., 622-625. Zu diesem Thema vgl. Johannes Heil, Agobard, Amulo, das Kirchengut und die Juden von Lyon, in: Francia 25 (1998) 39-76; zu Jonas’ Überlegungen dazu Appleby, Sight and church reform, passim. Zu Jonas als Autor des Libellus de rebus ecclesiasticis non inuadendis, an Pippin im Zusammenhang mit dem Konzil von Aachen 836 siehe Dubreucq, Metier de roi 34.

${ }_{97}$ Jonas, Vita et Translatio 2, ed. de Smedt 808.

98 Siehe z.B. Concilium Parisiense (829) I, 4, ed. Werminghoff 611f: et per exempla sanctorum sacerdotum, quorum vice ecclesiae Christi sanguine redemptae praelati sumus, vitam et actus moresque nostros in melius componere satageremus, quoniam praedicatio sacerdotalis contempnitur, quando quod verbis predicat operibus non implet. Vgl. auch Concilium Parisiense (829) I, 12, ed. Werminghoff 618; I, 20, ed. Werminghoff 626.

${ }^{99}$ Vgl. Savigni, Giona di Orleans 46f., Appleby, Sight and church reform 22.

100 Jonas, Vita et Translatio 1, ed. de Smedt 808: Post gloriosum beatissimi ac praecellentissimi antistitis Lantberti a rebus humanis excessum, qui pontificalem apicem apud urbem Tungrensem quadraginta annis strenue ferens, vitae quidem exempla posteris dereliquit, mortis autem acerbae viriliter ferendo discrimina, et summi pastoris vestigiis inhaesit, et quantum amoris circa dominicas oves haberet aperuit, utpote quibus et vivens vitae contulit pascua et pro quibus non metuit mortis subire dispendia, Hugbertus venerandus praesul ejus sedi subrogatur episcopus; cui non erat virtute secundus. Vgl. Vita Huberti prima 1, ed. Levison 483: Beatissimus igitur Landbertus pontifex, cum pontificali apice XL annis functus esset officio, triumphum sui certaminis martyrii palmam adeptus, martyrum collegio sociatus, exultat in perpetuum. Post cuius sacro martyrio [...].(Hervorhebungen G.H.). Dabei ist auch nicht auszuschließen, daß diese Auslassungen mit möglicherweise ambivalenten Erinnerungen an dessen Ermordung zu tun haben könnten, vgl. oben Anm 62.

101 Jonas, Vita et Translatio 1, ed. de Smedt 808: Juvabatur namque praedictus Domini famulus, non modo Christi exemplis, sed et praedecessoris sui nuperrimis institutis, quia et humanam mentem non tam instruunt prisca quantum praesentia, nec eo infirmi convalescunt exemplo multo sibi superiorum, quo ad aemulationem provocantur ex visione coaequalium. 
Dazu paßt auch die Umdeutung der Erinnerung an Lambert, die in Jonas' Bearbeitung weniger von Huberts Trauer über die Trennung von seinem Lehrer, dessen Tod noch nicht lange zurückliegt, geprägt ist als vom Gefühl der eigenen Unzulänglichkeit, denselben Grad an perfectio zu erlangen - gleichzeitig relativieren Kommentare des Erzählers den Vorrang des Martyriums vor den Verdiensten eines Confessors deutlich. ${ }^{102}$ In seinem Widmungsbrief an Walcaud legte Jonas ihm die Lektüre der Vita mit dem Hinweis auf die zentrale Funktion nahe, die das Studium von Texten über heilige Bischöfe der Vergangenheit hat, um zeitgenössischen Bischöfen die Teilnahme an der Gemeinschaft der sancti pastores zu sichern. ${ }^{103}$

Die pädagogische Funktion von Heiligen- und besonders von Reliquienkulten zu unterstreichen, ist auch ein wesentlicher Effekt von Jonas’ Überarbeitung der Translationserzählungen in der Vita. Die Kontrolle über Lamberts Reliquien bedurfte in Jonas' réécriture offenbar nicht mehr so stark der Affirmation wie in der Vita prima. Die Veränderungen, die Jonas an der entsprechenden Stelle vornahm, bewirkten allerdings eine stärkere Betonung der bischöflichen Sorgfalt im Umgang mit den Reliquien. ${ }^{104}$ Auch anhand der Elevation von Huberts Reliquien 743 wird in den beiden Fassungen eine jeweils anders akzentuierte Erzählung formuliert. In der Vita prima ist die posthume Geschichte Huberts vom ersten Wunder am Grab bis zur Elevation der Gebeine vor allem eine Geschichte der langsamen Offenbarung und Anerkennung seiner Heiligkeit durch seine Schüler, seine Gemeinde und den Hausmeier Karlmann, den die fama von der Reliquienerhebung noch am selben Tag erreicht und der die Reliquien höchstpersönlich aus dem Grab hebt. Die Akzeptanz Huberts als heilig bedurfte zu diesem Zeitpunkt offensichtlich einiger Argumentation, was nicht zuletzt der Bericht über die Elevation mit dem vorsichtigen Herantasten an das Wunder der körperlichen Unversehrtheit zeigt. ${ }^{105}$

Jonas verfügte hingegen über größeren Spielraum, diese Stellen des Textes zur Durchsetzung anderer Anliegen zu nutzen. Die einzelnen Ereignisse, die zur Reliquienerhebung führten, werden von ihm mit größerer Souveränität erzählt und gedeutet. Das wird schon bei der Erzählung von der Reaktion der Gläubigen auf den Tod Huberts deutlich. Während die Klagerede der grex auf Hubert, die die Aufzählung von Huberts Tugenden am Beginn des Textes wieder aufnimmt, in der Vita prima in ihrer Funktion als Affirmationsstrategie nicht explizit gemacht wird, leitete Jonas den Bericht über die Reaktion des Volkes und der Schüler Huberts durch einen Kommentar ein, der die richtige Interpretation der Stelle verdeutlicht: Eratque videre pauperum fletibus ora rigata et pastoris se conquerentium destitutos optima praesentia, monachorumque greges, jejuniis pallida ora gerentes incultoque habitu despectum mundi protestantes, ad viri Dei inferiarum exsequias deducere concurrere; quamque pie et sancte pontificis sui vita decucurrerit, sedulum eorum officium altaque devotio testabatur. ${ }^{106}$ Bereits das erste posthume Wunder am Grab versah Jonas mit Bemerkungen, die dessen Beweisfunktion für Huberts Heiligkeit noch deutlicher hervorstreichen als in der Vita prima. ${ }^{107}$ Die ohnehin vielsagenden Bibelzitate der Vita prima am Beginn der Elevationserzählung selbst paraphrasierte er,

\footnotetext{
102 Jonas, Vita et Translatio 2, ed. de Smedt 809. Vgl. Vita Huberti prima 1, ed. Levison 483.

103 Jonas, Vita et Translatio, Epistola dedicatoria, ed. de Smedt 806: Cum animus modernorum venerabilium praesulum ad imitationem excitatur Deo placentium priscorum sacerdotum, id est maxime fieri reor ex assidua lectione sanctissimae vitae eorum. Unde non dubium est vel esse vel fieri velle vos sanctorum pastorum participem, cujus pascit assidua lectio referens actuum eorum probitatem insatiabilem mentem.

104 Jonas, Vita et Translatio 3, ed. de Smedt 809.

${ }^{105}$ Im Vergleich zu den Berichten über die Lambert-Translation, die die Grundlage für den Text der Vita prima bilden, entsteht in der Vita Huberti großer Textzuwachs durch die außergewöhnlich detaillierte Beschreibung des Zögerns der Gläubigen beim Öffnen des Grabes - sie haben Angst, den Körper verwest und zu Staub verfallen vorzufinden, was die Nichtakzeptanz des Kultes zur Folge hätte. Schließlich wird die Schönheit und Unversehrtheit des Körpers, der solidum atque inlibatum gefunden wird, auffallend ausführlich beschrieben. Vgl. Vita Huberti prima 19-20, ed. Levison 494-496, mit Vita Lamberti vetustissima 25, ed. Krusch 308. Weitere Hinweise auf die Notwendigkeit zur Argumentation von Huberts Heiligkeit sind außerdem die häufige Verwendung von Adjektiven wie electus oder sacratissimus, die bei Jonas fast vollständig fehlen, und die réécriture eines Wunders aus der Vita Lamberti: Aus dem Grab beider Heiliger hört man Engelsstimmen; während diese in der Vita Lamberti als Grenze fungieren, die das Grab schützen, ist dasselbe Ereignis in der Huberti für die custodes der Basilika ein vorbereitendes Zeichen für die folgenden Wunder und Visionen, durch die sie zur Erhebung der Reliquien aufgefordert werden: Vita Huberti prima 17, ed. Levison 493; zum Vergleich Vita Lamberti vetustissima 19, ed Krusch $372 f$.

106 Jonas, Vita et Translatio 19, ed. de Smedt 814. Ähnlich verläßt sich Jonas auch im Kapitel über Huberts Predigt nicht auf die Wirkung der direkten Rede Huberts, sondern bemüht sich, den Erfolg seiner Predigt explizit festzuschreiben: Jonas, Vita et Translatio 15, ed. de Smedt 813.

107 Jonas, Vita et Translatio 22, ed. de Smedt 815.
} 
um so den Zweck des Wunders, nämlich Hubert den Menschen zum Vorbild zu geben, zu verdeutlichen und seine Aufnahme in den Himmel stärker zu betonen. ${ }^{108}$ Die Teilnahme Karlmanns an der Elevation schließlich nutzte Jonas dazu, die Rolle, die ein rex memorabilis (!) bei der Förderung von Heiligenkulten spielen sollte, festzuschreiben. ${ }^{109}$

Auch seine Umarbeitung der Rede der Zeugen des Elevationsrituals zeigt das Bemühen um Verdeutlichung und Sicherstellen der Interpretation ebenso wie die subtile Verschiebung der Akzente im Vergleich zur Vita prima. ${ }^{110}$ Wie in der Vita prima verursacht der Anblick des unversehrten Körpers bei der Gemeinde auch in Jonas’ Text Selbstvorwürfe. Während die Vita prima diese Vorwürfe mit der eigenen Glaubensschwäche und dem zweifelnden Zögern begründet, das dem heiligen Leben Huberts unwürdig ist, arbeitet Jonas den Gegensatz zwischen der vorbildhaften Lebensführung Huberts und der nachlässigen der Gläubigen stärker heraus. Deren Zerknirschung ist hier klarer durch den gedanklichen Vergleich der eigenen Sündhaftigkeit mit der Güte und Vorbildhaftigkeit des lebendigen Hubert motiviert, den der Anblick seines Körpers auslöst. In der Vita prima fehlt auch der Vorsatz der Gemeindemitglieder, diese Verfehlungen durch Buße wieder gut zu machen - durch diese Einfügung verstärkt Jonas die Verbindung dieser Szene zum Bericht über die Predigt Huberts in der Mitte des Textes, ${ }^{111}$ und demonstriert so die Wirksamkeit seiner pastoralen Arbeit. Das Elevationswunder wird auf diese Weise zu einer Demonstration für den pastoralen Nutzen eines Reliquienkultes, der besonders groß ist, wenn der betreffende Heilige eng mit der eigenen Vergangenheit verbunden ist. ${ }^{112}$

Schließlich legte Jonas auf das Wunder der körperlichen Integrität noch größeren Nachdruck als die Vita prima, indem er den Gegensatz zwischen heiligen Körpern und denen gewöhnlicher Sterblicher systematischer ausarbeitete und argumentativ untermauerte. ${ }^{113}$ Ausgehend von einem Zitat aus Lukas $(L k 21,18)$ in der Vita prima machte Jonas die Bedeutung des Körperwunders als Zeichen für die Erfüllung des Auferstehungsversprechens explizit und sprach die prinzipielle Möglichkeit eines solchen Wunders auch in jüngerer Zeit an: ita ut quamquam de resurrectionis redintegratione veracissime a Salvatore dictum et fideliter a fidelibus constet susceptum: capillus de capite vestro non peribit, tamen et hoc tempore in hujus sancti viri corpore videretur impletum. ${ }^{114}$ Mit der Frage nach der körperlichen Integrität des Heiligen, die das Symbol für seine Aufnahme in den Himmel ist und seine Doppelpräsenz und Interzessionsfähigkeit begründet, berührte Jonas einen Kernpunkt in den Auseinandersetzungen um den Reliquienkult. ${ }^{115}$ In ihren Traktaten gegen Claudius betonten sowohl Jonas als auch Dungal nachdrücklich, daß Heilige durch ihre Reliquien schon vor der endgültigen Auferstehung zum Wohl der Lebenden wirken können, weil ihre Körper durch ihr verdienstvolles

108 Jonas, Vita et Translatio 24, ed. de Smedt 815: ut [...] pastor pastorum vicarium suum, quanti apud se esset meriti voluit ostendere [...] et populi perfruentes suavitate signorum, glorificarent Deum patatrorem tantorum operum. Et quia membrum parsque magna erat civitatis supernae, noluit eum Dominus super se positum delitescere, sed cunctis ejus civibus in exemplum proferri.

109 Jonas, Vita et Translatio 26, ed. de Smedt 816: Ut autem in tanto miraculo Domini potentia potissimum magnificaretur et virtus nota redderetur, pars permaxima princeps clarissimus atque orthodoxus extitit Carlomannus. Zur Bezeichnung Karlmanns als rex siehe ebd. 24, ed. de Smedt 815.

110 Vgl. Jonas, Vita et Translatio 25, ed. de Smedt 816, mit Vita Huberti prima 19, ed. Levison 494f.

111 Jonas, Vita et Translatio 14, ed. de Smedt 812f.

112 Vgl. die Kommentare zu dieser Stelle der Jonas-Vita bei Appleby, Sight and church reform 18.

113 Jonas, Vita et Translatio 25, ed. de Smedt 816: et introspicientes, gloriosum ejus corpus nulla detrimenta passum, illaesum a dissolutione atque putredine reppererunt, et pro tabo atque putredine, quae mos est mortalium corpora defuncta contrahere, aromatum more illud senserunt odorifico odore fervere. Vgl. dagegen Vita Huberti prima 19, ed. Levison 493: Sed cum timore magno summatim accedentes, lumen ab intro aspicientes invenerunt gloriosum corpus eius in sepulchro solidum atque inlibatum [...]. Die Überschreitung der Naturgesetze wird auch an weiteren Stellen in Jonas' Kapitel betont: Quis namque tibi similis in misericordia, qui non solum animas servorum tuorum in paradisi sedibus collocans, aeternam eis felicitatem attribuis, sed etiam corpora eorum, naturae quodammodo vim auferens, illibata custodis? Cujus enim meriti apud te iste nitet, cujus exuviae tanto honore tantaque gratia pollent, ut praeclusae terrae ventre, vim quodammodo ei intulerint, ne quod suum est ei liceret, scilicet ne caro de terra sumpta terra fieret, sed contra legem mortalium etiam terrae mandata caro maneret! (Vita et Translatio 25, ed. de Smedt 816).

114 Jonas, Vita et Translatio 25, ed. de Smedt 816. Vgl. damit Vita Huberti prima 19, ed. Levison 494: Sed cum timore magno summatim accedentes, lumen ab intro aspicientes invenerunt gloriosum corpus eius in sepulchro solidum atque inlibatum, mirum suavissimum odorem flagrantem, et respicientes ad caput illius, viderunt vultum eius in sudore conversum tamquam ros humidum, et capilli eius cum corona inlesi prolixiores et integri, non sicut in senectute canitiae, sed sicut in iuventute demutati. Et haec mutatio dextere excelsi est, iuxta illud quod altissimus ait: Et capillus de capite vestro non peribit. Vgl. dazu Sansterre, Les justifications 88.

115 Angenendt, Corpus incorruptum; Sansterre, Les justifications 87-90. 
Leben geheiligt sind, und belegten dies mit einer langen Reihe von Beispielen für Wunder an Reliquienschreinen aus patristischen Texten. ${ }^{116}$

In seinem Bericht über die Translation 825 setzte Jonas alles daran, sie als Inbegriff einer korrekten Reliquientranslation zu präsentieren: Nachdem Walcaud drei Jahre lang über die Anfrage der Mönche aus Andagne nachgedacht hatte, wandte er sich mit der Bitte um Zustimmung an seinen Metropoliten, Hildebald von Köln, der seinerseits Ludwig den Frommen konsultierte, der wiederum eine Synode mit der entgültigen Entscheidung betraute. Damit entsprach der Instanzenzug den Bestimmungen des Konzils von Mainz von 813, die auf eine strengere Kontrolle der Zirkulation von Reliquien durch Episkopat und König abzielten und diesbezügliche Bestimmungen früherer Synoden verschärften. ${ }^{117}$ Trotzdem mußte Jonas erneut vehement über den Status von Huberts Reliquien verhandeln: Wieder diskutierte er, unter Berufung auf Walcaud als Augenzeuge, die Auffindung des Körpers frei von jeglicher Verwesung, die normalerweise eine Folge der Erbsünde ist, und die Möglichkeit eines solchen Wunders in der Gegenwart. Um die Zweifel auch besonders skeptischer Leser zu zerstreuen, lud Jonas sie ein, die Translation mit dem - wiedergeschriebenen - Bericht über die Ereignisse von 743, die durch den vorhergehenden Vitentext als etabliert vorausgesetzt wurden, zu vergleichen. ${ }^{118}$

Der Rückgriff auf das frühere Wunder und der Einsatz der (literarischen) Parallelität mit dem subtil veränderten Vitentext als Argument für die Wahrhaftigkeit des eigenen Translationsberichtes setzt die Akzeptanz des wiedergeschriebenen Textes als autoritative Quelle zu den Ereignissen des 8. Jahrhunderts voraus. In diesem Sinn wird der Bericht über die Translation 825 auch wie folgt eingeleitet: Haec de vita et mirabilibus beati Hugberti, antistitis almi, et de his quae circa corpus ejus ob ejus reverentiam et Domini immensam gloriam praedicandam priscis temporibus caelebrata sunt, quamquam infacundo, fideli tamen stilo exarata, ad nos scripta commearunt. ${ }^{119}$ Im Widmungsbrief an Walcaud definierte Jonas als Ziel seiner Wiederschrift die Verbesserung des Stils der alten Vita und wehrte sich ausdrücklich dagegen, als Autor des Textes angesprochen zu werden: Sed neque compilatoris vel nomen vel officium mihi debet imputari, quasi qui alienum opus verbaque pervaserim. ${ }^{120}$ Wie konsequent Jonas diese Strategie der Annäherung an den Text eines fremden Autors umsetzte, zeigt ein Bericht über die Seenot der discipuli Huberts, aus der sie durch die Interzession des Heiligen gerettet werden. In der Vita prima wird hier der Erzähler, der bis dahin in der dritten Person berichtet hat, zu einer Figur der Geschichte, deren besondere Erlebnisse bei diesem Ereignis geschildert werden. Jonas übernimmt nicht nur an einigen anderen Stellen die beobachtende wir-Form, sondern beläßt auch an diesem Punkt den plötzlichen Fokus auf das ego des Erzählers und verstärkt diesen Effekt sogar noch: Mihi quoque, qui haec scripsi, in eodem naufragio tale quid accidit. ${ }^{121}$ Auf den Erfolg dieser Strategie weist

116 Vgl. dazu Sansterre, Les justifications 87f.; Appleby, Holy relic 337. Siehe das lange Zitat aus Augustinus’ De civitate Dei bei Dungal, Responsa 189f., ed. Zanna 146-143; vgl. Aurelius Augustinus, De civitate Dei XXII, 8 (ed. Bernhard Dombart/Alphons Kalb, CC SL 48, Turnhout 1955) 816-827. Vgl. auch Jonas, De cultu imaginum, PL 106, 326B-329B, 372C-373D, 377B - 379C, 382B - 383B, 384C-D. Agobard von Lyon hingegen zitierte zu diesem Thema Augustinus' wunderskeptische Positionen, wonach sichtbare Wunder in Zeiten der Institutionalisierung der Kirche aufhören müßten, um die Gläubigen nicht in der Abhängigkeit von sichtbaren Dingen zu belassen: Agobard, De picturis XXV, ed. van Acker 174. Zur Problematisierung des Wunders in Spätantike und Frühmittelalter siehe Martin Heinzelmann, Die Funktion des Wunders in der spätantiken und frühmittelalterlichen Hagiographie, in: Mirakel im Mittelalter. Konzeptionen, Erscheinungsformen, Deutungen, ed. ders./Klaus Herbers/Dieter R. Bauer (Beiträge zur Hagiographie 3, Stuttgart 2002) 23-61; Marc van Uytfanghe, La controverse biblique et patristique autour du miracle, et ses répercussions sur l'hagiographie dans l'Antiquité tardive et le haut Moyen Âge, in: Hagiographie, cultures, et sociétés. IVe-XII siècles, ed. Evelyne Patlagean/Pierre Riché (Paris 1981) 205-233. Für die theologischen und christologischen Hintergründe dieser Debatten Chazelle, The Crucified God 14-131, bes. 119ff.; für die patristischen Diskussionen Caroline W. Bynum, The Resurrection of the Body in Western Christianity, 200-1336 (New York 1995) 19-114, bes. 104ff.

117 Jonas, Vita et Translatio 30-32, ed. de Smedt 817f.; Concilium Monguntinense (813) 51, ed. Werminghoff 272. Vgl. oben Anm. 27.

118 Jonas, Vita et Translatio 33, ed. de Smedt 818.

119 Jonas, Vita et Translatio 28, ed. de Smedt 817.

120 Jonas, Vita et Translatio, Epistola dedicatoria, ed. de Smedt 806. Siehe zu mittelalterlichen Widmungsbriefen Gertrud Simon, Untersuchungen zur Topik der Widmungsbriefe mittelalterlicher Geschichtsschreiber bis zum Ende des 12. Jahrhunderts, in: Archiv für Diplomatik 4 (1958) 52-119; 5/6 (1959/60) 73-153.

121 Vita Huberti prima 8, ed. Levison 487f. Nachdem zunächst in noch eher distanzierter Form, aber bereits unter Verwendung der 1. Person Plural, der Schiffbruch der von Hubert getrennten discipuli geschildert wird, leitet der Erzähler seine eigenen Erfahrungen folgendermaßen ein: Et hoc cur sileam, quod me servo eius in ipsa accione contigit? Cum essem humatus [...]. In der Folge wird die Rolle des Erzählers wieder zurückgenommen und auf die eines Beobachters reduziert, und die Verbformen wechseln 
auch die Tatsache hin, daß Leser späterer Generationen Jonas’ Text als den Bericht eines Zeitgenossen akzeptieren konnten. ${ }^{122}$

4.

Anhand von Jonas’ Vita et Translatio lassen sich die Strategien der réécriture als eine Arbeit der Übersetzung untersuchen, die die Relevanz der Vita Huberti in zeitgenössischen Diskussionen herstellen konnte. Die Adaption des Textes an die Diskussionszusammenhänge der 820er Jahre erforderte eine Vielzahl an kleineren und größeren textlichen Eingriffen und die Verwendung eines aktualisierten Vokabulars. Dabei wird deutlich, wieviel Aufwand nötig war, um Text und Translation als Ressource für die Formulierung von Positionen zur Theorie des Bischofsamts und zur Legitimität von Reliquienkulten zu nutzen. Die Strategien der Wiederschrift können auch als Wille zur Kontrolle über Bedeutungen und Deutungen verstanden werden. Dieser Effekt geht vor allem auf die verstärkte Präsenz des Erzählers in seiner kommentierenden Funktion zurück, wodurch an vielen Stellen der Deutungsspielraum eingeschränkt, Interpretationen festgeschrieben oder Ereignisse umgedeutet werden. Diese Strategie unterscheidet sich vom Einsatz der intertextuellen Bezüge in der Vita prima - Jonas beanspruchte für die so formulierten Positionen explizit die Autorität einer bereits vorhandenen Texttradition.

Gemeinsam mit den Lièger Viten des 8. Jahrhunderts kann die Vita et Translatio auch daran erinnern, daß weder die Kontrolle über Reliquienkulte noch die über die Bedeutung der Reliquien als gegeben vorausgesetzt werden konnte - vielmehr mußte sie in den Texten erst etabliert werden. ${ }^{123}$ Aufbau und Aneignung der spirituellen Traditionen in Maastricht/Liège standen in jeder ihrer Etappen in spezifischen lokalen, politischen und theologischen Diskussionszusammenhängen, und gingen jeweils mit Auseinandersetzungen um Deutungen und Interpretationen einher. In einer Zeit, in der die Grundlagen, die Formen und der spirituelle Nutzen der Verehrung von materiellen Objekten und besonders von Reliquien zur Diskussion stand, bedeuteten diese Verhandlungsprozesse besonderen Aufwand und erforderten sehr viel Umsicht.

Jonas' Text ist dafür nur ein besonders explizites und differenziertes Beispiel - auch wenn seine Auseinandersetzung mit diesen Fragen für den Autor eines Traktates über die Bedeutung und den Nutzen der Verehrung materieller Objekte in der christlichen Praxis naheliegend scheint, ist die Vita et Translatio in ihrer Reaktion auf diese Diskussionen nicht ganz so außergewöhnlich, wie man vielleicht annehmen könnte. Auch in anderen hagiographischen Texten der Zeit zeichnet sich die Notwendigkeit ab, Zweifel über die Authentiztität und den richtigen Umgang mit den Reliquien zu zerstreuen. In manchen Fällen mußten alle gesellschaftlichen Gruppen überzeugt werden, wie etwa die zwischen 822 und 838 entstandene Commemoratio brevis über den Heiligen Genesius, der bereits unter Karl dem Großen nach Schienen gebracht worden war, zeigt. ${ }^{124}$ In den Annales regni Francorum schließt der Bericht über die Sebastianstranslation mit einem emphatischen Argument gegen die Begrenztheit menschlichen Glaubens an die unerhörten Wunder, die durch

zwischen der 1. und der 3. Person. Vgl. zur Unterscheidung zwischen heterodiegetischer und homodiegetischer Erzählung und den verschiedenen Graden der Anwesenheit des Erzählers in der Geschichte Genette, Die Erzählung 174-186 und 257-278.

${ }^{122}$ Die von de Smedt (AASS 3. November, Bd. 1, 829-831) edierte anonyme Vita tertia Huberti (12. Jahrhundert), die ein Exzerpt der Vita Lamberti des Nicolas von Liège ist (Mitte des 12. Jahrhunderts, vgl. Kupper, Saint Lambert 41f.), substituiert den nicht näher identifizierbaren libellus, den Nicolas als Quelle für sein Wissen über Hubert angibt, mit dem Text des Jonas: Sed et de vita et miraculis quae in episcopatu gessit, quae quidem ex libro domini Jonae episcopi, qui inter ceteros familiari ei contubernio adhaesit, decerpens meo opusculo alibi indidi, hic aliquid retexere supersedi (Vita tertia Huberti 7, ed. de Smedt 831, Hervorhebung G.H.). Vgl. van der Essen, Étude critique 65f.

${ }^{123}$ Brown, Relics and social status; zur sozialen Konstruktion des Wertes von Reliquien auch Patrick J. Geary, Sacred commodities: the circulation of medieval relics, in: Commodities and Culture, ed. Arjun Appadurai (Cambridge 1986) 169-191, wieder abgedruckt in: Geary, Living with the Dead 194-218; ders., The ninth century relic trade.

${ }^{124}$ Commemoratio brevis de miraculis sancti Genesii martyris Christi (ed. Wilhelm Wattenbach, Die Übertragung des h. Genesius nach Schienen, in: Zeitschrift für die Geschichte des Oberrheins 24 [1872]) 1-21. Siehe z.B. ebd. 2, 5 und 6, ed. Wattenbach 12f., 14f. Deutliche Sorge um den Ruf des Schreines gegen den Verdacht von profitorientierter Scharlatanerie ebd. 21, ed. Wattenbach 20f. In St. Gallen versah eine Hand der 2. Hälfte des 9. Jahrhunderts den Eintrag der Commemoratio im Bibliothekskatalog mit dem Zusatz mendacissima et cetera inutilia: Paul Lehmann, Mittelalterliche Bibliothekskataloge Deutschlands und der Schweiz 1: Die Bistümer Konstanz und Chur (München 1918) (nr. 16) 78. Vgl. Theodor Klüppel, Reichenauer Hagiographie zwischen Walahfrid und Berno (Sigmaringen 1980) 18-25. 
die göttliche Allmacht am Sebastiansschrein gewirkt wurden. ${ }^{125}$ Über Fragen der Authentizität hinausgehend werden Reflexionsbedarf und Problembewußtsein aber auch an der Sorgfalt deutlich, mit der in vielen Texten auf Konformität mit der Theologie geachtet und immer wieder die Grundlagen, Möglichkeiten und der Sinn von Wundern an Reliquienschreinen als Mittel der Interaktion zwischen Gott und den Menschen thematisiert wird. ${ }^{126}$ Auch Hrabanus Maurus' Umgang mit den von ihm im Lauf der 830er Jahre aus Rom importierten Reliquien und ihre Inszenierung in den Kirchen rund um Fulda kann unter anderem als Antwort auf die Frage nach Zugängen zum Heiligen und nach der spirituellen und pastoralen Funktion von Reliquienkulten und materiellen Objekten verstanden werden. ${ }^{127}$ Der Text über diese Translationen, Rudolf von Fuldas Miracula sanctorum, nutzt die Wundergeschichten an den Reliquienschreinen häufig für sehr spezifische Instruktionen über moralische Normen, Besserung und Buße und verdeutlicht so auch die edifikatorische Funktion von Heiligenkulten. ${ }^{128} \mathrm{Zu}$ einer weit skeptischeren Konklusion bezüglich des spirituellen Ertrags von Reliquienkulten kam einige Jahre später Paschasius Radbertus im Prolog zur Passio Rufini et Valerii. Er kontrastierte systematisch Reliquien und Texte, und bewertete dabei den Nutzen von Reliquien als gering im Vergleich zu dem von Texten, die den Gläubigen vita et doctrina der Heiligen ins Gedächtnis rufen. ${ }^{129}$ Jonas war auch nicht der einzige Teilnehmer der Debatten, der auf die Ambivalenz der Reliquien und die Unsicherheit im Umgang mit ihnen mit der Betonung der klerikalen und vor allem bischöflichen Kontrolle über Reliquienkulte reagierte, ein Standpunkt, der sowohl in De cultu imaginum als auch in der Vita et Translatio deutlich wird.

\section{STRATEGIEN DER NIEDERSCHRIFT: EINHARDS TRANSLATIO}

Auch Einhards Translatio Marcellini et Petri muß in vielerlei Hinsicht in diesem Spannungsfeld verstanden werden. Die eingangs zitierten Versuche, die römischen Reliquien als Ressourcen für Autorität im Diskurs zu nutzen, machten mühsame Verhandlungen über ihren Status und ihre Bedeutung notwendig, standen aber auch in Bezug zu den Debatten über die gesellschaftliche Bedeutung von Heiligen- und Reliquienkulten. ${ }^{130}$ Anders als Jonas und Walcaud konnte Einhard nicht auf eine bereits vorhandene Texttradition zurückgreifen oder auf die Autorität des Bischofsamtes zählen, um seinen Umgang mit den Reliquien zu legitimieren.

Die Translatio Marcellini et Petri wurde zwar in den Jahren nach ihrer Entstehung rasch zum Modell ähnlicher Texte - zur Zeit der Abfassung aber war Einhards Entscheidung, einen Translationsbericht zu schreiben, eher ungewöhnlich und ist wohl vor allem auf den großen Rechtfertigungsbedarf zurückzuführen, der mit diesem Projekt einherging. Anders als Hilduins Erwerb der Sebastiansreliquien war Einhards Translation das Ergebnis eines Diebstahles und der Zusammenarbeit mit dem zwielichtigen Reliquienhändler Deusdona. ${ }^{131}$ Einhards detaillierte Erzählung von den Vorgängen und dem Diebstahl in Rom ist daher nicht zuletzt ein Argument für die Authentizität der Reliquien, das außerdem durch die sorgfältige Aneignung der posthumen Geschichte der Märtyrer und der Topographie ihrer Grabstätte untermauert wurde. ${ }^{132}$ Ein weiteres

125 Annales regni Francorum a. 826, ed. Kurze 172.

126 Vgl. Goetz, Wunderberichte 220f.

127 Janneke Raaijmakers, Word, image and relics. Hrabanus Maurus and the cult of saints (820s-840s), in: Hraban Maur et son temps (vers 780-856). Actes du colloque international d’Amiens - Lille III, 5-8 juillet 2006, ed. Philippe Depreux/ Stéphane Lebecq/ Michel Perrin/Olivier Szerwiniak (Collection Haut Moyen Âge 9, Turnhout, im Druck) 385-401.

128 Siehe z.B. Rudolf von Fulda, Miracula sanctorum 2; 6; 12, ed. Waitz 331, 334f., 337f. Zu diesem Text Janneke Raajmakers, Sacred time - sacred space. History and identity at the monastery of Fulda, 744-856 (Proefschrift, Universiteit Amsterdam 2003) 104-111 und 167-201; dies., Een sacraal landschap: Rudolf van Fulda over Hrabanus’ reliekentranslaties, in: Millenium. Tijdschrift voor middeleeuwse studies 14 (2000) 5-20.

${ }^{129}$ Paschasius Radbertus, Passio SS. Rufini et Valerii, Prolog, PL 120, 1489-1508, hier 1489-1491. Für die teilweise Übersetzung des Prologes und die Diskussion der Passio siehe Walter Berschin, Biographie und Epochenstil im lateinischen Mittelalter 3: Karolingische Biographie, 750-920 n. Chr. (Quellen und Untersuchungen zur lateinischen Philologie des Mittelalters 10, Stuttgart 1991) 304-308.

${ }^{130}$ Heinzelmann, Hagiographische Reformschrift 295-297. In diesem Zusammenhang sei auch auf Einhards Auseinandersetzung mit ähnlichen Fragen in De adoranda cruce verwiesen: Einhard, Quaestio de adoranda cruce (ed. Ernst Dümmler, MGH EE 5, Aevi Karolini 3, Berlin 1898/99, ND München 1978) 146-149.

131 Zu Deusdona Geary, Furta sacra, 44-49.

${ }^{132}$ Vgl. dazu Seeliger, Einhards römische Reliquien 64f. Zur Geschichte und Topographie der Katakombe Inter duas lauros Jean Guyon, Le cimetière aux deux Lauriers. Recherches sur les catacombes Romaines (Roma sotteranea cristiana 7, Bibliothèque des écoles françaises d’Athènes et de Rome 264, Vatikan 1987); Hans Reinhard Seeliger, Die Geschichte der Katakombe „inter duas 
wesentliches Anliegen in den ersten beiden Büchern des Textes ist die Widerlegung von Hilduins Ansprüchen auf Teile der heiligen Körper und die systematische Unterminierung der Glaubwürdigkeit Hilduins und seines Mittelsmannes Hunus. ${ }^{133}$ Wie für die ursprüngliche Translation aus Rom verfolgte Einhard auch für den Ortswechsel der Reliquien von Michelstadt-Steinbach nach Seligenstadt die bekannte Argumentationsstrategie, diese Entscheidung als dem Willen der Märtyrer gemäß zu präsentieren, den diese in mehreren Visionen kundtaten. ${ }^{134}$

Die neugebaute Kirche in Seligenstadt ist eines der vielzitierten Beispiele für Kirchenbauten nach dezidiert römischem Modell und ermöglichte den Zugang zu den Reliquien wie in St. Peter in Rom. ${ }^{135}$ Die Kanonikergemeinschaft, die die Anwesenheit der Reliquien in Seligenstadt begründete, hebt sich in Einhards Text durch die Abgrenzung von den herabgekommenen mores anderer religiöser Einrichtungen der Region als Ort ab, an dem der Glaube an die Macht Gottes in seinen Reliquien und die korrekte Liturgie Zugang zu Heilung und Besserung für die Menschen eröffnen. ${ }^{136}$

Vor allem in den letzten beiden Büchern der Translatio lassen sich die Verhandlungen um die Bedeutung und den Platz der Reliquien im Verhältnis zu bereits etablierten Kulten und zu lokalen spirituellen Traditionen nachvollziehen. So ist die Abfolge der Wundergeschichten auch eine Erzählung von der langsamen Durchsetzung von Marcellinus und Petrus. ${ }^{137}$ Ein gutes Beispiel dafür ist die Geschichte eines Mannes, der bereits seinen gesamten Besitz an verschiedene Heiligenschreine verschenkt hatte, als ihn sein Diener darauf aufmerksam machte, quod perperam ac valde neglegenter ab eis factum esset in eo, quod nihil de bonis eius sanctis nuper de Roma venientibus datum esset. ${ }^{138} \mathrm{Um}$ das spezielle Prestige seiner Märtyrer zu betonen, wies Einhard in einem anderen Fall darauf hin, daß die Geheilten bereits eine Odysee entlang unzähliger loca sanctorum hinter sich hatten, bevor sie schließlich durch die Interzession der römischen Märtyrer von ihren

lauros“ nach den schriftlichen Quellen, in: Die Katakombe „Santi Marcellino e Pietro“. Repertorium der Malereien, ed. Johannes Deckers/Hans Reinhard Seeliger/Gabriele Mietke (Roma sotteranea cristiana 6, Textband, Münster 1987) 50-90. Zum Diebstahl als Argumentationsstrategie siehe Geary, Furta sacra 57f.

133 Zu den Rivalitäten zwischen Einhard und Hilduin Heinzelmann, Hagiographische Reformschrift 284ff. und 293f.; Smith, Emending evil ways 201-205; Seeliger, Römische Reliquien 61f. Der Priester Hunus wird nur ein einziges Mal beim Namen genannt und ansonsten als „Hilduins Priester“ bezeichnet; vgl. auch die komplizierte Erzählung von der Aufsplitterung der Gruppe auf der Rückreise (Einhard, Translatio I, 7, ed. Waitz 242f.), wodurch die Version der Ereignisse von Einhards Boten Ratleik glaubwürdiger erscheint als die Hilduins (II, 2, ed. Waitz 246), und die einige Kapitel vorher eingestreute Beobachtung Einhards, daß Marcellinus’ Körper kleiner erschien als der von Petrus, die ebenfalls Einhards Sicht der Ereignisse unterstützte: Einhard, Translatio I, 9, ed. Waitz 243. Im Gegenzug schürte Einhard Zweifel an der Echtheit der Tiburtius-Reliquien: Ebd. I, 5, ed. Waitz 240.

${ }^{134}$ Einhard, Translatio I, 2, ed. Waitz 240, für die Vision von Ratleiks Diener auf der Reise nach Rom; ebd. I, 9-12, ed. Waitz 243f., für die Translation von Steinbach nach Seligenstadt. Vgl. zu den Gründen für diesen Ortswechsel Heinzelmann, Hagiographische Reformschrift 183f.; Smith, Emending evil ways 197-201.

135 Vgl. Smith, Emending evil ways 206-210, die auch auf S. Prassede als mögliches Modell hinweist. Vgl. Werner Jacobsen, Allgemeine Tendenzen im Kirchbau unter Ludwig dem Frommen, in: Charlemagne's Heir. New Perspectives on the Reign of Louis the Pious, ed. Roger Collins/Peter Godman (Oxford 1990) 641-654. Für Kritik an Jacobsens scharfen Kontrasten zwischen den Phasen bevorzugter Baumodelle und deren Juxtaposition mit der Reformbewegung siehe Dieter Geuenich, Kritische Anmerkungen zur sogenannten „,anianischen Reform“, in: Mönchtum - Kirche - Herrschaft. 750-1000, ed. Dieter R. Bauer/Rudolf Hiestand/ Brigitte Kasten/Sönke Lorenz (Sigmaringen 1998) 99-112, hier 99ff. Zu Einhards Bauten Günther Binding, Multis artis fuit utilis. Einhard als Organisator am Aachener Hof und als Bauherr in Steinbach und Seligenstadt, in: Mittellateinisches Jahrbuch 30 (1996) 39-46.

${ }^{136}$ Den Zusammenhang zwischen Reliquienkult und correctio hat zuletzt vor allem Julia Smith betont: Smith, Emending evil ways; dies., Einhard, the sinner and the saints; siehe schon Fleckenstein, Einhard, seine Gründung und sein Vermächtnis. Für den Kontrast zwischen Seligenstadt und anderen religiösen Einrichtungen der Umgebung siehe Einhard, Translatio I, 11, ed. Waitz 244. Eine große Zahl von Wundern geschehen während der Liturgie. Vgl. auch die Kritik am sinnlosen Rückgriff auf profane Medizin, die manchmal gerade in Klöstern praktiziert wird: Einhard, Translatio III, 20, ed. Waitz 255. Dazu auch III, 16; IV, 6 ed. Waitz 254, 257. Vgl. außerdem Einhard, Epistola 53 (ed. Karl Hampe, MGH EE 5, Karolini aevi 3, Berlin 1898/99, ND München 1978) 105-145, hier 136, wo Einhard die Kanoniker in Seligenstadt zur Einhaltung ihrer Gelübde und zur korrekten Ausführung des Dienstes an den Märtyrern auffordert, damit sie so würdige Interzessoren und Beispiel für andere sein können.

137 Vgl. zu miracula als Kartographierung der (tatsächlichen oder gewünschten) Einflußsphäre von Heiligenschreinen Hedwig Röckelein, Über Hagio-Geo-Graphien. Mirakel in Translationsberichten des 8. und 9. Jahrhunderts, in: Mirakel im Mittelalter. Konzeptionen - Erscheinungsformen - Deutungen, ed. Martin Heinzelmann/Klaus Herbers/Dieter R. Bauer (Beiträge zur Hagiographie 3, Stuttgart 2002) 166-179, bes. 174ff.; siehe auch Smith, Emending evil ways 203.

138 Einhard, Translatio III, 3, ed. Waitz 249. 
Leiden befreit wurden. ${ }^{139}$ Heilungen, die spezifisch als Konkurrenzwunder gegen andere Kultorte verstanden werden können, sind insgesamt selten, richten sich aber ausgerechnet gegen den Sebastiansschrein in Soissons und den Lambert-Kult in Liège. ${ }^{140}$

Einhard gab Teile der Märtyrerreliquien auch an andere Klöster weiter, darunter mit St. Servatius in Maastricht und St. Bavo in Gent an zwei der Gemeinschaften, denen er als Laienabt vorstand. ${ }^{141}$ Anders als in Seligenstadt trafen die römischen Reliquien hier auf die jeweiligen lokalen Kulte, die teilweise ebenfalls von Einhard selbst gefördert worden waren. ${ }^{142}$ Einhard versuchte sehr nachdrücklich, Integration und Prestige der römischen Importe im Verhältnis zu und in Auseinandersetzung mit den lokalen Traditionen zu argumentieren. In das vierte Buch der Translatio nahm er eine Reihe von Berichten über die Wundertätigkeit der Märtyrer an diesen Orten in Form von libelli miraculorum auf, die ihm von den jeweiligen Gemeinschaften zugesandt worden waren. ${ }^{143}$ Seine einleitenden Kommentare zu diesen libelli nutzte Einhard dazu, ihre Entstehung zu erklären und ihre Glaubwürdigkeit mit dem Hinweis zu bekräftigen, er habe die Texte praktisch wörtlich in die Translatio übernommen. ${ }^{144}$ Die so integrierten Textbausteine zeigen allerdings deutliche Spuren der Redaktion durch Einhard. ${ }^{145}$ Die dichten Aneinanderreihungen meist sehr kurz gehaltener Wunderberichte etablieren mit auffallend monotoner Rhetorik Marcellinus und Petrus als alleinige Urheber der Heilungen. Am eindrucksvollsten ist in dieser Hinsicht der libellus aus St. Bavo, wo in beinahe jedem Satz der confessor

139 Einhard, Translatio III, 15, ed. Waitz 254. Siehe auch ebd. III, 4, ed. Waitz 249, wo Marcellinus und Petrus in Seligenstadt einen taubstummen Rompilger heilen.

${ }^{140}$ Marcellinus und Petrus heilten einen taubstummen Mann, der nach einem Besuch beim Schrein des Sebastian in Soissons nach wie vor mehr schlecht als recht hörte und kaum zu verstehen war, vollständig: Einhard, Translatio IV, 15 (Wunder vom 23. Juni), ed. Waitz 262. Für die Heilung eines Mannes aus Liège, das explizit als Kultort des Lambert identifiziert wird, ebd. III, 10, ed. Waitz 251.

${ }^{141} \mathrm{Zu}$ Einhards Aktivitäten in Gent siehe Georges Declercq, Een karolingisch lekenabt in Gent. Einhard en de Gentse abdijen van Sint-Pieters en Sint-Baafs, in: Handelingen der Maatschappij voor Geschiedenis en Oudheidskunde, nieuwe reeks 55 (2001) 37-56; ders./Adriaan Verhulst, Einhard und das karolingische Gent, in: Einhard. Studien zu Leben und Werk, ed. Hermann Schefers (Darmstadt 1997) 223-246. Zu Einhard als Laienabt Josef Semmler, Einhard und die Reform geistlicher Gemeinschaften in der ersten Hälfte des 9. Jahrhunderts, in: Einhard. Studien zu Leben und Werk, ed. Hermann Schefers (Darmstadt 1997) 179-189; Franz Josef Felten, Äbte und Laienäbte im Frankenreich. Studie zum Verhältnis von Staat und Kirche im früheren Mittelalter (Monographien zur Geschichte des Mittelalters 20, Stuttgart 1980) $263 \mathrm{ff.}$

142 Dies ist etwa beim heiligen Bavo in Gent der Fall. Die Vita Bavonis entstand möglicherweise zur Zeit von Einhards Abbatiat. Siehe für diese Diskussion van der Essen, Étude critique 351ff. Skeptisch Declercq, Karolingisch lekenabt 69ff.; ders./Verhulst, Einhard und das karolingische Gent 235f. Vgl. Anne-Marie Hélvetius, Les modèles de sainteté dans les monastères de l'espace belge du VIII ${ }^{e}$ au IX ${ }^{\text {e }}$ siècle, in: Revue bénedictine 103 (1993) 53-67, hier 60ff. Adriaan Verhulst, S. Bavon et les origines de Gand, in: Revue du Nord. Histoire et Archéologie 69 (1986) 455-470, datiert die Vita auf um 825. Auch abseits der Vita gibt es eine Reihe von Hinweisen für Bemühungen Einhards um die Förderung des Bavo-Kultes. So ist unter Einhard erstmals der Name St. Bavo für das Kloster belegt, unter anderem in der Translatio und Einhards Briefen. Bei Einhard, Epistola 56, ed. Hampe 137, wird auch eine missa Bavonis erwähnt. Zudem taucht Bavos Name im Martyrologium des Hrabanus Maurus auf: Hrabanus Maurus, Martyrologium Kal. Oct. (ed. John McCulloh, CC CM 44, Turnhout 1979) 3-134, hier 100; vgl. Maurice Coens, S. Bavon était-il évêque?, in: Analecta Bollandiana 63 (1945) 220-241, hier 236ff.; Declercq, Karolingisch Lekenabt 40 Anm. 7 und 70 Anm. 129.

${ }^{143}$ Einhard, Translatio IV, 8-14, ed. Waitz 258-262. Zu solchen libelli miraculorum Martin Heinzelmann, Une source de base de la littérature hagiographique latine: le receuil de miracles, in: Hagiographie, cultures et sociétés, IV - XII ${ }^{\mathrm{e}}$ siècles. Actes du Colloque organisé à Nanterre et à Paris (2-5 mai 1979) par le centre de Recherches sur l'Antiquité tardive et le Haut Moyen Age, Université de Paris X (Études augustiniennes, Paris 1981) 235-259, bes. 245.

144 Vgl. Einhard, Translatio IV, 11, ed. Waitz 260: Haec sunt miracula atque virtutes, quas dominus noster Ihesus Christus per meritam sanctorum martyrum suorum Marcellini et Petri in vico Valentianas ad salutem humani generis operari dignatus est, quae memoratus Georgius presbyter brevi libello collecta nobis mittere curavit et nos huic operi nostro censuimus inserenda. [...] Alter libellus mihi oblatus est de monasterio Sancti Bavonis [...] in quo haec per ordinem digesta reperta sunt. Vgl. auch IV, 9, ed. Waitz 259: De caeteris autem quae nunc dicenda sunt ab eo libellum accepi, cuius ordo vel series hunc modum habere cognoscitur.

145 Vgl. z.B. Einhard, Translatio IV, 10, ed. Waitz 259, wo Einhard den Text des libellus unterbricht, um die Wiederholung eines Wunders, von dem er bereits im vorangegangenen Kapitel ausführlicher berichtet hat, zu erklären. Siehe auch die Einleitung zum libellus aus Maastricht in IV, 13, ed. Waitz 261: Tertium quoque libellus mihi oblatus est [...] cuius textus, si bene recolo, in hunc modum videtur esse compositus; im Text des Mirakelberichtes finden sich an zwei Stellen Verbformen in der ersten Person, deren Subjekt unklar bleibt, wodurch mit dem ansonsten distanzierten Berichtstil der libelli gebrochen wird. Dabei ähneln die Beschreibungen der Heilungen aus Maastricht denen anderer Wunder in der Translatio stärker als die in den übrigen libelli, vgl. z.B. Translatio IV, 14, ed. Waitz 262 (Wunder vom 23. Juni). 
Bavo durch wiederkehrende Phrasen wie coram sacris martyris reliquiis, ante sacras martyrum reliquias etc. von der Mitwirkung an den Wundern ausgeschlossen wird. ${ }^{146}$ Möglichen Mißinterpretationen von ambivalenteren Formulierungen etwa im Zusammenhang mit Salvius von Valenciennes, der ebenfalls ein Märtyrer war, steht bereits die Einleitung zu Buch IV entgegen. Hier spricht Einhard den lokalen Patronen auf sehr direkte Weise jegliche Wunderkraft ab:

Es wirkten die heiligen Märtyrer, wie ich im Folgenden zeigen werde, auch an den Orten anderer Heiliger viele Zeichen und Wunder. Es kann manchen Leuten nicht ganz zu unrecht so scheinen, als ob diese [Wunder] jenen und den Heiligen, in deren Kirchen sie geschehen sind, gemeinsam [zuzuschreiben] sind, vor allem deswegen, weil es nicht abwegig ist zu denken, daß die, von denen man glaubt, daß sie vor Gott gleich an Verdienst sind, beim Wirken von Wundern mit vereinten Kräften zusammenarbeiten. Daß sich dies aber anders verhält, wird durch das Argument überzeugend bewiesen und klar gezeigt, daß an diesen Orten keine Wunder geschehen sind, bevor die Reliquien der heiligen Märtyrer dorthin gebracht wurden. ${ }^{147}$

Wenn Einhard versuchte, die Reliquien zur Durchsetzung vielfältiger Anliegen zu nutzen, so zeigt die Translatio ähnlich wie die Lièger Bischofsviten, wie wenig für diese Nutzungsversuche von einer souveränen Kontrolle über die Bedeutung der involvierten Reliquien ausgegangen werden konnte. Daher erforderte die Durchsetzung ihrer Autorität im politischen Diskurs besonders großen erzählerischen und argumentativen Aufwand. Einhard versuchte nicht nur in mehreren Briefen, Ludwig dem Frommen und Lothar das Potential seiner Heiligen als Schutzpatrone des Reiches nahezulegen. ${ }^{148}$ Auch in der Translatio bilden vielfältige Argumente zur Anbindung des Kultes an den Hof und den Kaiser den Kontext für die Rolle der römischen Reliquien in den Beratungen in Aachen im Winter 828/9 und für den Bericht über die beiden libelli mit Gabriels Reformvorschlägen und dem Protokoll über Wiggos Exorzismus. ${ }^{149}$ Der eigentliche Inhalt von Gabriels Anleitung zur Reform blieb ausdrücklich aus dem Text der Translatio ausgespart - Einhard berichtete ausschließlich von der Entstehung des libellus und seiner Übergabe an Ludwig den Frommen, und merkte an, daß dieser die Vorschläge nur sehr halbherzig umgesetzt hatte. ${ }^{150}$ Im Gegensatz dazu nahm Einhard die Aussagen des Dämon Wiggo sehr wohl in seinen Text auf. ${ }^{151}$ Sie vermitteln ein sehr eindrückliches Bild von den inneren

146 Translatio IV, 12, ed. Waitz 260f. Von den dreizehn Wunderbeschreibungen enthalten acht Phrasen wie coram sacris martyrum reliquiis/cineribus; dazu kommen für vier weitere Wunder vagere Formulierungen wie ibidem, ante memoratas sanctorum reliquias.

147 Einhard, Translatio, Praefatio zu Buch IV, ed. Waitz 256: Fecerunt idem beatissimi martyres, sicut in sequentibus demonstrabimus, in aliorum sanctorum locis multas virtutes atque miracula, quae quibusdam velut communia illis cum his sanctis, in quorum basilicis facta sunt, non inmerito videri possunt, ob hoc praecipue, quoniam, qui apud Deum aequalis creduntur meriti, non absurde putantur in patrandis miraculis communiter operari. Sed hoc aliter esse ea ratione convincitur, qua liquido demonstratur, nullas in his locis factas esse virtutes, antequam in illa memorata beatorum martyrum essent delatae reliquiae. Vgl. die englische Übersetzung bei Dutton, Charlemagne’s Courtier 111. Zudem legt die explizite Nennung der Namen Marcellinus und Petrus in den ersten beiden Episoden des Büchleins aus Valenciennes die entsprechende Interpretation der weiteren Formulierungen nahe. Für die Wunder, die Marcellinus und Petrus in Maastricht in der Basilika des ehrwürdigen Stadtpatrons Servatius wirkten, kann bei der Beschreibung wieder auf die Unterscheidung zwischen Märtyrern und Confessores zurückgegriffen werden, was allerdings mit weniger Vehemenz geschieht als im Bericht für Gent.

148 Einhard, Epistola 10, ed. Hampe 113, an Ludwig den Frommen: Quamvis certissime credam, piissimum dominum meum semper memorem esse patronorum suorum, beatissimorum Christi martyrum M[arcellini] et P[etri], qui occulto Dei iudicio Roma relicta ad exaltationem et protectionem regni vestri in Franciam venerunt [...]; siehe auch Epistola 15, ed. Hampe 118 (Einhards Bitte an Ludwig um Dispens von der Anwesenheit bei Hof); 33, ed. Hampe 126 (an Ludwig den Deutschen). Vgl. Smith, Emending evil ways 205, 210; Dutton, Politics of Dreaming 92f.

149 Vgl. Heinzelmann, Hagiographische Reformschrift 286f.; Smith, Emending evil ways 201f. Siehe z.B. den Bericht über die Verehrung der Reliquien durch Ludwig und Judith, deren Inszenierung allerdings auf starken Widerstand Hilduins stieß, Einhard, Translatio II, 6, ed. Waitz 246. Vgl. auch ebd. IV, 7, ed. Waitz 258. Teil dieser Argumentation ist auch die Anordnung der Wunder nach Orten, wodurch sich ein Block von Wundern in Aachen ergibt: Praefatio zu Buch IV, ed. Waitz 256: In relatione signorum atque virtutum [...] illae in capite ponendae videntur, quae in palatio factae non solum ad plebis, verum etiam ad ipsius principis ac procerum omniumque, ut ita dicam, auliculorum pervenere notitiam [...]. Von den insgesamt nicht sehr zahlreichen Wundern, die eine moralische Deutung erhalten, tragen sich die meisten in Aachen oder der Umgebung zu, z.B. ebd. IV, 2, ed. Waitz 256; II, 8, ed. Waitz 247; III, 19, ed. Waitz 255.

150 Einhard, Translatio III, 13, ed. Waitz 252: Quid autem illa capitula continerent, aut quid ab eo [Ludwig] factum quidve dimissum sit, alio potius in loco quam in isto commemorandum est. Illud tamen non solum non praetereundum, quin immo aperte ac dilucide censeo conscribendum, qualiter revelatum et iussum sit, ut libellus ille fieri atque regi dare debuerit.

151 Einhard, Translatio III, 14, ed. Waitz 253f. 
und äußeren Bedrohungen für das Reich, als deren Grund die Sündhaftigkeit des populus und seiner rectores festgemacht wird. Mit der Interpretation von äußeren Übeln als Gottesstrafen für innere Verfehlungen bewegte sich Einhards Dämon ebenso im Mainstream der zeitgenössischen Rufe nach correctio wie mit der näheren Definition dieser Verfehlungen, die fast alle zum Standardrepertoire der normativen Texte dieser Jahre gehören. ${ }^{152}$ Vor allem mit dem Unternehmen der Reformkonzilien des Jahres 829 teilt Einhards Text den Ansatz, zwischen den Sünden der rectores und denen des populus zu differenzieren, sowie die Betonung der Verantwortung ersterer für die Gestaltung und Aufrechterhaltung einer nach christlichen Prinzipien ausgerichteten Gesellschaftsordnung. ${ }^{153}$

Aufgrund ihrer politischen Brisanz sind diese beiden libelli in der modernen Forschung vieldiskutiert. ${ }^{154}$ Zuletzt hat sie vor allem Matthias Tischler als Zeichen für Einhards Unzufriedenheit mit der politischen Entwicklung und für seine „steigende innere Distanz“ zum Hof im Vergleich zur Abfassungszeit der Vita Karoli gewertet und sie in ein Umfeld der Kritik an Ludwig eingeordnet, in dem Jenseitsvisionen eines der Mittel zur Artikulation von Mahnungen und Reformaufrufen darstellten. ${ }^{155}$ Um die politische Funktion des Textes zu bestimmen, ist aber nicht nur seine Einordnung in einen Kontext ähnlicher Berichte und Visionen aus dem Jenseits wichtig, mit denen er einen kritischen Ton, aber auch die Kritierien zur Authentifizierung teilt. Wie Mayke de Jong betont hat, ist es für das Verständnis des Kommunikationsmodus, in dem sich derartige Texte bewegen, darüber hinaus bedeutsam, sie im Kontext einer politischen Kultur zu sehen, in der die Diagnose von Mißständen und Aufrufe zur Buße und Besserung - admonitio - für Intellektuelle und Berater des Kaisers eine Verpflichtung darstellten, umso mehr, wenn diese Aufrufe göttlich inspiriert waren. In diesem Kontext mußte nicht nur über die Regeln und akzeptablen Formen von Kritik, sondern auch über die Be-

${ }_{152}$ Die Liste der Katastrophen, die Wiggo gemeinsam mit elf Gefährten seit Jahren über das Frankenreich bringt, ähnelt der Aufzählung in der Langfassung der Epistola generalis der Akten von Paris 829, aber auch den unheilvollen Vorzeichen, die in den Annales regni Francorum in einer Weise zusammengestellt sind, die Paul Dutton treffend als „ordering of disorder“ bezeichnet hat: Dutton, Politics of dreaming 87. Vgl. die Einträge in den Annales regni Francorum vor allem zu 820 und 823, ed. Kurze 154, 163f., mit der Liste von Katastrophen bei Einhard (Translatio III, 14, ed. Waitz 253: frumentum et vinum et omnes alias fruges [...] enectando delevimus, pecora morbis interfecimus, luem ac pestilentiam in ipsos homines inmisimus; omnes adversitates et cuncta mala [...]). Für die Auflistung der Verfehlungen und Katastrophen in der Langfassung des kaiserlichen Einberufungsbriefes zu den Konzilien von 829 siehe Hludowici et Hlotharii epistola generalis (ed. Albert Werminghoff, MGH Concilia 2,2, Hannover/Leipzig 1906) 597-601, und vgl. Concilium Parisiense (829) 69 [2], ed. Werminghoff 669: patratores diversorum malorum, pro quorum etiam diversis sceleribus et flagitiis populus fame et pestilentia flagellatur. Viele der bei Einhard aufgezählten Sünden (ebrietates, adulteria, homicidia, ungerechte Maße und Gewichte, falsches Zeugnis, Sonntagseinhaltung etc.) haben außerdem Parallelen mit anderen Bestimmungen der Zusammenfassung der Beratungen durch die Konzilsväter (Concilium Parisiense [829] 68 [1] -94 [27], ed. Werminghoff 667-680).

153 Einhard, Translatio III, 14, ed. Waitz 253: „Propter malitiam“, inquit, „populi huius et multimodas iniquitates eorum qui super eum constituti sunt [...]. Im folgenden geht es einerseits um die Unterdrückung von Armen, um ungerechte Urteile, superbia und inanis gloria der Regierenden, aber auch um das Problem, daß Sünden der Untergebenen ungestraft bleiben oder gar nicht erst durch Verbote verhindert werden. Vgl. z.B. Hludowici et Hlotharii epistola generalis (Langfassung), ed. Werminghoff 601: In quibus conventibus tractare, querere et cum Deo adiutorio invenire debent de causis ad religionem Christianam et eorum curam pertinentibus, quid a principibus et reliquo populo vel ita, ut divina auctoritas docet, aut aliter teneatur vel quid inde ex parte vel ex toto dimissum sit, ut non teneatur; deinde quid in ipsorum, qui pastores populi constituti sunt, moribus, conversatione et actibus inveniri possit, quod divinae regulae atque auctoritati non concordet, simulque inveniant, quae occasiones in utroque ordine id effecerint, ut a recto tramite deviatum sit. Vgl. auch die Praefatio der Bischöfe, ed. Werminghoff 608.

${ }^{154}$ Für die Diskussion dieser beiden Stellen siehe vor allem Heinzelmann, Hagiographische Reformschrift 288ff.; Smith, Emending evil ways 189 und 204f.; de Jong, Penitential State 157-164; dies., Sacrum palatium 1260f.; mit anderem Akzent Dutton, Politics of Dreaming 92ff.; Matthias Tischler, Einharts Vita Karoli. Studien zur Entstehung, Überlieferung und Rezeption (MGH Schriften 48, 1-2, Hannover 1998) 167ff.

155 Tischler, Einharts Vita Karoli 166-210. Die Vita Karoli, in der Tischler einen Gegenentwurf zum aktuellen Karlsbild und eine Mahnung an Ludwig den Frommen sieht, datiert ihm zufolge in das Jahr 828. Im Vergleich dazu habe Einhard seine Kritik in der Translatio weitaus schärfer formuliert; siehe auch Fleckenstein, Einhard, seine Gründung und sein Vermächtnis 106ff. Siehe Dutton, Politics of Dreaming 51-112, für Visionen, die Kritik an Karl mit an Ludwig gerichteten Untertönen formulieren. Zur Kritik an Tischlers Argumentation de Jong, Penitential State 67-70; dies., Sacrum palatium 1260f. Für die Interpretation von Einhards Intervention als „Reichseinheitskult“ mit konstantinischen Implikationen siehe Seeliger, Römische Reliquien 67ff.; vgl. Heinzelmann, Reformschrift 290. Für Johannes Fried, Ludwig der Fromme, das Papsttum und die fränkische Kirche, in: Charlemagne's Heir. New Perspectives on the Reign of Louis the Pious, ed. Roger Collins/Peter Godmann (Oxford 1990) 231-273, hier 263, sind Einhards Translationen ebenso wie die Hilduins eines der Symbole für den von ihm angenommenen Umschwung in der Rompolitik seit der Mitte der 20er Jahre des 9. Jahrhunderts weg von fränkischer Autonomie hin zu mehr Romorientiertheit. 
gründung von Positionen, von denen aus diese Kritik auf legitime Weise geäußert werden konnte, verhandelt werden. ${ }^{156}$

Insofern kann Einhards Versuch, die Autorität der Märtyrer auf diese Weise zu nutzen, auch im Zusammenhang der Auseinandersetzungen um die Definitionsmacht über Mißstände und Ansatzpunkte zur Verbesserung, über sichtbare Zeichen des göttlichen Zornes und ihre Interpretation, verstanden werden. Wie eng das Geschehen an Reliquienschreinen mit der Diskussion solcher Fragen verbunden sein konnte, zeigt der oben erwähnte Brief, den Agobard von Lyon etwa zur selben Zeit an Bischof Bartholomäus von Narbonne schrieb, nachdem am Schrein des zweifelhaften Heiligen Firminus in Usèz viele Gläubige epileptische Anfälle erlitten und sich auf wundersame Weise merkwürdige Brandwunden zugezogen hatten. Agobard und seine Mitarbeiter entschieden die Frage nach der Echtheit der Firminus-Reliquien souverän innerhalb weniger Zeilen und schlossen Firminus aufgrund von biblisch begründeten Differenzierungslinien zwischen richtigen und falschen Wundern aus dem Kreis der akzeptierten Kulte aus. ${ }^{157}$ Wichtiger als die Entscheidung über die Authentizität der Reliquien scheint allerdings die ausführliche Diskussion über die Möglichkeiten und Bedingungen des Eingreifens übernatürlicher Mächte - seien es Engel oder Dämonen - in die sichtbare Welt, ebenso wie über das Erkennen, Differenzieren und Interpretieren solcher Phänomene. Vor allem geht es um die Frage, wie sich aus diesen Zeichen Hinweise auf die eigene Sündhaftigkeit und Anleitungen zur Reaktion gewinnen lassen. Unter den verschiedenen Kategorien von Wundern, die entlang der biblischen exempla entwickelt werden, ist die der percussiones, mit denen Gott durch Engel oder Teufel, Tiere, Unwetter oder Trockenheit ad eruditionem et conversationem seines populus eingreift, eine wichtige Gruppe. ${ }^{158}$ Die Beispiele für Strafwunder sind vorzugsweise dem Alten Testament entnommen; neben den Plagen Ägyptens werden auch Beispiele genannt, in denen Menschen in Leitungsfunktionen Fehler im Zusammenhang mit dem cultus divinus begehen oder wie der rex superbus Usija (2 Chr 26) unautorisiert priesterliche Funktionen usurpieren. ${ }^{159}$ Die Verfasser des Briefes legen dabei großen Wert auf die Frage, warum und unter welchen Voraussetzungen die Machenschaften des Teufels Auswirkungen auf die res humanae haben können. Wie in Einhards Text wird auch hier bestätigt, daß Dämonen im Dienste Gottes die Menschen verfolgen können - diese Verfolgung kann aber nur dann wirksam sein, wenn sie die potestas dazu von Gott erhalten haben. ${ }^{160} \mathrm{Im}$ Gegensatz zu solchen göttlich autorisierten Strafwundern, in denen die Menschen Sinn suchen und sich dementsprechend verhalten müssen, können übernatürliche Erscheinungen auch Täuschungen des Teufels sein, die zu unnötiger Furcht oder leerer Bewunderung führen. ${ }^{161}$ Daher wird die Unterscheidungskraft und die auf biblischem Wissen basierende Definitionsmacht der Experten umso bedeutsamer. ${ }^{162}$

Agobards Text zeigt, wie umsichtig und differenziert bei der Interpretation solcher Ereignisse vorgegangen werden mußte, und steckt so auch die Grenzen für Einhard als Kommunikator von Gabriels und Wiggos Beiträgen zur schwierigen Lage des Reiches ab. Mit seiner Diskussion über Formen der Kommunikation zwischen Gott und den Menschen, über Reliquienschreine als Ort dieser Kommunikation und über die autoritative Auslegung der dort geschehenen signa besprach Agobard ein Problem, das sich in ähnlicher Weise auch für Einhards himmlische und dämonische Boten stellte. Daher mußte nicht nur die Akzeptanz der Heiligen und ihrer Reliquien als verläßliche Vermittler zwischen Gott und den Menschen durchgesetzt werden.

\footnotetext{
${ }^{156}$ De Jong, Penitential State bes. Kap. 4, 112-147; dies., Sacrum palatium 1260f.

157 Agobard, De quorundam inlusione signorum 1 und 12, ed. van Acker 237, 243.

158 Agobard, De quorundam inlusione signorum 1, ed. van Acker 237. Die grundlegende Differenzierung innerhalb des Textes läuft zunächst entlang der Unterscheidung zwischen Zeichen und Strafwundern, die direkt und ausschließlich durch Gott, und solchen, die durch seine Engel gewirkt werden. Diese Formen göttlichen Eingreifens werden weiter unterschieden, je nachdem ob sie auf Verfehlungen der Menschen zurückzuführen sind (Exempel ebd. 4, ed. van Acker 239) oder keine sündhafte Handlung als Grund vorliegt (Exempel ebd. 5, ed. van Acker 239f.).

159 Agobard, De quorundam inlusione signorum 4, ed. van Acker 239. Die weiteren genannten Beispiele sind Usa (1 Chr 13, 10f.), der die Bundeslade berührte und deshalb starb; Nadab und Abihu (Lev 10, 2) und Mirjam, die aufgrund der detractio des Moses mit Lepra bestraft wurde (Num 12, 10). Vgl. auch die Erwähnung des rex impius Achas (2 Chr 28, 22ff.) ebd. 8, ed. van Acker 241. Für die Plagen Ägyptens ebd. 8 und 10, ed. van Acker 241f.

160 Agobard, De quorundam inlusione signorum 2, ed.van Acker 238: Sed quia hanc percussor potestatem habere numquam potest, nisi acceperit ab eo, in cuius potestate et ipse potestate est [...]; vgl. ebd. 10, ed. van Acker 242. Vgl. Einhard, Translatio III, 14: quanam de causa eis fuisset huiusmodi concessa potestas [...] „permissi, immo iussi sumus ea facere [...] “.

161 Agobard, De quorundam inlusione signorum 7, ed. van Acker 240.

162 Agobard, De quorundam inlusione signorum 11-12, ed. van Acker 242f.
} 
Weil Einhards admonitio an Ludwig und den Hof untrennbar mit der Autorität der römischen Reliquien verknüpft war, mußte Einhard außerdem die Authentizität der beiden libelli als übernatürliche Botschaften und seine Position als legitimer Vermittler dieser Botschaften durchsetzen.

Moderne Kommentare zur Translatio Marcellini et Petri betonen häufig den Ausnahmecharakter dieses Textes - vor allem die für vergleichbare frühmittelalterliche Texte in ungewöhnlich ausgeprägter Weise gestaltete Präsenz des erzählenden ego verleiht der Translatio gerade im Vergleich zu Einhards opus magnum, der Vita Karoli, einen zweitweise sehr intimen Charakter. ${ }^{163}$ Vor allem aber kann diese Präsenz als wesentlicher Teil der Strategien gesehen werden, mit denen Einhard auf die zahlreichen Schwierigkeiten mit seiner Position als Autor der Translatio reagierte. ${ }^{164}$ Gerade der Bericht über die Vision des Erzengels Gabriel ist für diese Schwierigkeiten ein besonders gutes Beispiel. Ähnlich wie sich die Erzählung über Wiggo und seine Diagnose der Mißstände im Frankenreich in einem Rahmen von geteilten Maßstäben und akzeptablen Formen der Kritik bewegen mußte und somit alles andere als beliebig war, mußte der Status dieses ersten libellus mit Gabriels Anweisungen zur correctio als eines auf göttlichen Befehl zustandegekommenen Textes gerechtfertigt werden. Wieder und wieder wird in Einhards Bericht darüber ein Punkt betont: Der libellus enthielt göttliche Gebote (vera et ab angelo Deo mandata), wurde auf Gottes Befehl niedergeschrieben und mußte Ludwig dem Frommen übergeben werden. Formen wie divina voluntas, auctoritas, iubere und praecipere erinnern den Leser den gesamten Bericht hindurch beständig an die göttliche Inspiration dieses Textes. Diese Häufung derartiger Ausdrücke erreichte Einhard dadurch, daß er eine Reihe von direkten Reden ineinander verschachtelt wiedergab, deren Effekt eine Vervielfältigung der Resümees der Ereignisse und damit auch der Anweisungen Gabriels war. ${ }^{165}$ Gleichzeitig bleibt die Erzählperspektive dadurch konsequent diejenige Einhards, und die Person des Autors ins Zentrum einer Erzählung gerückt, die auf beeindruckende Weise wieder und wieder den Befehl zum Schreiben und die Autorität des Gesprochenen formulierte.

Diese „Rhetorik des göttlichen Befehls“ paßt gut zu der Art und Weise, in der auch an zahlreichen anderen Stellen der Translatio versucht wird, die Wahrnehmung der signa und miracula als Botschaften, die nicht Einhards eigene, sondern übernatürliche sind, durchzusetzen. Während, wie im Fall Gabriels, das reformatorische Potential der Reliquien dabei meist eher allgemein bekräftigt als durch konkrete Beispiele erläutert wird, ${ }^{166}$ wird immer wieder betont, daß das Schreiben darüber eine Verpflichtung darstellt. Am Ende des Prologs zum dritten Buch, das die Serie der Wunder der Heiligen im Frankenreich eröffnet, diskutiert Einhard die Organisation der Wunderberichte in den folgenden Büchern, die sich nicht nach deren chronologischer Reihenfolge richtet, sondern nach den Orten, an denen sie sich zugetragen haben. Der Sinn dieser Anordnung, so die weitere Argumentation, besteht darin, auf diese Weise keines der Zeichen und Wunder, die Einhard bekannt waren, unerwähnt zu lassen: ut, hoc ordine in relatione servato, nihil remaneat ex omnibus signis atque miraculis, quae ad nostra parvitatis notitiam pervenire potuerunt. Sed nunc, praefatione completa, ipsa quae dicenda sunt miracula proferamus. ${ }^{167}$ An mehreren anderen Stellen der Translatio finden sich Ausdrükke, die das Erzählen in ähnlicher Weise als Gebot formulieren. Auch da, wo mit einem altbekannten Topos

${ }_{163}$ Vgl. zuletzt vor allem Smith, Einhard: the sinner and the saints. Der Eindruck der Intimität, der sich durch die Einordnung der Translation in die biographische Situation Einhards am Beginn des Textes und durch die Zentrierung der Perspektive auf Einhard ergibt, wird durch die parallele Lektüre der Briefe verstärkt, die im Zusammenhang mit den römischen Heiligen stehen. Das gilt vor allem für den Brief, den Einhard nach dem Tod seiner Frau Imma an Lupus von Ferrières schrieb: Lupi abbatis Ferrariensis epistolae nr. 3 (ed. Ernst Dümmler, MGH EE 6, Karolini Aevi 4, Berlin 1902-25, ND München 1978) 1-126, hier 9f. Siehe auch seine Überlegungen im ebenfalls an Lupus adressierten De adoranda cruce.

${ }^{164}$ Die folgenden Überlegungen gehen von Konzepten zum Verhältnis zwischen Autor, Text und Autorität aus, die im Zusammenhang mit Theorien Pierre Bourdieus entwickelt wurden, insbesondere von dessen Konzept der posture als spezifische Weise, die Figur des Autors innerhalb und außerhalb des Textes zu positionieren. Siehe dazu Pierre Bourdieu, Die Regeln der Kunst. Genese und Struktur des literarischen Feldes (Frankfurt am Main 2001); Jérôme Meizoz, Die posture und das literarische Feld. Rousseau, Céline, Ajar, Houllebecq, in: Text und Feld. Bourdieu in der literaturwissenschaftlichen Praxis, ed. Markus Joch/Christian Wolf (Studien und Texte zur Sozialgeschichte der Literatur 108, Tübingen 2005) 177-188; Georges Moliné/Alain Viala, Approches de la réception. Sémiostylistique et sociopoètique de Le Clézio (Perspectives Littéraires, Paris 1993) bes. 215ff.

165 Einhard, Translatio III, 13, ed. Waitz 252f.

166 Vgl. die offen gelassenen Deutungen bei dem Wunder am Weg nach Aachen und der Verwandlung von Bier in Wein (Einhard, Translatio III, 19 und III, 20, ed. Waitz 255f.). Ausnahmen sind einerseits die Kritikpunkte des Dämons Wiggo, andererseits einige wenige Wunder, die mit einer moralischen Botschaft verbunden werden. So bewirkt die Verehrung für die Märtyrer z.B. die Versöhnung zwischen Feinden und das Erlassen von Geldschulden: II, 8, ed. Waitz 247.

167 Einhard, Translatio, Praefatio zu Buch III, ed. Waitz 248. 
die menschliche Sprache versagt, darf nicht geschwiegen werden: quantum gaudii quantumque laetitiae de illarum adventu reliquiarum populis in eadem via consistentibus accesserit, neque mihi silendum est, nec tamen ita ut fuit plene dici atque enuntiari potest. Dicendum tamen est, ne res ad Dei laudem maxime pertinens quasi per desidiam silentio supressa videatur. ${ }^{168}$ Diese Sichtweise der miracula, die Gott zum Wohl der Menschen auf der Erde wirkt, als ein Gegenstand, der möglichst vollständige Aufzeichnung nötig macht, erinnert an die diesbezügliche Forderung des Augustinus. ${ }^{169}$ Der Grund für diese Verpflichtung liegt im spirituellen Nutzen für Gläubige, die diese Geschichten hören und durch die sinnfälligen Zeichen zum Gotteslob angespornt und im Glauben an die körperliche Auferstehung und die Möglichkeit der Rettung am jüngsten Tag bestärkt werden. ${ }^{170}$ Auch für Einhard entsteht also eine Verpflichtung zu schreiben. Diese Definition seines Textes als Bericht über göttliches Wirken im Frankenreich und somit als etwas, das gesagt werden mußte, eröffnet ihm die Möglichkeit, die Position als Autor der Translatio einzunehmen. Bezeichnenderweise rechtfertigt Einhard die Aufnahme der Geschichte von Gabriels Erscheinung in den Text der Translatio mit der wundersamen Selbstentzündung von Kerzen in der Hand des Boten Alberich, die auf die Vision folgte. Das von Gabriel angekündigte Lichtwunder, das die Authentizität der Vision bestätigte, gehört zu den facta mirabilia, die durch die Märtyrer geschehen sind, und muß daher - anders als der Inhalt seiner Instruktion - durch Schriftlichkeit der Erinnerung zugänglich gemacht werden. ${ }^{171}$

Die Erzählung über die Vision wird außerdem durch die Vernetzung mit anderen Episoden in den vorangehenden und nachfolgenden Kapiteln vorsichtig vorbereitet und in ihrer Glaubwürdigkeit abgestützt. ${ }^{172}$ Die Notwendigkeit, die Definition der Translatio als Text über die heilbringenden Taten Gottes in dieser Welt aufzubauen und abzusichern, zeichnet sich aber auch an vielen anderen Stellen des Textes ab. ${ }^{173}$ Wie sehr

${ }_{168}$ Einhard, Translatio II, 8, ed. Waitz 247. Vgl. z.B. Einhard, Translatio IV, 15, ed. Waitz 262: Restant adhuc duo valde praeclara miracula, quae non solum silentio tegenda non censeo, quin potius illorum conscriptione convenientissimum quarto volumini[...] finem me facturum esse confido. Ac proinde, omissa praefatione, ad ipsa quae dicenda sunt miracula veniamus; III, 20, ed. Waitz 258: Verum quia cuncta quae de martyrum virtutibus scribenda suscepimus nequaquam possunt praesenti sermone compleri, hic liber iste finem accipiat [...].

169 Vgl. Heinzelmann, Hagiographische Reformschrift 291f. und die Diskussion über den „Sitz im Leben“ der Miracula im Zusammenhang mit Augustinus; siehe ders., Funktion des Wunders 41ff.; ders., Source de base; Uytfanghe, Controverse 211f. Augustinus, De civitate Dei XXII, 8, ed. Dombart/Kalb 823f.: Vrget huius operis implenda promissio, ut non hic possim omnia commemorare quae scio; et procul dubio plerique nostrorum, cum haec legent, dolebunt me praetermisisse tam multa, quae utique mecum sciunt. Quos iam nunc, ut ignoscant, rogo, et cogitent quam prolixi laboris sit facere, quod me hic non facere suscepti operis necessitas cogit. Si enim miracula sanitatum, ut alia taceam, ea tantummodo uelim scribere, quae per hunc martyrem, id est gloriosissimum Stephanum, facta sunt in colonia Calamensi et in nostra, plurimi conficiendi sunt libri, nec tamen omnia colligi poterunt, sed tantum de quibus libelli dati sunt, qui recitarentur in populis. Id namque fieri uoluimus, cum uideremus antiquis similia diuinarum signa uirtutum etiam nostris temporibus frequentari et ea non debere multorum notitiae deperire. Zum literarischen und politischen Kontext Conrad Leyser, Homo pauper, de pauperibus natum: Augustine, church property, and the cult of Stephen, in: Augustinian Studies 36 (2005) 229-237.

${ }^{170}$ Heinzelmann, Funktion des Wunders 44f. Vgl. z.B. Augustinus, De civitate Dei XXII, 8, ed. Dombart/Kalb 815: Nam facta esse multa miracula, quae adtestarentur illi uni grandi salubrique miraculo, quo Christus in caelum cum carne in qua resurrexit ascendit, negare non possumus; XXII, 9, ed. Dombart/Kalb 827f.

171 Einhard, Translatio III, 13, ed. Waitz 253: Idcirco visum est mihi, inter caetera miracula libelli huius facere mentionem, quia per occasionem, qua ille scribere iubebatur, contigit illa mirabilis et inusitata caereorum accensio, quam per merita beatorum martyrum fieri debere, ipse qui eos inluminavit angelus praenuntiavit.

172 Das Medium Alberich, ein blinder alter Mann, wird zunächst als Subjekt einer Wunderheilung als privilegierte Kontaktperson der Märtyrer in die Erzählung eingeführt: Einhard, Translatio III, 6, ed. Waitz 250. Das Resümee der Geschichte bildet einen Vorgriff auf die Visionen, die Alberich in den kommenden Jahren fast jede Nacht haben sollte, und die sich aus der zeitlichen Distanz der Abfassung bereits als wahrhaftig herausgestellt hatten: Einhard, Translatio III, 6, ed. Waitz 250: nulla nox in hoc biennio fuit, in qua per somnium eosdem qui eum salvum fecerunt martyres non vidisset, multa quoque ab eis audisset, quae aliis dicere iubebatur. Ex quibus pleraque nunc impleri cernimus, quae ille tunc futura esse praedixit. Vgl. dazu Einhard, Epistola 14 (April 830), ed. Hampe 117: Omnia, que nunc in hoc regno geruntur, revelantibus Christi martyribus ante biennium futura predicta sunt. Auch der Fall des taubstummen Prosper, der ebenfalls eine spezielle Position als Empfänger von Botschaften der Märtyrer hat und bei dessen Heilung Einhard Augenzeuge ist, bestätigt die Möglichkeit dieser Form der Kommunikation zwischen Himmel und Erde - im Gegensatz zu Alberich erweist sich Prosper aber als vergeßlicher und nachlässiger Bote, wogegen sich die Zuverlässigkeit des klugen Alten abhebt (Einhard, Translatio III, 17, ed. Waitz 254). Ein konkreter Test für diese Zuverlässigkeit steht unmittelbar vor den Berichten über Gabriels libellus. Hier befiehlt Alberich Einhards Boten in Seligenstadt, seine Abreise zu verzögern, damit er einem angekündigten Wunder beiwohnen kann, dessen Verlauf Alberich auf Befehl der Märtyrer organisiert: Einhard, Translatio III, 12, ed. Waitz 252.

173 Zur Verhandlung über die Authentizität der Wunder in der Translatio siehe schon Bondois, La translation 56-64. 
Einhard dabei auch die verschiedenen Ebenen der Diskussion über den Status von Reliquien und den Nutzen ihres Kultes mitdachte, zeigt die große Sorgfalt, mit der er sich bemühte, in seinem Text ein bestimmtes Verständnis der spirituellen und gesellschaftlichen Bedeutung der römischen Reliquien als Vermittler zwischen Gott und den Menschen zu verdeutlichen. Die konsequente Zuschreibung der Wunder an das Wirken Gottes ist nicht nur theologisch korrekt, sondern kann auch die Funktion der Märtyrer als Stellvertreter Christi zum Ausdruck bringen, die Einhard immer wieder betont. ${ }^{174}$ Durch die Verdienste, die sie durch die Nachahmung der Passion Christi erlangt haben, setzen sich Gottes Heilstaten in der Gegenwart fort. Marcellinus und Petrus, die Gott ad salutem humani generis ins Frankenreich geschickt hat, verbinden durch die signa et prodigia die eigene Zeit mit dem initium ecclesiae nascentis. ${ }^{175}$ Die Präsenz der Märtyrer an ihrem Kultort wird in Einhards Text auf sehr distinkte Weise dargestellt. Einhard suggeriert eine fast greifbare physische Anwesenheit der Heiligen nicht nur durch Hinweise auf den obligaten Duft, ${ }^{176}$ sondern auch durch seine überaus plastischen Beschreibungen der Heilungswunder und durch Berichte über Klerikergestalten, die die Kranken entweder zur Heilung auffordern und geleiten oder während des Heilungsprozesses für sie sichtbar sind. ${ }^{177}$ Um diese Botschaft durchzusetzen, arbeitete Einhard systematisch mit der Differenz zwischen der Wahrnehmung der anwesenden Zeugen, unter denen er sich in den meisten Fällen auch selbst befand, und den Erfahrungen der Geheilten. Diese Differenz wird jeweils durch die Befragung der Betroffenen durch Einhard überbrückt. ${ }^{178}$ Kommentare des Erzählers stellen die Deutung des Geschehens als heilend sicher und affirmieren den Wahrheitsgehalt der Visionen. ${ }^{179}$ Die Episoden, in denen so über die Wahrnehmungsweise und Deutung der Aktivität der Heiligen verhandelt wird, folgen dicht aufeinander und stützen einander dadurch wechselseitig in ihrer Glaubwürdigkeit ab. Knapp bevor die Serie der entsprechenden Wunder beginnt, wird außerdem aprupt mit der chronologischen Anordnung der Wunder gebrochen und die Aufmerksamkeit der Leser explizit auf den Heilungsvorgang selbst gelenkt: Reliquias virtutes atque miracula, quae per eos Dominus ad salutem hominum operatus est, quoniam quo ordine dicantur nihil referre video, ita ut memoriae occurrerint censui describendas, quia in earum relatione magis quid et quare, quam quando aliquid gessum sit, considerandum est. ${ }^{180}$ Die repressive Organisation der Botschaft durch überlappende Wahrheitsstrategien zeigt, wie wichtig die Durchsetzung dieser Auffassung offenbar war - möglicherweise auch vor dem Hinter-

${ }^{174}$ Vgl. z.B. Einhard, Translatio, Praefatio zu Buch III, ed. Waitz 248; ebd. I, 5 und IV, 14, ed. Waitz 245, 261. Dazu gehört auch die Konformität der Wundererzählungen mit den Maßstäben für richtige Wunder, die einerseits dem biblischen Kanon folgen (vgl. Einhard, Translatio II, 5, ed. Waitz 247), andererseits kontinuierliche physische Heilung bewirken müssen, was sowohl Agobard als auch Amolo in ihren Briefen über die zweifelhaften Reliquien betonen (Agobard, De quorundam inlusione signorum 1, ed. van Acker 237; Amolo, Epistola ad Theutbaldum 5, ed. Dümmler 365). In der Translatio erfordert das Ausbleiben dieses heilenden Effektes Erklärung, vgl. Einhard, Translatio IV, 2, ed. Waitz 256. Zur karolingischen Diskussion um den Status von Wundern vgl. oben Anm. 116.

175 Einhard, Translatio IV, 10, ed. Waitz 259: [...] cum ad corroborandam christiani populi fidem, sicut initio nascentis ecclesiae, signa et prodigia in ipso regis palatio per merita sanctorum suorum Dominus dignaretur ostendere. Vgl. z.B. auch IV, 11, ed. Waitz 260, wo Christus miracula atque virtutes durch seine Märtyrer ad salutem humani generis vollbringt.

176 Einhard, Translatio III, 9, ed. Waitz 251; vgl. auch II, 4 und IV, 2, ed. Waitz 247, 256f.

177 Einhard, Translatio III, 5-7, ed. Waitz 249f.; III, 9 und IV, 2, ed. Waitz 251, 256f. Für Visionen der Klerikergestalten siehe z.B Einhard, Translatio III, 7, ed. Waitz 250, wo ein clericus veneranda canitie, stola alba indutus einen alten Mann in die Kirche zur Heilung geleitet. Vgl. auch ebd. III, 8; IV, 4, ed. Waitz 250f., 257.

${ }_{178}$ Ein besonders deutliches Beispiel ist Einhard, Translatio III, 9, ed. Waitz 251: Einhard beschreibt zunächst, wie ein gelähmter und stummer alter Mann sich während der Messe unter Stöhnen aufrichtet und danach auf seinen eigenen Beinen steht, und fährt fort: Et nos quidem haec vidimus; ipse autem fatebatur, sibi visum fuisse, quod se iacentem quasi duo quidam adprehendissent, unus per umeros et brachia, alter per crura et pedes, acsi trahendo nervos suos, qui contracti erant, extendissent. Vgl. auch ebd. III, 7, ed. Waitz 250: Is, cum ab eo quaereremus, si aliud aliquid praeter quod nos omnes videre potuimus sibi visum fuisset [... ].

179 So kommentiert Einhard die Erzählung über die Heilung des Alberich, der von einem Unbekannten einen Schlag in den Nacken erhalten hatte, wie folgt: Caeterum hunc ictum tam salutarem ei fuisse constat, ut ex illo temporis momento nullum illius foedae agitationis vestigium in eius corpore ulterius appareret (Einhard, Translatio III, 6, ed. Waitz 250). Bei den Wundern in Aachen affirmieren die umstehenden Zeugen die Präsenz der Heiligen. Sie verstehen, daß divinam adesse virtutem: Einhard, Translatio IV, 2, ed. Waitz 256; vgl. auch ebd. IV, 3, ed. Waitz 257. Für die taubstumme puella, deren Vision und den bestätigenden Kommentar des Erzählers (et ita vere erat) siehe ebd. III, 5, ed. Waitz 249f.

180 Einhard, Translatio III, 4, ed. Waitz 249. Wie sehr es dabei um das Lenken der Aufmerksamkeit des Lesers auf den Heilungsvorgang geht, zeigt sich daran, daß die chronologische Reihenfolge der Wunder nirgends vorher angekündigt worden ist; außerdem werden gerade die Wunder in Buch III bis auf wenige Ausnahmen sehr wohl in ihrer zeitlichen Abfolge berichtet und die chronologische Einordnung an vielen Stellen als Überleitung benutzt. Z.B. ebd. III, 5; III, 7; III, 8; III, 15, ed. Waitz 249f., 250, $250 f ., 254$. 
grund zeitgenössischer Diskussionen und Zweifel über den Heiligenschrein als privilegierten Ort der Präsenz der Heiligen. ${ }^{181}$

Wie der oben diskutierte Umgang mit Gabriels Instruktion oder den libelli miraculorum aus anderen religiösen Gemeinschaften zeigt auch diese Verhandlung über die Präsenz der Märtyrer, in der Einhard als Erzähler zwischen den für alle sichtbaren Ereignissen und der nur für die Betroffenen wahrnehmbaren Realität des Heilungsvorganges vermittelt, wie geschickt er seine Funktion als Erzähler zur Einschränkung des Deutungsspielraumes und zur Durchsetzung von Wahrnehmungsmustern einsetzte. Die sorgfältige Inszenierung von Einhards Doppelrolle als Erzähler, der für die Organisation des Materials verantwortlich war, und als Protagonist der Geschichte steht im Zentrum der Strategien, mit denen das Verständnis und der Status seines Textes aufgebaut und abgesichert werden sollte.

In seiner Rolle als Handelnder und Beobachter reflektiert Einhard immer wieder über die symbolische Bedeutung mancher Wunder und bezeugt ihre Wahrhaftigkeit. So folgt auf die Beschreibung eines Wunders, bei dem durch die Verdienste der Märtyrer im Keller der königlichen villa Sinciacus Bier in Wein verwandelt wird und sich ausgelöschte Fackeln von neuem entzünden, eine lange Passage, in der Einhard in seiner Schlafkammer über die Zeichenhaftigkeit des Ereignisses nachdenkt. Die endgültige Deutung des Wunders bleibt zwar in diesem Fall offen - trotzdem werden Ausrichtung und Bedeutung des Wirkens der Märtyrer für den Hof in Aachen relativ unmißverständlich festgelegt, indem Einhard darauf hinweist, daß die Verwandlung von Bier in Wein als eine Transformation zum Besseren zu verstehen ist, die sich ausgerechnet in einer domus regia zuträgt. ${ }^{182}$ Ähnlich wie im Fall von Gabriels libellus kann die Deutungsmacht über die Geschehnisse deshalb bei Einhard belassen werden, weil sie im Rahmen eines Berichtes darüber erzählt werden, wie Einhard selbst von den Ereignissen erfuhr, und somit der Fokus der Erzählung auf seine Person gerichtet bleibt.

Die größte Bedeutung bei der Durchsetzung der Wahrheit des Berichteten kommt allerdings Einhard in seiner Rolle als Augenzeuge zu. In der Praefatio zu Buch III diskutierte Einhard die Schwierigkeiten mit der Erzählung von Wundern, bei denen er nicht selbst Augenzeuge war:

Wenn ich ansetze, die Zeichen und Wunder aufzuschreiben, die die heiligen Märtyrer Christi, Marcellinus und Petrus, an verschiedenen Orten gewirkt haben, nachdem ihre heiligen Körper von Rom nach Francien gebracht worden sind, vielmehr, die Wunder, die durch ihre seligen Verdienste und frommen Fürbitten der König der Märtyrer selbst, unser Gott und Herr Jesus Christus zum Heil der Menschen gnädig sich entschloß zu vollbringen, halte ich es für notwendig in einem kurzen Vorwort zu erwähnen, daß von den Dingen, die ich mir vorgenommen habe niederzuschreiben, der größte Teil durch die Erzählung anderer zu meiner Kenntnis gelangt ist. Daß ich ihnen dennoch Vertrauen schenken kann, davon bin ich durch jene Dinge, die ich selbst gesehen und leibhaftig erfahren habe, so fest überzeugt, daß ich ohne jeden Anflug von Zweifel für wahr halte, was von denen gesagt wurde, die bezeugten, daß sie es selbst gesehen haben, auch wenn ich die Personen, von denen ich solches erfahren habe, kaum oder gar nicht kenne. ${ }^{183}$


Augustinus' De cura pro mortuis gerenda, der aber gerade diese Frage nicht beantwortet: Jonas, De cultu imaginum, PL 106, 329B. Dungal, der die entsprechende Augustinus-Stelle ausführlich zitiert, mußte daher auf ein von ihm dementsprechend interpretiertes Hieronymus-Zitat ausweichen. Dungal, Responsa 187f., ed. Zanna 142-145. Vgl. Aurelius Augustinus, De cura pro mortuis gerenda 16 [19f.] (ed. Joseph Zycha, CSEL 41, Wien/Prag/Leipzig 1900) 619-660, hier 653f.: Quamquam ista quaestio uires intelligentiae meae uincit, quemadmodum opitulentur martyres his, quos per eos certum est adiuuari: utrum ipsi per se ipsos adsint uno tempore tam diuersis locis et tanta inter se longinquitate discretis, siue ubi sunt eorum memoriae siue praeter suas memorias, ubicumque adesse sentiuntur, an ipsis in loco suis meritis congruo ab omni mortalium conuersatione remotis et tamen generaliter orantibus pro indigetia supplicantum [...] et ideo, quid horum duorum sit, an uero fortasse utrumque sit, ut aliquando ista fiant per ipsam praesentiam martyrum, aliquando per angelos suscipientes personam martyrum definire non audeo. mallem $a b$ scientibus ista perquirere. In dem oben erwähnten Brief an Theutbald von Langres über die zweifelhaften römischen Reliquien in Dijon akzeptierte Amolo den Reliquienschrein nicht als Ort der besonderen Präsenz und Wirkmächtigkeit der Heiligen. Er verwies die Gläubigen in die Grenzen ihrer eigenen Gemeinden, wo sie alle Heiligen anbeten könnten, die so wie Gott überall dort gegenwärtig sind, wo sie auf richtige Weise angerufen werden: Amolo, Epistola ad Theutbaldum 7, ed. Dümmler $367 f$.

${ }^{182}$ Einhard, Translatio III, 11, ed. Waitz 252: Sed licet ad huius quaestionis certam indaginem longa ac sollicita cogitatione pervenire nequirem, certum habui et certum semper habebo, illam divinam atque supernam virtutem, per quam haec et alia huiusmodi miracula fieri creduntur, nihil umquam sine causa vel facere vel fieri sinere in creaturis, quas ad suam providentiam et gubernationem pertinere non dubito.

${ }^{183}$ Einhard, Translatio, Praefatio zu Buch III, ed. Waitz 248: Scripturus virtutes atque miracula, quae beatissimi martyres Christi Marcellinus et Petrus, postquam eorum sacratissima corpora de Roma in Franciam delata sunt, per diversa loca fecerunt, immo 
Tatsächlich ist die Differenzierung der Wunder je nach Anwesenheit oder Abwesenheit Einhards als Zeuge eines der wichtigsten Organisationsprinzipien in Buch III und IV. ${ }^{184}$ Den gesamten Text hindurch wird die Perspektive eines autodiegetischen Beobachters konsequent eingehalten: Wo Einhard nicht seine eigene Person zur Versicherung einsetzen kann, legt er seine Informationsquellen offen und berichtet in indirekter Rede. ${ }^{185}$ Das Beispiel Alberichs, des blinden alten Mannes, dem die Vision Gabriels zuteil wurde, kann das enorme Gewicht zeigen, das auf Einhards persönliche Integrität zur Bezeugung der Wahrheit gelegt wurde. Alberich wird als Objekt einer Wunderheilung als privilegierte Kontaktperson der Märtyrer in die Erzählung eingeführt. Obwohl er zum Zeitpunkt des Wunders nicht anwesend war, durchbricht Einhard an dieser Stelle explizit seine in solchen Fällen übliche Darstellungsweise. Sein Vertrauen in die Wahrheit der Berichte über das Wunder war so groß, daß er sich dafür entschied, es so zu erzählen, als hätte er es mit eigenen Augen gesehen: Miraculum autem quod nunc narraturus sum ego ipse non vidi, sed verbis eorum quorum hoc relatione mihi compertum est non minus quam propriis oculis credere possum; ideoque non ut auditum, sed potius ut a me ipso visum, incunctanter ac sine ulla dubitatione proferre decrevi. ${ }^{186}$ In zwei Episoden, die unmittelbar auf die Heilung Alberichs folgen (III, 7 und III, 9) berichtet Einhard von der Heilung weiterer Personen, die analog zu der Alberichs beschrieben wird und daher die Glaubwürdigkeit des ersten Wunders abstützt - im Unterschied zu Alberichs Geschichte ist Einhard in diesen Fällen persönlich anwesend und damit Zeuge sehr ähnlicher Vorgänge, was er auch besonders hervorhebt.

Als Erzähler ebenso wie als Akteur der Geschichte übernimmt Einhard somit die Verantwortung für den Status seines Textes als wahrhaftigen Bericht über göttliches Wirken. Diese Strategie zur Etablierung der Autorität des Textes hängt in besonders starkem Maß von der „Kooperationsbereitschaft“ seiner Leser ab ${ }^{187}$ - darin liegt auch ein Grund für die großen Risiken und Schwierigkeiten, die für Einhard mit seiner Position als Autor der Translatio verbunden waren.

Dies wird besonders in der Praefatio mit ihrer eigenartig defensiven Incipitformel und der negativen Definition der Adressaten des Textes deutlich. ${ }^{188} \mathrm{Im}$ Anschluß daran werden Autor und Text in eine Serie von Hagiograph(i)en eingereiht, deren Motivationen und Gegenstand vehement als lobenswert und heilbringend definiert werden: Qui vitas et facta iustorum ac secundum divina mandata conversantium hominum litteris ac memoriae mandaverunt, non aliud mihi efficere voluisse videntur, nisi ut ad emendandos pravos mores et conlaudandam Dei omnipotentiam per eiusmodi exempla quorumcumque animos incitarent. Weil es tam in propatulo est und lucidissime clareat, daß diese Hagiographen, durch caritas motiviert, praeter ea, quae dixi nihil aliud [...] efficere voluisse, kann Einhard keinen Grund sehen, warum dieses laudabile propositum nicht nachgeahmt werden sollte (cur a multis imitari non debeat, omnino non video). In der Folge wird Inhalt und Nutzen des eigenen Textes analog dazu festgelegt, und Einhard nimmt dieselben Intentionen und Motive des Schreibens für sich in Anspruch: Ac proinde, quia mihi conscius sum, quod libri, quos de translatione corporum beatorum Christi martyrum Marcellini et Petri signisque ac virtutibus, quae per eos Dominus ad salutem credentium fieri voluit, qua potui facultate conscripsi, eadem sunt voluntate atque intentio compositi, eosdem edere ac Dei amatoribus ad legendum offere decrevi. Auffallend ist dabei, daß ähnliche Formulierungen, die sich an Sulpicius Severus’ Vita Martini anlehnen, in der Vita Karoli dazu dienen, die Authentizi-

quae per illorum beata merita et pias orationes ipse rex martyrum Deus et dominus noster Ihesus Christus ad salutem hominum operari dignatus est, necessarium iudicavi brevi praefatione perstringere, quod ex his quae scribere disposui maior pars ad notitiam meam aliorum relatione perlata est. Quibus tamen ut fidem haberem, ex his quae ipse vidi et coram positus agnovi tam firmiter mihi persuasum est, ut sine ullo dubitationis scrupulo vera esse crederem quae ab his dicebantur qui se illa vidisse testati sunt, tametsi personarum, a quibus haec audieram, aut parvam aut nullam eatenus notitiam haberem. Vgl. die Übersetzung bei Dutton, Courtier 93.

${ }^{184}$ Vgl. zur Anordnung der Wunder Heinzelmann, Hagiographische Reformschrift 286.

185 Diese Offenlegung der Informationswege wird gleichzeitig dazu genutzt, andere Anliegen durchzusetzen, so wie im Fall einer Heilung, von der Einhard erfährt, als der Bibliothekar Gerward Ludwig dem Frommen darüber berichtet, wodurch die Anerkennung Ludwigs und die Reaktionen auf die wundertätigen Märtyrer in der aula regis in Aachen hervorgehoben werden: Einhard, Translatio IV, 7, ed. Waitz 258.

186 Einhard, Translatio III, 6, ed. Waitz 250 (Hervorhebung G.H.).

187 Umberto Eco, Lector in fabula. Die Mitarbeit der Interpretation in erzählenden Texten (München 1990).

${ }^{188}$ Einhard, Translatio, Praefatio, ed. Waitz 239: Veris veri Dei cultoribus et Ihesu Christi domini nostri sanctorumque eius non fictis amatoribus Einhardus peccator. Vgl. die Kommentare zur Praefatio, die auch als subtiler Angriff auf Hilduin gelesen werden kann, bei Heinzelmann, Hagiographische Reformschrift $293 \mathrm{ff}$. 
tät und Wahrheit des Berichteten zu unterstreichen. ${ }^{189}$ Die Thematik und zum Teil auch die Wortwahl der Praefatio haben Parallelen zum „Epilog“ des Translationsberichtes, in dem Einhard sich gegen „nicht kooperationsbereite Leser“ verteidigt. ${ }^{190}$ Hier begegnet zwar ein bereits weitaus selbstbewußterer Autor, der nicht mehr am spirituellen Nutzen seines Textes zweifelt. ${ }^{191}$ Wie in der Praefatio wird aber auch im Epilog eine Gruppe von Menschen aus der Leserschaft ausgeschlossen, die - in Abgrenzung zu den amatores Christi und den Verehrern der Märtyrer - als ungläubig und die Ehre der Heiligen herabsetzend bezeichnet wird. In einer parallelen Bewegung weist Einhard Angriffe auf den Gegenstand ${ }^{192}$ des Textes und auf dessen Gestaltung und Autor als Blasphemie und Mißgunst (invidentia) zurück, und interpretiert sie als Zeichen für mangelnde Gottes-, aber auch Nächstenliebe: incredulis autem ac sanctorum gloriae derogantibus, quia fastidiosa esse non dubito, ne omnino legere velint, censeo suadendum, ne forte vilitate nostri sermonis offensi, blasfemiam et invidentiam devitare non valeant, ac sic Deum et proximum, quos amare iubentur, se odisse declarent. Dadurch wird die Person des Autors eng an den als wahr definierten (aut a nobis aut fidelium veraci relatione comperta) Inhalt des Textes gebunden.

Diese enge Anbindung des Autors an den Text ist sehr wichtig für das Verständnis von Einhards Position als Autor. ${ }^{193}$ Für die Übernahme der Autorfunktion baute Einhard auf die Wechselwirkung zwischen seinem sozialen Status und Prestige als Autor der Translatio und dem Text als Bericht über heilbringende Ereignisse. Die Definition des Geschriebenen als inspirierter Text bedarf der ständigen Argumentation und Absicherung, für die Einhard als Akteur und als Autor verantwortlich ist. Diese Art der Durchsetzung der Wahrheit eines Textes, die damit jeglicher Diskussion entzogen werden sollte, war mit Risiken verbunden, korrespondierte aber auch mit Einhards sozialer und politischer Position. ${ }^{194}$ Das komplexe Spiel mit dem Gewicht seiner Person und seiner Funktion als Autor, das Einhard inszeniert, zeigt, wie essentiell die Konstruktion des Verhältnisses zwischen dem sprechenden Ich und der Erzählung für die Etablierung der Autorität des Textes ist. Insofern kann Einhards Translatio auch als Verhandlung über die Legitimität seines eigenen Diskurses über die und mithilfe der römischen Reliquien verstanden werden.

\section{ZUSAMMENFASSUNG: RELIQUIEN, TEXTE, AUTORITÄT}

Einhards Strategien zum Aufbau einer Position, von der aus er schreiben und über die Autorität des Geschriebenen verhandeln konnte, unterscheiden sich stark von denen, die Jonas in der Vita et Translatio entwickelte. Doch auch wenn die Vita et Translatio von sehr unterschiedlichen Voraussetzungen ausgehend geschrieben wurde, unterliegt die Konstruktion von Jonas’ Position als Autor einer ähnlichen Spannung wie Einhards Bewegung der (Selbst-)versicherung, mit der zwischen Praefatio und Epilog die Autorität des Erzählers an den Status des Berichteten geknüpft wird. Im Widmungsbrief definierte Jonas seine Funktion als Autor über das Verhältnis zwischen neuem und altem Text und beanspruchte - ebenso wie im Vitentext selbst - die

189 Zu den Parallelen mit Sulpicius Severus siehe David Ganz, The Preface to Einhard’s „Vita Karoli“, in: Einhard. Studien zu Leben und Werk, ed. Hermann Schefers (Darmstadt 1997) 299-310, hier 307. Vgl. Vita Martini 27 (ed. Jacques Fontaine, Vie de Saint Martin 1, SC 133, Paris 1967) 316: Ego mihi conscius sum me, rerum fide et amore Christi impulsum ut scriberem, manifesta exposuisse, uera dixisse [...]; Einhard, Vita Karoli magni, Praefatio (ed. Oswald Holder-Egger, MGH SS rer. Germ. in usum schol. sep. ed. [25], Hannover 1991) 1: quando mihi conscius eram nullum ea veracius quam me scribere posse [...].

190 Einhard, Translatio IV, 18, ed. Waitz 264: Haec sunt, quae de innumeris sanctorum virtutibus, aut a nobis visa aut fidelium veraci relatione comperta, litteris ac memoriae mandare decrevimus; quae Christi amatoribus ac martyrum eius veneratoribus ad legendum grata fore non ambigo; quoniam nihil eis videtur inpossibile, quod ut fiat, Deo omnipotenti placuerit; incredulis autem ac sanctorum gloriae derogantibus, quia fastidiosa esse non dubito, ne omnino legere velint, censeo suadendum, ne forte vilitate nostri sermonis offenso, blasfemiam et invidentiam devitare non valeant, ac sic Deum et proximum, quos amare iubentur, se odisse declarent.

${ }^{191}$ Einhard entscheidet recht selbstbewußt, die Wunder der Erinnerung anzuvertrauen (decrevi); und zweifelt nicht (non ambigo) am Nutzen. Vgl. im Gegensatz dazu Einhard, Translatio, Praefatio, ed. Waitz 239: Arbitror enim, quod hoc opus non solum inane ac supervacuum cuilibet fidelium videri non debeat, sed etiam fructuose atque utiliter me laborasse praesumo [...].

192 Zur Verwendung des Begriffes fastidium nicht nur in Verbindung mit prolixitas, sondern auch für die Ablehnung eines Gegenstandes durch die Leser, in der Vita Karoli und der zeitgenössischen Literatur siehe Ganz, Preface 303f.

${ }^{193}$ Vgl. Heinzelmann, Reformschrift 286: „in dem durchaus kurzen Vorwort [der Praef. zu Buch III] zeigen sechzehn persönliche Formen im Text ... wie essentiell ihm diese Beziehung der eigenen Person zum Berichteten erscheint.“

194 David Ganz, Einhardus peccator, in: Lay Intellectuals in the Carolingian World, ed. Patrick Wormald/Janet L. Nelson (Cambridge 2007) 37-50. 
Glaubwürdigkeit des erzählenden ego der Vita prima. Im Gegensatz zur Glaubwürdigkeit ihres Inhalts steht der Ausschluß der Vita prima aus der Reihe der stilistisch und grammatikalisch korrekten Texte. Dabei spielte Jonas auch mit der Möglichkeit, aufgrund seiner Offenheit für Kritik am eigenen Text seine Bereitschaft zur emendatio morum zu bekunden und so selbst als vorbildhafter Bischof gesehen zu werden. ${ }^{195}$ Jonas' Argumente zur Theorie des Bischofsamtes und zur sozialen Funktion von Reliquienkulten unter bischöflicher Kontrolle bezogen ihre Autorität aus dem Postulat der wahrheitsgetreuen Wiederschrift eines Textes, der nicht sein eigener ist. Gleichzeitig vermittelte Jonas diese Standpunkte gerade durch die Ausdehnung der Präsenz und Deutungshoheit des Erzählers in einer Vielzahl an kleineren und größeren Veränderungen und Einschüben. Bei der Wiederschrift der Vita Huberti mußte die Balance zwischen der Adaption des Textes an den Interpretationshorizont der eigenen Zeit und dem Bewahren der Autorität der Vorlage sorgfältig aufrechterhalten werden.

Während Jonas die so aufgebaute Autorität seines Textes nutzte, um Positionen innerhalb einer breiteren Diskussion um die Legitmität und Kontrolle von Reliquienkulten zu formulieren, basierte die Autorität von Einhards Intervention in den Diskussionen über die politische Lage des Reiches auf dem Zusammenspiel zwischen prestigereichen Reliquien und „inspiriertem“ Text. Die unterschiedlichen Strategien, mit denen Jonas und Einhard ihre Positionen als Autoren entwickelten, verweisen auf Unterschiede im Zugriff auf und im Umgang mit Reliquien als spirituellen Ressourcen. Die Widersprüche und Spannungen, die in beiden Texten auf jeweils unterschiedliche Weise deutlich werden, können aber auch die besonderen Schwierigkeiten und Beschränkungen verdeutlichen, die mit dem Schreiben von Texten über Reliquien in den späten 20er Jahren des 9. Jahrhunderts einhergingen. Beide Texte entstanden in einem Feld der konkurrierenden Bemühungen und der Diskussionen über Reliquienverehrung und die Bedeutung von Reliquien in pastoralen und politischen Kontexten. In beiden Texten zeichnet sich auf unterschiedliche Weise die Notwendigkeit zur Reflexion dieser breiteren Debatten ebenso ab wie die besondere Umsicht, die die Mobilisierung von Reliquien als spirituelle Ressourcen in diesem Kontext erforderte. So sehr sie jeweils auch von lokalen und persönlichen Interessen motiviert waren, sind die Texte auch Teil eines gemeinsamen Diskurses über Modelle der Orientierung, Ordnung und Kontrolle einer christlichen Gesellschaft, in dem Reliquien ein ebenso wichtiges wie prekäres Element waren.

\footnotetext{
195 Jonas, Vita et Translatio, Epistola dedicatoria, ed. de Smedt 807. Dieses Spiel wird unter anderem durch die literarische Parallelität von korrektem Latein und korrektem Leben möglich. Siehe Jonas, Vita et Translatio, Praefatio, ed. de Smedt 806f., hier 807: Erit autem prudentis studiosique lectoris inscientiae compati, superflua quaeque discreto confodere calamo, hiantia supplere, incorrecta corrigere, et ut bona bene dicantur, fructuoso studio elaborare; und vgl. damit z.B. Admonitio generalis, ed. Boretius 53f.: Quapropter et nostros ad vos direximus missos, qui [...] una vobiscum corrigerent quae corrigenda essent [...]. Ne aliquis, huius pietatis ammonitionem esse praesumtiosam iudicet, qua nos errata corrigere, superflua abscidere, recta cohortare studemus [...]. Vgl. Anton, Zum politischen Konzept 63.
} 